\title{
Carbon Quantum Dots for Energy Applications: A Review
}

Akash S. Rasal ${ }^{a}$, Sudesh Yadav ${ }^{b}$, Anchal Yadav $^{c}$, Anil A. Kashale ${ }^{d}$, Subrahmanya Thagare Manjunatha ${ }^{e}$, Ali Altaee ${ }^{b}$, Jia-Yaw Chang ${ }^{a, f^{*}}$

aDepartment of Chemical Engineering, National Taiwan University of Science and Technology, Taipei, 10607, Taiwan, Republic of China

${ }^{b}$ Centre for Green Technology, School of Civil and Environmental Engineering, University of Technology Sydney, 15 Broadway, NSW 2007, Australia

'School of Chemistry, Faculty of Science, Monash University-Clayton Campus, Melbourne, VIC-3800, Australia ${ }^{d}$ Department of Applied Science, National Taitung University, Taitung City, 95092, Taiwan, Republic of China eAdvanced Membrane Materials Research Centre, Graduate Institute of Applied Science and Technology, National Taiwan University of Science and Technology, Taipei, 10607, Taiwan, Republic of China

fTaiwan Building Technology Center, National Taiwan University of Science and Technology, Taipei, 10607, Taiwan, Republic of China

Corresponding author: jychang@mail.ntust.edu.tw 
Graphical Abstract

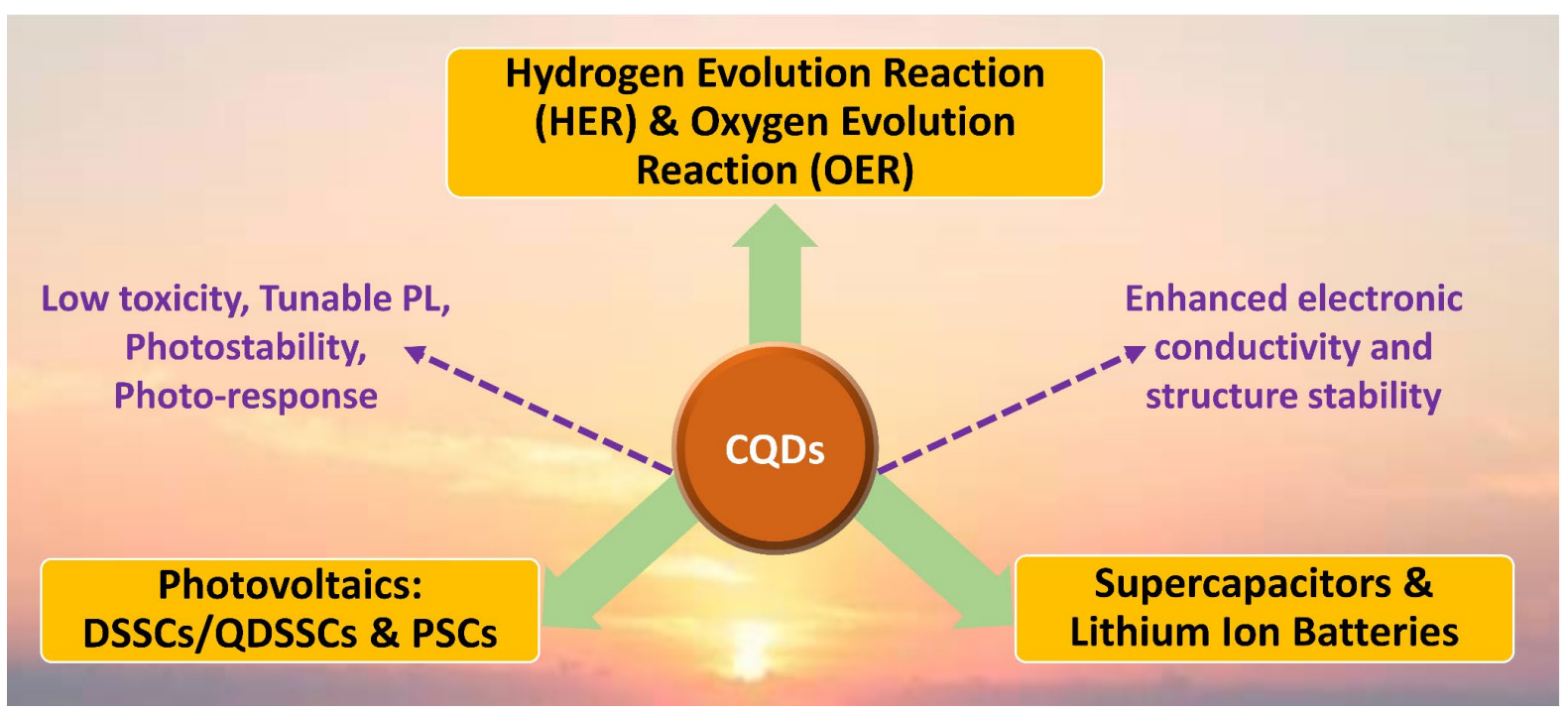




\begin{abstract}
Carbon quantum dots (CQDs) are a class of carbon nanomaterials that have recently gained recognition as current entrants to traditional semiconductor quantum dots (QDs). CQDs have the desirable advantages of low toxicity, environmental friendliness, low cost, photostability, favorable charge transfer with enhanced electronic conductivity, and their comparable easy synthesis protocols. This article examines advancements in CQD research and development, with a focus on their synthesis, functionalization, and energy applications. Initially, various synthesis methods are discussed briefly with pros and cons. Herein, first top-down methods including arc discharge technique, laser ablation technique, plasma treatment, ultrasound synthesis technique, electrochemical technique, chemical exfoliation, and combustion were discussed briefly. The later section presents bottom-up (microwave synthesis, hydrothermal synthesis, thermal pyrolysis, and MOF template-assisted approach) and waste-derived CQDs synthesis methods. The next section is focused on the energy applications of CQDs including supercapacitors, lithium-ion batteries, photovoltaics, hydrogen (HER), and oxygen evolution reaction (OER). Finally, challenges and perspectives in this exciting and promising area are presented.
\end{abstract}

Keywords: Carbon quantum dots (CQDs); energy applications; supercapacitors; photovoltaics; hydrogen evolution reaction (HER) and oxygen evolution reaction (OER)

\title{
1. Introduction
}

Earlier, semiconductor quantum dots (QDs) have been studied extensively for their quantum confinement effect, and tunable fluorescence emission properties, which allow them to be used in biosensing and bio-imaging for many years. ${ }^{1,2}$ Change in particle size of semiconductor QDs leads to change in photostability and optical properties including adsorption and emission wavelength. However, due to the use of heavy metals (such as cadmium (Cd), lead $(\mathrm{Pb})$, and mercury $(\mathrm{Hg})$ ) in their production, semiconductor QDs have some drawbacks, such as high toxicity. Heavy metals are known to be highly toxic even at low concentrations, which could make large production impossible. ${ }^{3,4}$ Thus, carbon quantum dots (CQDs) were developed as an alternative for semiconductor QDs to conquer the extreme recalcitrance and toxicity of heavy metal ions. ${ }^{3}$ CQDs outperform traditional organic fluorophores and semiconductor QDs in terms of low cytotoxicity, high emission quantum 
yield, and chemical inertness ${ }^{5,6}$. Xu et al. discovered CQDs in 2004 while trying to make singlewalled carbon nanotubes (SWCNTs), which were identified as carbon nanoparticles. ${ }^{7}$ Since then CQDs, have piqued researchers' interest due to their unique properties, which include excellent optoelectronic properties, photoluminescence, simple synthetic routes, facile surface functionalization, good biocompatibility, large specific surface area, and low toxicity. ${ }^{8-}$ 10 Sun et al. proposed laser ablation technique to produce CQDs with much-enhanced fluorescence emissions via surface passivation, coined the term "carbon quantum dots" for fluorescent carbon nanoparticles in 2006 using graphite powder as precursor. ${ }^{11}$ In general, the top-down route and the bottom-up route are used to synthesize CQDs. ${ }^{12,13}$

CQDs are considered as a type of zero-dimensional carbon-dominated nanomaterial, compared to spherical, tubular, and sheet fillers, and in the graphene-family nanomaterials. As a structure encompassing a few layers of graphene oxide (GO) nanosheets, CQDs offer numerous beneficial characteristics of $\mathrm{GO}$ even though having their own distinguishing properties. ${ }^{14}$ Because of their larger edge effects and quantum confinement, CQDs reveal unique electronic and optical characteristics; better than GO nanosheets as well as they can also easily separated into electrons and holes owing to their high dielectric constant and extinction coefficient. Further, long-term in-vivo experimental results on CQDs revealed that it is much less cytotoxic than micrometer-sized GO sheets; it may be safer for in-vivo biological research. ${ }^{15,} 16$ Apart from, energy applications carbon based nanomaterials are widely explored for water and wastewater treatment. ${ }^{17-19}$ Among them, CQDs have been able to achieve remarkable enhancements in membrane filtration efficiencies, notably in membranefouling resistance. ${ }^{20,21}$

CQDs have a quasi-spherical structure with amorphous to nanocrystalline carbon cores smaller than $10-20 \mathrm{~nm}$ in diameter. ${ }^{22}$ CQDs are further divided into graphene quantum dots (GQDs), carbon nanodots (CNDs), and polymer dots (PDs) based on the different carbon cores. $^{23}$ Similar to that of CQDs, GQDs also a type of zero dimensional nanomaterial in the graphene family that possesses the features of both the graphene and carbon dots that are anisotropic with lateral dimensions most commonly less than $20 \mathrm{~nm} .{ }^{24}$ Whereas, CNDs are fluorescent carbon nanomaterials that can be derived from numerous carbon materials such as graphene, fullerenes, graphite, and carbon nanotubes at the size of molecules that fall within the range of $10 \mathrm{~nm} \cdot{ }^{25} \mathrm{~A}$ PDs are a class of CDs comprising of a polymer/carbon hybrid 
structure that contains plentiful carbon-based linkages on the surface and an abundant polymeric network in the interior. ${ }^{26}$

Due to ease of fabrication via green synthesis protocols and the vast availability of raw materials, CQDs demonstrated favorable application prospects in a variety of fields such as medicine, chemistry, food, and the environment. ${ }^{27-30}$ It's important to note that modifying CQDs allows for the detection and attachment of various specific analytes on their surface via electrostatic interactions and hydrogen bonding, which serves as a platform for specific sensing. ${ }^{31}$ Oxidized CQDs contain polar functional groups on the surface including hydroxyl and carboxyl groups allowing further chemical functionalization and stable dispersion in an aqueous medium. The oxygen content of oxidized CQDs varies depending on the synthetic route, ranging from 5 to 50 weight percent. ${ }^{32,33}$ Surface passivation and modification alter the fluorescence and physical properties of CQDs.

To date, there are only a few literature reviews of CQDs that focus on their use in energy applications. This article gives an overview of the advancements and energy applications of CQDs. The first section provides newly developed synthetic methods for the synthesis of CQDs. Herein, the surface modification of CQDs with reactive functional groups and heteroatom doping were highlighted via various physical and chemical approaches. The following section focused on various energy applications of CQDs including solar cells, supercapacitors, and lithium-ion batteries. The review also provides new insights for hydrogen and oxygen evolution reactions using CQDs. Finally, to conclude, current and future challenges are described to heighten the physicochemical properties of CQDs.

\section{Synthesis of carbon quantum dots (CQDs)}

Several techniques for the synthesis of CQDs using a variety of complex structured raw materials have been reported. Unlike GQDs, CQDs do not exhibit a proper graphitic domain. More intriguingly, each synthesis technique has a significant impact on the physicochemical properties of CQDs, allowing CQDs to be used in a wide range of applications. For instance, size-dependent photoluminescence (PL) for bioimaging, bio labeling, and optoelectronic applications, ${ }^{34-37}$ as photo-blinking materials in multichromophoric systems and optoelectronic applications, ${ }^{38-40}$ for excitation-dependent PL for fabricating luminescent materials, ${ }^{41}$ as hydrophilic surfaces and surface ligands in bio imaging. ${ }^{42}$ Because of such diverse applications of CQDs, it is extremely important to analyze the properties of CQDs 
based on their structure and sizes obtained through different synthesis techniques. ${ }^{43}$ Generally, CQDs synthesis techniques are broadly categorized into two approaches namely top-down and bottom-up strategies as shown in Figure 1. A further strategy, known as wastederived CQDs synthesis, has recently been introduced (Figure 1).

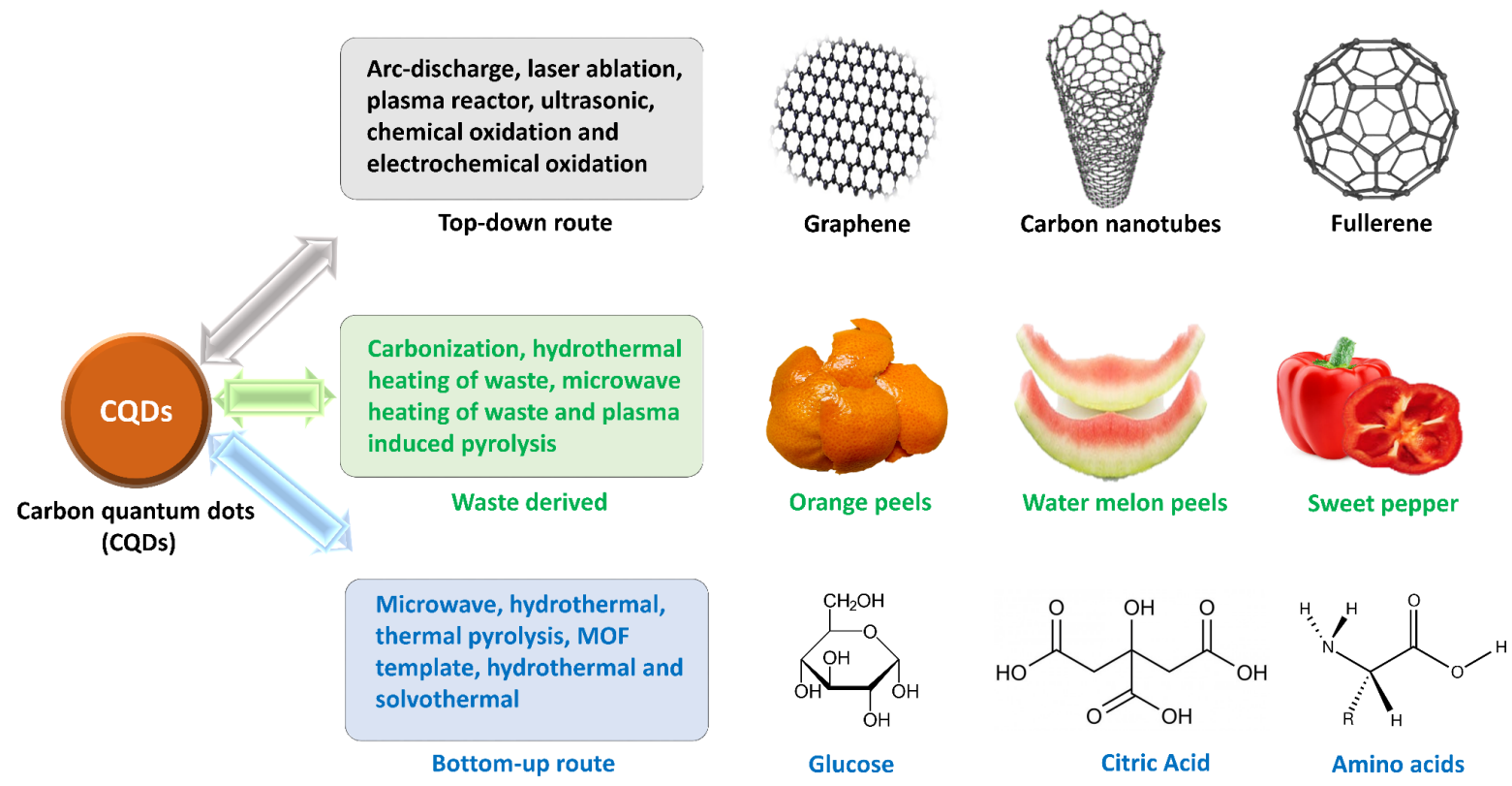

Figure 1: Schematic representation for the synthesis of CQDs through various techniques of "top-down", "bottom-up", and "waste-derived" approaches.

\subsection{Top-down route}

In a top-down strategy, CQDs can be synthesized from a variety of carbon-based raw materials such as activated carbon, carbon fibers, graphite, allotropes of carbon such as graphene, carbon nanotubes (CNTs), etc., through a variety of techniques. Herein, we briefly describe some of the important top-down strategies for synthesizing CQDs.

\subsubsection{Arc Discharge technique}

The arc-discharge technique is a high-energy method in which a bulk carbon raw material undergoes decomposition in an anode electrode in the presence of plasma generated between two electrodes placed at an optimal distance under the influence of high voltage within a sealed reactor. ${ }^{44}$ In the presence of high-energy plasma, the temperature of the reactor reaches up to $3727{ }^{\circ} \mathrm{C}$. At this temperature, the carbon atoms vaporize from the anode and get reassembled in the cathode to form CQDs. CQDs produced by this method will be rich in oxygen content and they exhibit sharp fluorescence property without any surface 
treatment. ${ }^{45,46}$ The only downside is that CQDs made this method are difficult to purify due to the existence of complex impurities. However, their particle size distribution will be high in most cases, decreasing CQD surface area and potentially reducing the number of active reactions. The specific surface area of CQDs is reduced as particle size increases, decreasing the number of active reaction sites in the electrocatalytic process. ${ }^{47}$

\subsubsection{Laser ablation technique}
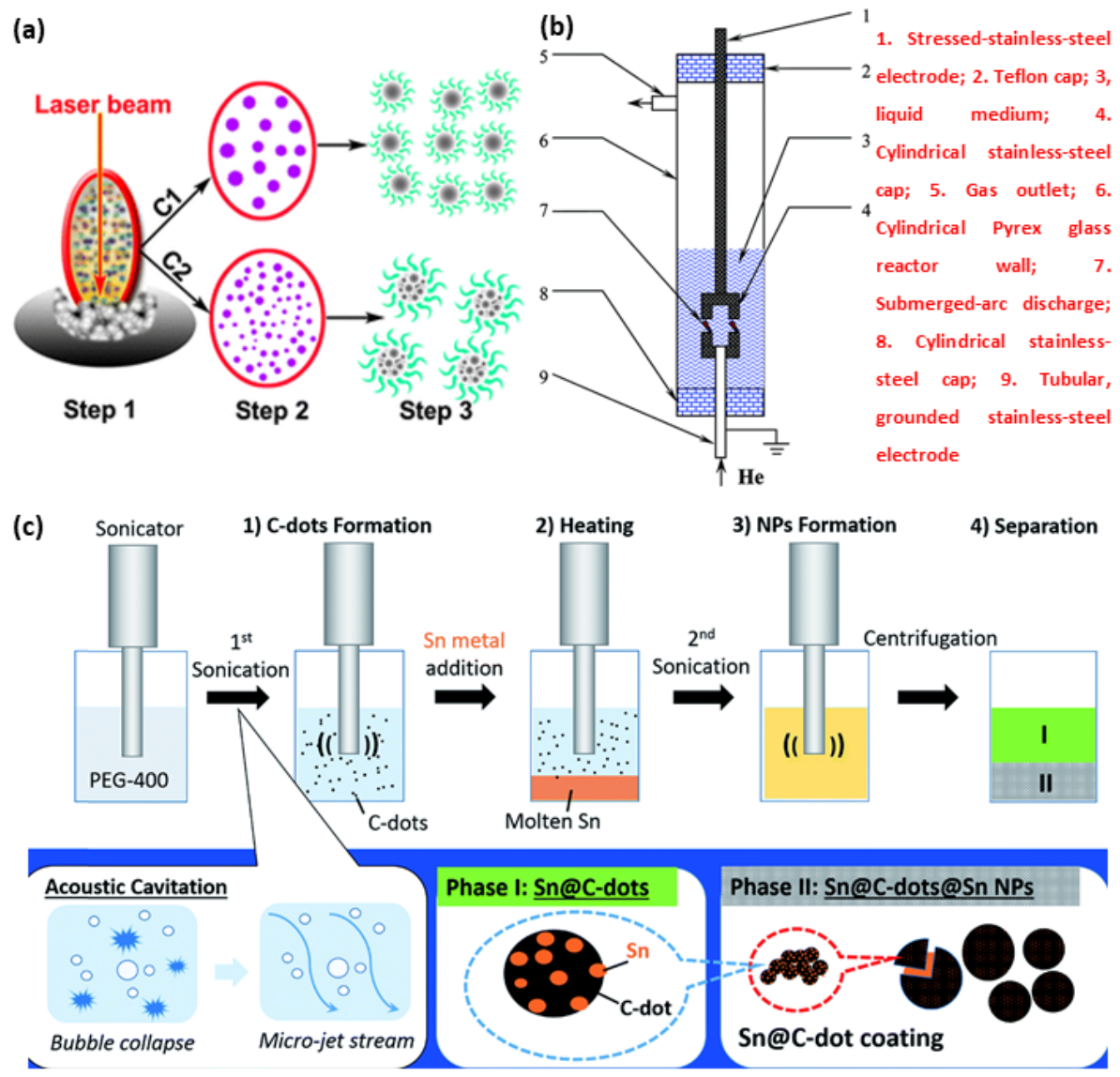

Figure 2: Schematic of different top-down synthesis techniques for CQDs: (a) CQDs formation through laser ablation; short-pulse laser (C1) and long laser pulse widths (C2). Reproduced with permission from ref 48. Copyright 2011 Springer Nature. Schematic of the plasma reactor used for the synthesis of CQDs (b). Reproduced with permission from ref 49. Copyright 2010 American Chemical Society. Schematic of sonochemical technique for the synthesis of CQDs (c). Reproduced with permission from ref 50. Copyright 2016 The Royal Society of Chemistry. Laser ablation is a widely accepted and advanced technique to synthesize CQDs of different morphology. Figure 2a shows the schematic for the synthesized CQDs. ${ }^{48}$ The laser ablation technique was first proposed by Sun et al. they irradiated the carbon raw material (target 
material) using Nd:YAG laser source $(1064 \mathrm{~nm}, 10 \mathrm{~Hz})$ and treated the product with the use of acid. ${ }^{42}$ The resultant CQDs were initially not able to emit the light, however after the surface functionalization by using two different oligomers such as poly (ethylene glycol) and poly (propionylethyleneimine-coethyleneimine), the CQDs were able to exhibit a highintensity PL emission. Afterward, several research groups successfully demonstrated the synthesis of CQDs of the desired size, by controlling the nucleation by varying the laser pulse width. ${ }^{48}$ High energy laser can localize the plasma pulse at the interface between the solid target and the liquid medium surrounding the target (Step 1 of Figure 2a) to initiate a quickly expandable bubble. Under the influence of pressure exerted by the surrounding liquid the bubble shrinks, while the cooling core slowly initiates the nucleation of CQDs (Step 2 of Figure 2a). CQDs of various cluster densities can be obtained using this method by tuning the laser pulse width, which gives them unique properties. The CQDs produced by this technique exhibit narrow particle size distribution, excellent water solubility, and fluorescence properties. However, process complication and high cost restrict its application in various fields.

\subsubsection{Plasma reactor}

In 2010, Denes et al. demonstrated the use of an Arc plasma reactor for single-step synthesis of functionalized CQDs (Figure 2b). ${ }^{49}$ In this technique, the free radicals responsible for the formation of CQDs were produced by helium plasma, and in-situ functionalization of the CQDs was carried out by using ethylene diamine. This technique enabled the uniform dispersibility of CQDs in an aqueous medium due to the presence of primary amine functionality. A cylindrical compartment of Pyrex glass (Figure 2b) was used to build a submerged-arc plasma reactor. PTFE caps were used for the electrical connections and cavitation gas supply. During the synthesis of CQDs, cavitation gas (benzene and helium) were passed into the reactor. While discharging, benzene instantly becomes black and ultimately turns into CQDs. In this technique, the composition and size distribution of CQDs mainly depends upon the precursor concentration and the operating voltage which leads to the difference in PL emission. The CQDs produced by this technique possess $\mathrm{C}=\mathrm{O}, \mathrm{C}-\mathrm{O}$, and $-\mathrm{OH}$ functional groups, which results in good water dispersibility/solubility of CQDs, as a result which exhibit strong blue emissions between the range of $365-490 \mathrm{~nm}$. This technique can be extended to prepare photoluminescent CQDs with different compositions by varying the carbon sources, like $\mathrm{N}$-, 
B- and P- doped reactants, which could enhance the quantum yields of CQDs and extend the emission wavelength ranges to red fluorescence. CQDs prepared by non-thermal plasma has potentialities for a variety of applications like sensing, optoelectronics, and bimodal bioimaging in the very near future. ${ }^{28}$

\subsubsection{Ultrasound synthesis technique}

Ultrasound synthesis techniques utilize high-energy ultrasound to develop carbon nano materials in a shorter time under ambient conditions like high pressures and temperatures. In this technique, multiple factors collectively decide the production or modification of CQDs, namely morphology (surface topography, size, and shape), chemical composition, solubility, and aggregation. Changes in the CQDs are due to the formation of acoustic cavity followed by the sudden disruption of the liquid bubbles as explained in Figure $2 c^{51}$ Hydrodynamic cavitation is initiated by an intensive local pressure decrease caused by supersonic liquid jets. This leads to the critical bubbles formation, ${ }^{52,53}$ which further induces the fragmentation of macro carbon materials into CQDs. Kumar et al. proposed the synthesis of Sn@CQDss@Sn (a hybrid anode) through ultrasound techniques. ${ }^{51}$ It can be concluded that compared to CQDs prepared by other techniques the CQDs synthesized through sonochemical technique are non-toxic and are excellent biocompatible materials for biomedical applications. Sonication parameters such as power, frequency, and sonication time need to be optimized to prepare the CQDs of desired properties. The photoluminescence properties and quantum yield of CQDs can be improved via doping of metal and other elements. CQDs prepared via this technique are suitable for variety of applications such as skin lotions, ointments, antimicrobial, bioimaging, drug delivery, cell labelling, catalysts, polymer synthesis, water treatment, superconducting devices, and energy storage devices due to their excellent physicochemical and fluorescence properties. ${ }^{54}$

\subsubsection{Chemical exfoliation and combustion}

In this technique, CQDs are produced via electrochemical cleavage of raw materials of carbon including graphene, carbon nanotubes, graphite rods, and rGO. The mechanism of this technique involves radicals like $\mathrm{OH} \bullet$ and $\mathrm{O} \bullet$ produced from the oxidation of water at the anode. The $\mathrm{OH} \bullet$ and $\mathrm{O} \bullet$ radicals function as electrochemical "scissors" to form CQDs. Exfoliation process normally starts at edge points and gets accelerated at the defective points. 
For the case of organic solvents, the process of exfoliation depends upon the electrical stress continued by the intercalation of anions between the layers of graphene. It has to be noted that the simple choice to synthesize CQDs is combustion. For combustion synthesis of CQDs, waste raw materials such as paraffin putty, candle soot, and natural gas soot have been used. For example, carbon nanoparticles ( $2 \mathrm{~nm}$ ) exhibiting multicolor fluorescence and watersolubility were obtained via combustion of candle soot. ${ }^{55}$ The candle soot was refluxed first with nitric acid and then purified by electrophoresis to obtain CQDs. There are some important aspects of oxidative acid treatment of CQDs synthesized via combustion process, they are (i) fragmentation of aggregates of CQDs into nano-sized carbon particles (ii) surface modification to enhance water dispersibility, and (iii) fluorescence property modulation for CQDs. The CQDs synthesized via these techniques exhibit strong fluorescence, high stability and high purity, and promising materials for drug delivery, bio-sensors, bioimaging, and solar cell applications. ${ }^{56}$

\subsubsection{Electrochemical technique}

This technique is the most popular, economically viable, and highly productive technique for the synthesis of CQDs. ${ }^{57-59}$ This technique was demonstrated for the first time by Zhou and co-workers. ${ }^{57}$ Authors employed this technique to synthesize CQDs (deep blue luminescent) using multiwall carbon nanotubes (MWCNTs). The synthesis of CQDs via this technique was carried out in a solution of degassed acetonitrile solution by adding $0.1 \mathrm{M}$ tetrabutylammonium perchlorate (TBAP), in a three-electrode system consisting of working electrode (WE) of carbon paper with chemical vapour deposited MWCNT, a counter electrode (CE) of Pt wire and reference electrode (RE) of an $\mathrm{Ag} / \mathrm{AgClO}$. Another simple route was proposed by Lu et al. to obtain CQDs through an ionic liquid-assisted electrochemical exfoliation. In their electrochemical cell, they used 2 different anodes namely a graphite rod and highly oriented pyrolytic graphite (HOPG) as two different experiments by using a Pt wire that is $\mathrm{CE}$ in 1-methyl-3-butylimidazolium tetra fluoroborate and 1-methyl-3butylimidazolium chloride ionic liquid electrolyte system. ${ }^{58}$ The CQDs synthesized via this technique, exhibit uniform size distribution, high crystallinity, and used potentially for chemical analysis and bio-related applications ${ }^{60}$.

\subsection{Bottom-up approach}


In the bottom-up approach generally, the carbonization of organic molecule such as citric acid and saccharides are used as building blocks for the synthesis of CQDs. In these approaches by tuning the experimental conditions it is possible to synthesize CQDs of the required size in a cost effective and scalable way. Under bottom-up approach, commonly used techniques are microwave synthesis, pressure and temperature assisted hydrothermal synthesis, thermal pyrolysis, and pore confined metalorganic framework (MOF) as templates to synthesize CQDs are briefly explained as below.

(a)

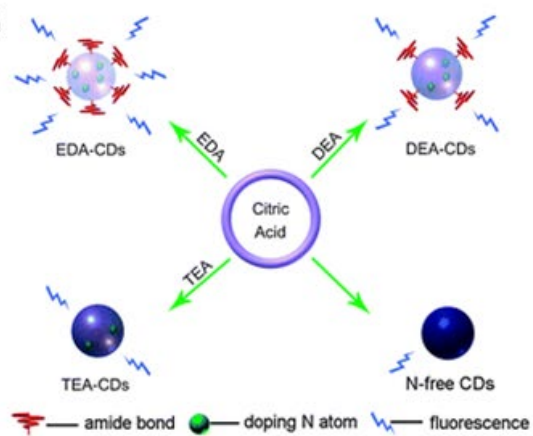

(b)

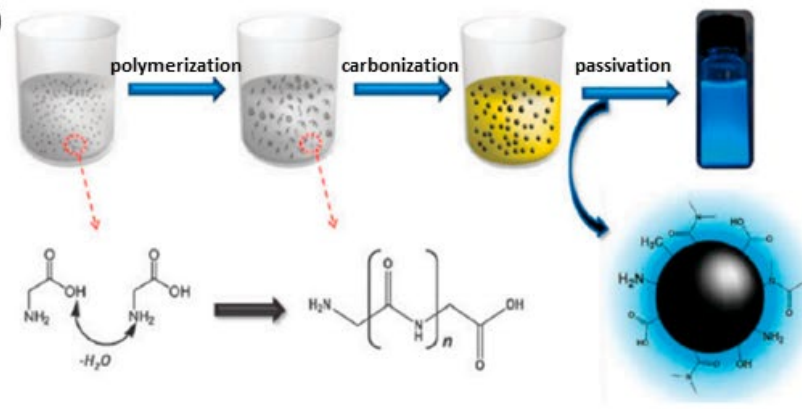

(c)

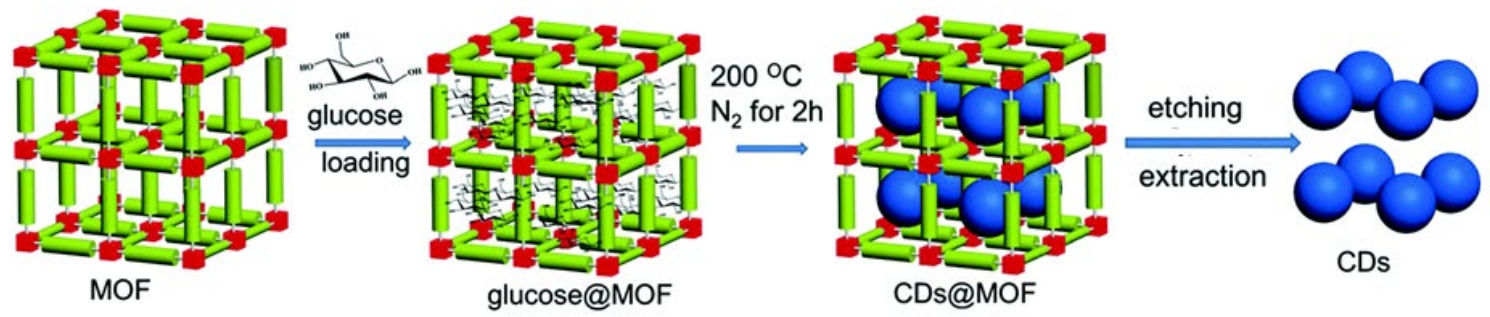

Figure 3: Schematics for bottom-up synthesis approaches of CQDs; (a) microwave techniquebased synthesis of CQDs by using different amines. Reproduced with permission from ref 61 . Copyright 2012 The Royal Society of Chemistry. (b) Model for CQDs growth following the different steps mentioned for glycine. Reproduced with permission from ref 62 . Copyright 2012 The Royal Society of Chemistry. (c) Steps involved in the synthesis of luminescent CQDs by using a MOF template. Reproduced with permission from ref 63. Copyright 2017 Wiley$\mathrm{VCH}$.

\subsubsection{Microwave synthesis}

In this technique the electromagnetic waves having wavelength around $1 \mathrm{~mm}$ to $1 \mathrm{~m}$ are used to break chemical bonds to allow the formation of CQDs within less than $10 \mathrm{~min} .{ }^{61,64,65} \mathrm{Zhu}$ et al. prepared the CQDs via microwave synthesis by using poly (ethylene glycol) and 
saccharides such as glucose and fructose as building blocks. ${ }^{64}$ In another report, Zhai et al. developed the microwave pyrolysis technique, by using citric acid they synthesized the high PLQY ( 30\%) as a starting block. ${ }^{61}$ Where, the surface of CQDs was made unreactive by using 1,2-ethylenediamine (EDA). They studied the luminescence of CQDs by using different amine functionalities such as diethylamine (DEA), triethylamine (TEA), and 1,4-butane diamine (BDA) for surface inactivation (Figure 3a). ${ }^{61}$ The CQDs prepared via this technique are highly biocompatible and have tremendous potential for bio and health related applications. ${ }^{28}$ The CQDs rich with oxygen-containing groups obtained by this technique act as coordination sites for metal ions for the development of CQDs-based electrocatalysts. ${ }^{46}$

\subsubsection{Hydrothermal synthesis}

It is a simple and cost effective technique for the synthesis of CQDs from saccharides or organic acids. ${ }^{62,66-69}$ This technique involves the synthesis of CQDs via carbonization of organic precursors in a sealed Teflon-lined hydrothermal reactor at high-temperature $(180-200 \circ \mathrm{C})$. For the first time Hsu et al. discovered the CQDs synthesis via hydrothermal route. They further explained that the model of growth of CQDs involves 4 steps namely, (i) dehydration, (ii) polymerization, (iii) carbonization, and (iv) passivation as explained in the (Figure 3b). ${ }^{62}$ Amino and carboxylic acid groups were useful for the CQDs formation. And in hydrothermal technique, $\mathrm{H}$ - bonds contribute for molecular assembly and heating to enable the growth of CQDs polymerization and nucleation. The CQDs synthesis via hydrothermal technique was also demonstrated by using precursors such as glucose and monopotassium phosphate $\left(\mathrm{KH}_{2} \mathrm{PO}_{4}\right){ }^{67}$ The facile technique can be used to synthesize water soluble or insoluble CQDs via changing the composition of reaction mixtures. ${ }^{70}$ Heteroatom doping enable this technique to design and synthesize new electrocatalysts with controllable doping composition and electronic structures. ${ }^{46}$

\subsubsection{Thermal pyrolysis}

This technique for the synthesis of CQDs was demonstrated for the first time by Giannelis and co-workers. ${ }^{71}$ In their study surface functionalized carbon nanoparticles were synthesized by the thermal carbonization of variety of ammonium citrate salts. The authors carbonized two different salts namely octadecyl ammonium citrate salt to obtain organophilic CQDs, and 2- 
(2-aminoethoxy)-ethanol salt to obtain hydrophilic CQDs. The ammonium carboxylate moieties undergo thermal dehydration to form -NHCO- bonding between the organic architecture and the cores. The same group demonstrated the mechanism of formation of carbogenic CQDs via citric acid (CA) and ethanolamine pyrolysis (EA) under the influence of different temperatures. ${ }^{72}$ They further showed the strong influence of pyrolysis temperature on CQDs PL behaviours during the synthesis. Under lower pyrolysis temperature $\left(180^{\circ} \mathrm{C}\right)$, the luminescence spectrum was due to the dehydration of CA-EA. When pyrolysis temperature was $230{ }^{\circ} \mathrm{C}$, they noticed both molecular fluorophores and the carbogenic core, which collectively form the PL spectrum. Furthermore, by increasing the pyrolysis temperature to the range between $300{ }^{\circ} \mathrm{C}-400^{\circ} \mathrm{C}$, they achieved the PL emission only from carbogenic cores. It is a cost effective and scalable technique to prepare CQDs from abundant low cost materials, and encapsulation of CQDs with biocompatible polymers make them useful for biomedical applications such as bimodal imaging, and drug delivery. ${ }^{73}$ The CQDs obtained via this technique have to be purified by dialysis. However, this technique can be used to synthesize monodispersed CQDs with average particle size with less than $10 \mathrm{~nm}$ by tuning the experimental variables. ${ }^{74}$

\subsubsection{MOF template-assisted approach}

MOFs possess well defined pores which act as a template for the synthesis of uniform-sized CQDs attributing to their rich isoreticular pore morphology (around $1-10 \mathrm{~nm}$ pore size). It is a latest approach demonstrated by Gu et al. in the year $2017 .{ }^{63}$ In their study, MOFs of three different pore size, HKUST-1 (largest at $1.35 \mathrm{~nm}$ ), ZIF-8 (pore diameter $1.9 \mathrm{~nm}$ ), and MIL101 (pore diameter $\sim 3.4 \mathrm{~nm}$ ) were used as the host templates. The MOF pores were filled with a glucose solution by dipping the MOF powder in that and heated at elevated temperature $\left(200^{\circ} \mathrm{C}\right)$ to selectively decompose the glucose filled in the MOF pores. Then to collect CQDs, MOF template was removed by washing with a $\mathrm{KOH}$ solution (Figure $3 \mathrm{c}$ ). ${ }^{63}$ Due to the ease of controlling size and morphology of CQDs, this technique encouraged researchers to use variety of MOFs to synthesize highly luminescent CQDs. ${ }^{75-77}$

\subsection{Waste derived synthesis of CQDs}


(a)

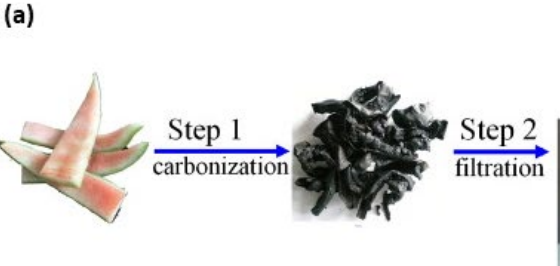

(c)

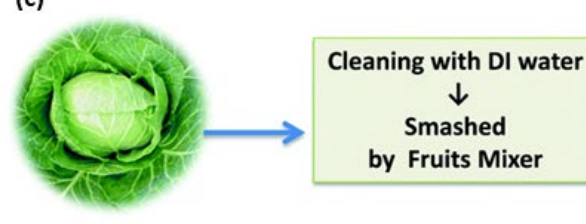

Cabbage

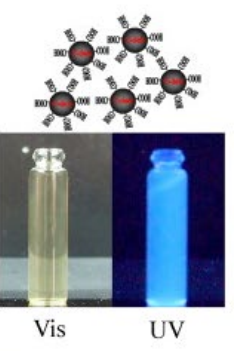

(b)
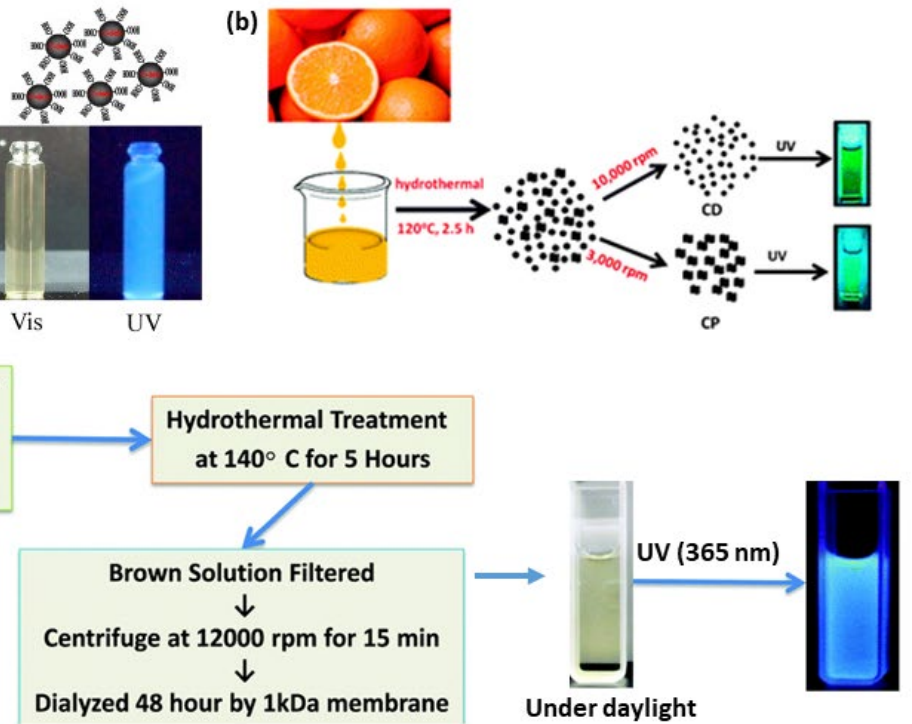

Figure 4: Waste derived synthesis of CQDs; (a) Synthesis of water-dispersible fluorescent CQDs using watermelon peel. Reproduced with permission from ref 78. Copyright 2012 Elsevier. (b) CQDs preparation via hydrothermal synthesis by using orange juice as a natural source of carbon. Reproduced with permission from ref 79. Copyright 2012 The Royal Society of Chemistry. (c) Synthesis of CQDs by using cabbage via hydrothermal technique and blue emission in response to UV light. Reproduced with permission from ref 80. Copyright 2015 The Royal Society of Chemistry.

This technique involves the use of waste materials as a source for carbon to synthesize CQDs. Generally, the waste source of carbon are the plant materials such as fruits and vegetables due to their eco-friendliness. ${ }^{78,79,81-83}$ For example, Zhou et al. synthesized the highly fluorescent CQDs (Figure 4a) by using watermelon peel waste as a natural source of carbon. ${ }^{78}$ Sahu et al. used orange juice to obtain CQDs showing a PLQY of $26 \%$ (Figure $4 \mathrm{~b}$ ). ${ }^{79}$ As far as vegetable sources concerned, cabbage was used by Alam et al. (Figure 4c). ${ }^{80}$ Cabbage peals were washed thoroughly and mixed with an ultrapure water and crushed into juice using a domestic fruit-juicer. The obtained cabbage juice was transferred to a hydrothermal reactor and heated at $140{ }^{\circ} \mathrm{C}$ for $5 \mathrm{~h}$. Finally, the resultant CQDs-solution was dialyzed by using Milli$\mathrm{Q}$ water and a tubular membrane for almost $48 \mathrm{~h}$. Synthesis of CQDs from waste sources has benefit of simple, low cost and easily availability in nature. Further, Table 1 summarizes all above-mentioned techniques with their pros and cons. 
The synthesis techniques like microwave, electrochemical synthesis, and confined pyrolysis are desirable to prevent carbonaceous agglomerations and to prepare monodispersed CQDs which are extremely important for their properties and applications. According to both economic and practical perspectives, photoluminescence $(\mathrm{PL})$ is a top contender for CQDs is among the most appealing features. Various scientific publications dealing with PL emissions have been noted in CQDs, all of which claim to be associated with different theories. ${ }^{5}$ It is typically proposed that two mechanisms of fluorescence quenching exist for CQDs: (a) firstly, the fluorescence initiating from the conjugated $p$-domains which is thought to be the result of band-gap transitions, (b) secondly, the fluorescence due to the presence of defects on the surface. To the fact, the emission spectrum of CQDs is very nearly identical to the spectral absorption spectrum at a given wavelength. The emission spectrum of CQDs differs greatly from that of those conventional dyes that are organic and has large stokes shifts in the spectrum. Other common characteristics among PLs of CQDs are distinct depending on their emission wavelength and intensity being roughly uniform. A possible explanation for this is that the optical selection uses different-sized particles with different wavelengths to select individual molecules, or that CQDs have different binding and emission ranges of molecules on their surface. ${ }^{84}$ Different sizes and intensity of the particles are simply a consequence of broad and light emission are reflected in the numerous and excitation-dependent PL emission spectrum ascertained the CQDs emission spectra as illumination at $470 \mathrm{~nm}$ and examine it under different irradiation conditions. ${ }^{42}$ Another advantage of traditional CQDs is that they are highly photo-stable, which means they're also less affected by the blinking issues, and unable to photo-bleach; meanwhile, most semiconductor QDs and organic ones are photounstable. As a novel and advanced nanomaterial CQDs have PL properties, electrical conductivity, chemical stability and high specific surface area and therefore suitable for variety of applications. ${ }^{85}$ 
Table 1: Comparison of pros and cons of CQD synthesis techniques and their precursors.

\begin{tabular}{|c|c|c|c|c|c|c|}
\hline Approach & Technique & Precursors & Pros & Cons & Applications & References \\
\hline \multirow[t]{4}{*}{$\begin{array}{l}\text { Top- } \\
\text { down }\end{array}$} & $\begin{array}{l}\text { Arc Discharge } \\
\text { technique }\end{array}$ & $\begin{array}{l}\text { Carbon, Graphite, } \\
\text { Graphene, CNTs }\end{array}$ & $\begin{array}{l}\text { CQDs will be rich in } \\
\text { oxygen content, highly } \\
\text { fluorescent, }\end{array}$ & $\begin{array}{l}\text { High energy and cost, } \\
\text { difficult to purify, } \\
\text { polydispersity in size, } \\
\text { high variation in } \\
\text { specific surface area }\end{array}$ & $\begin{array}{l}\text { Fluorescent, and } \\
\text { sensing }\end{array}$ & 86 \\
\hline & $\begin{array}{l}\text { Laser ablation } \\
\text { technique }\end{array}$ & $\begin{array}{l}\text { Graphite, } \\
\text { Graphene, CNTs }\end{array}$ & $\begin{array}{l}\text { Size and morphology can } \\
\text { be controlled, excellent } \\
\text { water solubility, } \\
\text { Fluorescent }\end{array}$ & $\begin{array}{l}\text { Process complication } \\
\text { and high cost } \\
\text { restrictions }\end{array}$ & $\begin{array}{l}\text { Biomedicine, } \\
\text { sensing, and } \\
\text { electrocatalysts }\end{array}$ & $5,46,87$ \\
\hline & Plasma reactor & Gaseous benzene & $\begin{array}{l}\text { Monodispersed in size, } \\
\text { good water solubility, } \\
\text { CQDs will be rich in } \\
\text { oxygen content, } \\
\text { Fluorescent }\end{array}$ & $\begin{array}{l}\text { Process complication } \\
\text { and high cost } \\
\text { restrictions }\end{array}$ & $\begin{array}{l}\text { Sensing, } \\
\text { optoelectronics, } \\
\text { and bimodal } \\
\text { bioimaging }\end{array}$ & 28 \\
\hline & $\begin{array}{l}\text { Ultrasound } \\
\text { synthesis } \\
\text { technique }\end{array}$ & $\begin{array}{l}\text { Polyethylene } \\
\text { glycol, Glucose }\end{array}$ & $\begin{array}{l}\text { Non-toxic, biocompatible, } \\
\text { highly fluorescent, } \\
\text { excellent physicochemical } \\
\text { stability }\end{array}$ & $\begin{array}{l}\text { Requires high energy, } \\
\text { pressure and } \\
\text { temperature }\end{array}$ & $\begin{array}{l}\text { Biomedicine, } \\
\text { water } \\
\text { treatment, }\end{array}$ & 54 \\
\hline
\end{tabular}




\begin{tabular}{|c|c|c|c|c|c|c|}
\hline & & & & & $\begin{array}{l}\text { energy storage, } \\
\text { catalysis }\end{array}$ & \\
\hline & $\begin{array}{l}\text { Chemical } \\
\text { exfoliation and } \\
\text { combustion }\end{array}$ & $\begin{array}{l}\text { Graphene, carbon } \\
\text { nanotubes, } \\
\text { graphite rods, rGO } \\
\text { and paraffin putty, } \\
\text { candle soot }\end{array}$ & $\begin{array}{l}\text { Enhance water } \\
\text { dispersibility, strong } \\
\text { fluorescence, high } \\
\text { stability and high purity }\end{array}$ & $\begin{array}{l}\text { Non uniform size } \\
\text { distribution }\end{array}$ & $\begin{array}{l}\text { Drug delivery, } \\
\text { bio-sensors, } \\
\text { bioimaging, and } \\
\text { solar cells }\end{array}$ & 88 \\
\hline & $\begin{array}{l}\text { Electrochemical } \\
\text { technique }\end{array}$ & $\begin{array}{l}\text { Graphite, } \\
\text { graphene }\end{array}$ & $\begin{array}{l}\text { Excellent purity and yield, } \\
\text { high crystallinity, } \\
\text { monodispersed size, and } \\
\text { reproducible }\end{array}$ & $\begin{array}{l}\text { Complication in } \\
\text { process }\end{array}$ & $\begin{array}{l}\text { Chemical } \\
\text { analysis, } \\
\text { biomedical, } \\
\text { solar cells }\end{array}$ & 60 \\
\hline \multirow[t]{2}{*}{$\begin{array}{l}\text { Bottom- } \\
\text { up }\end{array}$} & $\begin{array}{l}\text { Microwave } \\
\text { synthesis }\end{array}$ & $\begin{array}{l}\text { Acetyl acetone, } \\
\text { folic acid }\end{array}$ & $\begin{array}{l}\text { Less time consuming, } \\
\text { monodispersed size } \\
\text { distribution, size } \\
\text { controllability }\end{array}$ & $\begin{array}{l}\text { Requires more } \\
\text { energy and cost }\end{array}$ & $\begin{array}{l}\text { Bio and health- } \\
\text { related } \\
\text { applications, } \\
\text { electrocatalysts }\end{array}$ & 46 \\
\hline & $\begin{array}{l}\text { Hydrothermal } \\
\text { synthesis }\end{array}$ & $\begin{array}{l}\text { Citric acid, L- } \\
\text { cysteine, } \\
\text { melamine, } \\
\text { ethylene diamine }\end{array}$ & $\begin{array}{l}\text { Water soluble and } \\
\text { insoluble CQDs can be } \\
\text { prepared, non-toxic, high } \\
\text { quantum yield, cost } \\
\text { effective }\end{array}$ & Less productivity & $\begin{array}{l}\text { Electrocatalysts, } \\
\text { photocatalysis } \\
\text { and biomedical } \\
\text { applications }\end{array}$ & 89 \\
\hline
\end{tabular}




\begin{tabular}{|c|c|c|c|c|c|c|}
\hline & $\begin{array}{l}\text { Thermal } \\
\text { pyrolysis }\end{array}$ & $\begin{array}{l}\text { Ammonium citrate } \\
\text { salts, octadecene } \\
\text { (ODE) }\end{array}$ & $\begin{array}{l}\text { Cost effective, scalable, } \\
\text { non-toxic, }\end{array}$ & Polydispersity in size & $\begin{array}{l}\text { Biomedical, } \\
\text { drug delivery, } \\
\text { fluorescent }\end{array}$ & 90 \\
\hline & $\begin{array}{l}\text { MOF template- } \\
\text { assisted } \\
\text { approach }\end{array}$ & Glycol, glucose & $\begin{array}{l}\text { Morphology, shape and } \\
\text { size is controllable, highly } \\
\text { luminescent }\end{array}$ & $\begin{array}{l}\text { Less productive, } \\
\text { requires template } \\
\text { removal }\end{array}$ & $\begin{array}{l}\text { Fluorescent, } \\
\text { optoelectronics, } \\
\text { photocatalysis, } \\
\text { sensors, } \\
\text { bioimaging }\end{array}$ & 76 \\
\hline $\begin{array}{l}\text { Waste } \\
\text { derived }\end{array}$ & $\begin{array}{l}\text { Hydrothermal } \\
\text { synthesis, } \\
\text { carbonization }\end{array}$ & $\begin{array}{l}\text { Waste source of } \\
\text { carbon obtained } \\
\text { from plant } \\
\text { materials }\end{array}$ & $\begin{array}{l}\text { Photoluminescence, } \\
\text { electrical conductivity, } \\
\text { chemical stability, high } \\
\text { specific surface area }\end{array}$ & $\begin{array}{l}\text { Requires high } \\
\text { temperature, inert } \\
\text { gas atmosphere with } \\
\text { controlled flow rate } \\
\text { of gas }\end{array}$ & $\begin{array}{l}\text { Catalysis, water } \\
\text { treatment, } \\
\text { biomedical, } \\
\text { sensors }\end{array}$ & 85 \\
\hline
\end{tabular}




\subsection{Functionalization of CQDs}

Functionalization of CQDs is an effective way for tuning the properties of CQDs for desired applications. Generally, the CQDs are surface-functionalized through various chemical interactions such as covalent, ${ }^{91}, 92$ coordination ${ }^{93}$, and $\pi-\pi$ interactions. ${ }^{94}$ The CQDs synthesized through most of the techniques contain oxygen-containing functional groups, which helps for their surface functionalization through covalent bonding. ${ }^{5,28}$ Passivating the surface of CQDs through covalent bonding of entities with amine functionality helps to improve the photoluminescence property of CQDs. Blue-green light-emitting fluorescent CQDs were synthesized via hydrothermal carbonization of $2 \mathrm{Na}$.EDTA followed by surface functionalization using spiropyrans. The functionalized CQD's emission centered at $510 \mathrm{~nm}$ could be turned off, while being switched on at $650 \mathrm{~nm}$ through the transfer of energy between the CQDs and spiropyrans after ultraviolet (UV) light irradiation. ${ }^{95}$ This process could be reversed via visible light irradiation. The functionalized CQDs show excellent photoreversibility and high stability. Other than covalent bonding, coordination is another simple strategy for the functionalization of CQDs. A facile technique for phosphate detection was achieved by fabricating an on-off fluorescence probe of europium, which was efficient in detecting Phosphate ions in media like artificial wetlands. ${ }^{93}$ The fluorescence emission of CQDs was turned off upon coordination of $-\mathrm{COOH}$ groups on the CQDs surface with $\mathrm{Eu}^{3+}$, and it was switched on when the $\mathrm{Eu}^{3+}$ was specifically coordinated with phosphate ion. Some studies reported sol-gel technique for the functionalization of CQDs. For example, Liu et al. synthesized the highly luminescent (quantum yield $(Q Y)=47 \%$ ) amorphous CQDs by using organosilane as a coordinating solvent. ${ }^{96}$ The CQDs surface exhibited methoxysilyl groups, monodispersed with a diameter of $0.9 \mathrm{~nm}$ and enabled easy conversion into pure CQDs fluorescent films and monoliths via simple heating at $80^{\circ} \mathrm{C}$ for $24 \mathrm{~h}$.

Hola et al. synthesized the alkyl chain passivated CQDs. The alkyl chains present on the surface of CQDs were quickly converted to carboxylate groups by hydrolysis by treating with mild $\mathrm{NaOH}$ and resulted in emission between 402 to $440 \mathrm{~nm}$, red-shifted)) because of $\mathrm{COO}^{-}$surface functionality. ${ }^{97}$ An introduction of new surface functionalities by using organic molecules was demonstrated by Kwon et al. The CQDs surface-functionalized with anilines para-substitution) exhibited new energy levels, expressing long-wavelength PL ( around $650 \mathrm{~nm}$ ) of much shorter spectral widths with a high QY of $20 \% .{ }^{98}$ In another study Ding et al. demonstrated 
the technique to control the CQD surface functionalization via silica column chromatography separation. ${ }^{99}$ The resultant red-shift in the emission peaks (from 440 to $625 \mathrm{~nm}$ ) was attributed to the drastic reduction in the bandgap with the increase of infusion of oxygen species onto their surfaces. Overall surface functionalization of CQDs has a great impact on improving the intensity of $\mathrm{PL}, \mathrm{QY}$, water dispersibility/solubility, biocompatibility. This makes CQDs useful for various energy and environmental applications.

\section{Energy applications of CQDs}

CQDs had only a few applications until recently, but now that they've been discovered to have a variety of unique properties, and thus they're more popular than previously thought. Herein, applications of CQDS in various energy-related fields such as supercapacitors, photovoltaics, batteries, water splitting, and photodetectors are reviewed in this section.

\subsection{Supercapacitors}

In contrast to batteries, supercapacitors are energy storage devices that can sustain a high power output for long durations. Due to their distinct advantages, such as long life, environmental friendliness, and high power densities, supercapacitors have received a lot of recognition. ${ }^{100-102}$ For supercapacitors, a nanomaterial electrode with a higher specific capacitance and longer period stability is a good choice. ${ }^{101}$ Furthermore, supercapacitor expandable electrodes have proven to be very useful for fast energy storage, and providing rationally high energy densities and quick charging capacity.

Despite current efforts, further research is needed to develop novel porous, conducting, and wide surface area-based carbon materials with higher specific capacitance and longer cycle stability. CQDs have been used in energy storage applications due to their shape and size tuneable properties, and high electrical conductivity. ${ }^{103,104}$ For obvious reasons, using metal oxide/sulfide and CQDs to synthesise nanohybrid structures has been revealed as a promising method for fabricating effective and stable supercapacitors. ${ }^{105-107}$ To achieve high power density and specific capacitance Arul et al. synthesized $\mathrm{CQD}-\mathrm{MnO}_{2}$ nanostructures from a sustainable waste source by employing an environmentally friendly approach. ${ }^{108}$ The structural investigation established that $\mathrm{CQD}-\mathrm{MnO}_{2}$ exhibited a higher surface area and improved electrical conductivity than pristine $\mathrm{MnO}_{2}$ which reflected from the highly conductive CQDs. When these nanohybrid used as the electrode in symmetric 
supercapacitors demonstrated specific capacitance of $189 \mathrm{~F} \mathrm{~g}^{-1}$ with long cycle-life due to admirable coulombic efficiency and quick current-voltage response imitated from the electrochemical analysis.
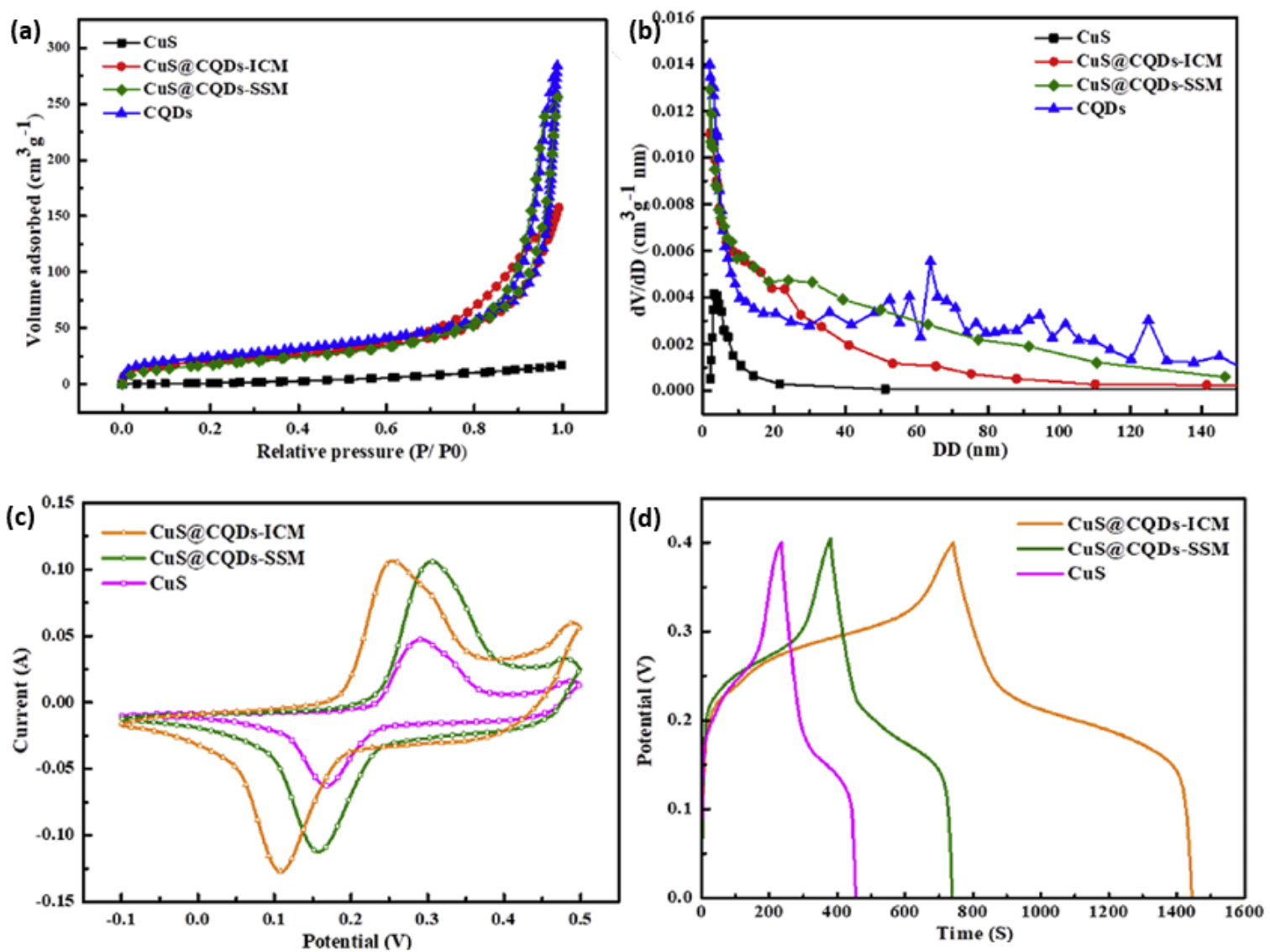

Figure 5: BET analysis (a) $\mathrm{N}_{2}$ adsorption-desorption isotherms; (b) pore sizes distribution curves; (c) cyclic voltammetry (CV) and (d) galvanostatic charge-discharge (GCD) curves of an asymmetric device based on CuS, CuS@CQDs-ICM, and CuS@CQDs-SSM nanocomposites. Reproduced with permission from ref ${ }^{109}$. Copyright 2020 Elsevier.

The CQDs can increase the electrical conductivity of the metal oxide-sulfide composites, but also better the electrochemical properties of the energy-storage devices. ${ }^{102,}$ 110, 111 Binesh et al. synthesized manganese oxide-graphene ( $\left.\mathrm{MnO}_{x}-\mathrm{CDGs}\right)$ nanohybrids using facile, environmentally being, and one-pot synthesis approach. For this purpose, CQDs cannot only use as a dispersing agent for graphene but also as a reducing agent for $\mathrm{KMnO}_{4}$ for the synthesis of $\mathrm{MnO}_{x}-\mathrm{CDGs}$ nanohybrid nanocomposites. The resulting solid-state supercapacitor with $\mathrm{MnO}_{x}-\mathrm{CDGs}$ displayed specific capacitance $\sim 280 \mathrm{~F} \mathrm{~g}^{-1}$ with long-term stability over $>10000$ charge-discharge cycles. ${ }^{112}$ Arul et al. stated that the CQD anchored 
Bismuth Oxide $\left(\mathrm{Bi}_{2} \mathrm{O}_{3}-\mathrm{CQD}\right)$ can be used as a promising material for energy storage applications. The $\mathrm{Bi}_{2} \mathrm{O}_{3}$ was prepared using a facile hydrothermal route while CQD was derived from the spoiled milk. The resulting $\mathrm{Bi}_{2} \mathrm{O}_{3}-\mathrm{CQD}$ nanocomposite provided a maximum energy density of $88 \mathrm{Wh} \mathrm{kg}^{-1}$ and possess good stability over the 2500 th cycle. ${ }^{113}$

From the aspect of the electronic features, transition metal sulfides are more appropriate to use in energy storage devices because of their high electrical conductivity and superior electrochemical activity. ${ }^{114-116}$ These features are advantageous for achieving stable and highperformance energy storage devices. For instance, in 2020, Quan et al. and co-workers synthesized a novel hierarchical porous nanoflower-like nanocomposite by doing CQDs into CuS nanostructure (CuS@CQDs). ${ }^{109}$ For this purpose, two different methods namely the impregnation combined method (ICM) and solvothermal synthesis method (SSM) was utilized to obtain CuS@CQDs nanocomposite. As shown in Figure 5a, the BET analysis revealed that these nanocomposites presented an improved surface area of $111.2 \mathrm{~m}^{2} \mathrm{~g}^{-1}$ than that of the pristine CuS $\left(22.8 \mathrm{~m}^{2} \mathrm{~g}^{-1}\right)$. Moreover, pore size distribution measurements demonstrated the presence of an abundance of mesopore structures for nanocomposites (Figure 5b). The electrode fabricated using CuS@CQDs nanocomposite displayed a higher specific capacitance and a power density of $920.5 \mathrm{~F} \mathrm{~g}^{-1}$ and $397.75 \mathrm{~W} \mathrm{~kg}^{-1}$, respectively, which attributed to the nanocomposites that plausibly afford ample electroactive sites as well as enable the transport of electrolytes and electrons as established from the cyclic voltammetry (CV) and chargedischarge profiles (Figure $5 c$ and $d$ ). Moreover, the device exhibited long-term stability remaining $92.8 \%$ of its original performance after 10,000 charge-discharge cycles. ${ }^{109}$ Likewise, nickel sulfide (NiS) and CQDs (NiS-CQDs) nanocomposite prepared from lemon juice using the facile hydrothermal method. The structural investigation demonstrated that these nanocomposites exhibited porous structure with an improved surface area of about $40 \%$ higher compared with its pure NiS nanostructures. As seen from the electrochemical measurements, these nanocomposite revealed improved charge transfer kinetics, surface area, and charge-discharge stability compared to that of pure NiS nanostructures. Additionally, NiS-CQDs nanocomposite displayed a higher specific capacity compared to that of pristine NiS electrodes as confirmed from the current density vs specific capacitance plots (Figure $6 a$ and b). ${ }^{117}$ Besides, the improved multiple cyclic stability after 2000 cycles with a high energy and power density were observed for the nanocomposite due to the synergistic 
effect between CQD and NiS. ${ }^{117}$ Similarly, the other nanocomposite materials based on CQD and transition metal sulfides such as CQDs/MoS ${ }_{2} @ Z \mathrm{ZS}^{118}$, copper-tin sulfides-CQD (CTSs@CQDs) ${ }^{119}$ have been employed to construct electrodes in supercapacitors.
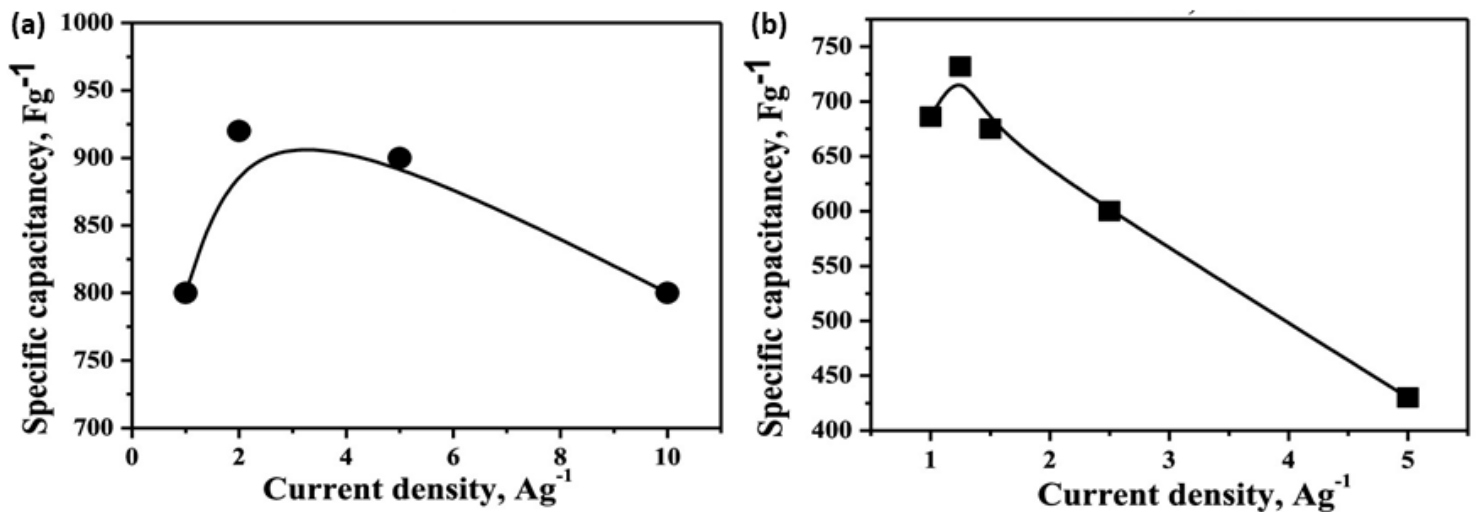

Figure 6: Specific capacitance vs current density measurements of NiS-CQDs nanocomposite (a) and pure NiS (b). Reproduced with permission from ref ${ }^{117}$. Copyright 2018 American Chemical Society.

Apart from nanocomposite strategy, the doping of CQDs with different heteroatoms has also been shown to be efficacious in improving the specific capacitance and life cycle of energy storage devices. The effect of different dopants such as $\mathrm{N}^{120-123}, \mathrm{P}^{124,125}, \mathrm{~B} \& \mathrm{P}^{126}, \mathrm{O}$ and $\mathrm{I}^{127}$ on the photoelectronic properties of carbon-based materials and the essential mechanism has been extensively investigated. Wang et al. prepared nitrogen-doped carbon quantum dot/polyaniline (N-CQD/PANI) nanocomposites using the chemical oxidative polymerization method and further used it as an electrode material for supercapacitors. The N-CQD/PANI nanocomposites demonstrated higher specific capacitance and cycling stability compared to that of the PANI or CQD which was attributed to the improved electrical conductivity and electrochemical properties of nanocomposites. ${ }^{128}$ Aneeya et al. fabricated supercapacitors with high energy and power density which exhibited robust cyclic stability over 5000 cycles by sandwiching reduced graphene oxide ( $\mathrm{rGO}$ ) and nitrogen, sulfur co-doped CQD (N, SCQDs). It demonstrated that the synergistic effect between the electron-rich heteroatoms and $\mathrm{rGO}$ could greatly enhance the active sites for the electrochemical reactions device. ${ }^{129}$

Careful preparation of innovative three-dimensional networks (3D) aerogels or hydrogelsbased electrodes is being done to reduce the potential issues caused by the metal oxide- 
based electrodes and to achieve excellent electrochemical energy storage properties through enlarging the surface area of the electrocatalyst. Hange and co-workers fabricated a flexible solid-state supercapacitor by using a highly porous, conductive, and three-dimensional (3D) interconnected network that was prepared from reduced graphene oxide hydrogel/carbon dots ( $\mathrm{rGH} / \mathrm{CDs}$ ). The $\mathrm{rGH} / \mathrm{CDs}$ electrodes with $130 \mu \mathrm{m}$ thickness deliberated specific capacitance of $264 \mathrm{~F} \mathrm{~g}^{-1}$ and stability over $>5000$ charge-discharge cycles. The authors stated that the CQDs electrode in the device can be served as an electron acceptor and electron donor which may plausibly moderate the charge transfer resistance at the interface thereby enhance electron transport. ${ }^{130}$ For the first time, the hollow, high electrical conductivity, and high surface area aerogel were prepared by Jingying et al. using heteroatom such as N, P codoped CQDs/rGO. Herein, authors claimed that the incorporation of the CQDs into the N, Pdoped rGO could cause a better synergistic effect between nanocomposite which in turn, not only enhance the electrical conductivity by providing ma large numbers of electrons to the $\pi$ conjugated system of rGO but also increase the active sites for the increase of specific surface area. As a result, the asymmetrical device with the architecture of $\mathrm{N}, \mathrm{P}-\mathrm{CQDs} / \mathrm{rGO}$ exhibited a specific capacitance of $453.7 \mathrm{~F} \mathrm{~g}^{-1}$ at $1 \mathrm{~A} \mathrm{~g}^{-1}$ and outstanding stability over $>10,000$ chargedischarge cycles.

In 2019, Ping et al. developed a novel cyano-metallic framework (CMF)-derived $\mathrm{Co}_{3} \mathrm{O}_{4}-$ $\mathrm{NiO} /$ graphene foam (GF) electrode composites by using binder-free solution immersion and following thermal treatment. Benefiting from the synergistic effect of metal oxide and graphene nanocomposite the resulting electrode demonstrated the improved specific capacitance of 766 at $1 \mathrm{~A} \mathrm{~g}^{-1}$ which was ascribed to the high pseudocapacitance of $\mathrm{CO}_{3} \mathrm{O}_{4}-\mathrm{NiO}$ and better electrical conductivity of the GF, respectively. Noticeably, the device fabricated using $\mathrm{Co}_{3} \mathrm{O}_{4}-\mathrm{NiO} / \mathrm{GF}$ electrode composites exhibited excellent stability about 5000 chargedischarge cycles. ${ }^{131}$ Apart from the above-mentioned metal oxide/sulfide nanocomposites, other several novel 2-dimensional (2-D) carbon materials such as carbon nanofibers ${ }^{132}$, carbon nanotubes ${ }^{133}, \mathrm{~S}-\mathrm{CQD} / \mathrm{PANI}^{100},{ }^{134}$, reduced graphene oxide decorated with $\mathrm{CDs}$ $(\mathrm{rGO} / \mathrm{CDs})^{135,136}$, CDs-graphene ${ }^{137}, \mathrm{GQDs}^{138}$, graphitic carbon nitride $\left(\mathrm{g}-\mathrm{C}_{3} \mathrm{~N}_{4}\right)^{139}$, and $\mathrm{MXene} \mathrm{1}^{140}$ have also been discovered as an electrode in supercapacitors. The carbon material is used in catalysis has the advantage of being inexpensive, as well as good conductivity and long-term stability. 
Generally, CQDs are blended with another electrocatalyst to form nanocomposites with improved porosity, surface area, electrical conductivity, and other electrochemical properties. When CQDs are mixed with transition metal oxide/sulfides or various heteroatoms, these nanocomposites act as both electron donors and acceptors thus enlarge the overall performance of devices by providing more surface-active sites. Therefore, more research is expected to synthesize stable and profitable electrodes by making novel nanocomposites using the heteroatom doping strategy because this approach is rather simple and provides more active sites for electrochemical performance and even mesmerizing synergetic properties.

\subsection{Photovoltaics}

Photovoltaic technologies (PV) are vital components of today's and tomorrow's renewable energy sources. PV tend to provide the most rational avenues for meeting the projected rise in global energy demand over the next 25 years as compared to other methods of generating electricity. To achieve more sustainable and renewable energy, the availability of such technologies must be maximised. To date, research into novel electrocatalysts, lightharvesting materials, and device modification engineering has enhanced the power conversion efficiency (PCE) of thin-film PV technologies. ${ }^{103,}$ 141-144 Nonetheless, a few remaining issues, such as low photon absorption of sensitizers, poor ability to collect electrons, and lack of conductivity of the electrodes, along with their low efficiency and stability, stymie wide implementations of these technologies. To conquer this issue, it is of paramount importance to use carbonaceous catalysts to obtain high-performance devices by improving their conductivity. Benefited from its excellent tunable energy levels, photon absorption, and electron excitation, electron acceptors, and donor ability, the CQDs are explored as a promising material for optoelectronic and energy storage applications. Table 2 summarizes the photovoltaic performance of different solar cells with CQDs as a photosensitizer. Further, the CQDs are capable of the capture and harness sunlight which makes them potential sensitizers for photovoltaic technology. ${ }^{145}$ Owing to their superior photophysical and optoelectronic properties, CQDs have been utilized to modify photoanode, counter electrode (CE), or dye/QDs sensitizer in photovoltaic applications. ${ }^{145-148}$

\subsubsection{DSSCs/QDSSCs}


In recent years, the use of CQDs in dye-sensitized-solar cells (DSSCs) and quantum-dotsensitized solar cells (QDSSCS) has been made to develop efficient and profitable lightharvesting materials. For example, Yuanyuan et al. fabricated highly efficient solar cells by combining long persistence phosphors (LPP) with biomass-converted CQDs (LPP-CQDs) which were derived from inexpensive soybean powders using the hydrothermal method. It observed that the resulted LPP-CQDs architecture capable of harvesting an adequate amount of light thus emitted monochromatic green light even in the dark condition when applied in the solar cell. The device with LPP-CQDs sensitizers achieved efficiencies as high as $7.97 \%$. Moreover, it stated that these CQDs could be served in all-weather conditions and can be capable of converting photons to electricity in the daytime and the dark. ${ }^{149}$ For example, Rama et al. fabricated efficient DSSCs based on the ZnO photoanode by employing N-doped CQDs (NCQDs) as a sensitizer. The device with ZnO-NCQDs architecture resulted in improved power conversion efficiencies (PCEs) of $1.18 \%$ which was higher than that of the ZnO device alone $(0.88 \%)$. The improved efficiencies of devices were mainly reflected from the enhanced short-circuit current density $\left(\mathrm{J}_{\mathrm{SC}}\right)$ which redirected from the increased light absorption as well as effective electron-hole separation. ${ }^{150} \mathrm{~N}$-CQDs can serve as a donor material, broaden absorption spectrum and also perform the important function of charge transfer kinetics. ${ }^{151}$ The charge collection efficiency, electron transport time, and electron diffusion length meso$\mathrm{TiO}_{2}$ photoanode were greatly improved by incorporating the fluorescent CQDs into the dye sensitizer. ${ }^{152}$ Based on the optical and electrochemical measurements, the authors proposed that CQDs could be served as dual functions of light-harvesting material and enable the electron electron-transport channel in the dye-sensitized $\mathrm{N} 19-\mathrm{TiO}_{2}$ film (Figure 7a). Nevertheless, the enhanced light-absorption was confirmed from IPCE curves in which the CQDs modified photoanode disclosed much higher absorption than those of pristine N719$\mathrm{TiO}_{2}$ film in the long-wavelength region (Figure $7 \mathrm{~b}$ ). When these photoanodes assemble in the device and are illuminated under the sunlight deliberated efficiencies of $8.70 \%$ which was $21 \%$ higher than those of pristine $\mathrm{N} 19-\mathrm{TiO}_{2}$ film (7.25\%), as revealed from photocurrent density-voltage $(J-V)$ curves measurements (Figure 7c). As well, a variety of CQDs and heteroatom doped CQDs have been investigated as sensitizers in DSSCs. ${ }^{153-157}$ Liu et al. established that the implementation of the energy-graded designs of heteroatom doped CQDs is a favorable approach to construct the defect-free absorbers for DSSCs. For that reason, the authors prepared $\mathrm{S}$ and $\mathrm{N}$ co-doped biomass-converted CQDs from the 
hydrothermal method. The resulting DSSCs with suitable energy level alignment exhibited high photovoltaic performance due to the enhanced electron extraction and broaden solar absorption region. ${ }^{157}$

On the other side, there are few reports which demonstrated that CDs modified photoanode can promote the flat band potential of the metal oxide semiconductor and also enhance the amount of dye adsorption. ${ }^{158}$ Herein, authors showed that the smaller-sized $\mathrm{ZnO}$ nanoparticles were greatly increased the dye adsorption of N719 dye because of its higher surface area which helps to faster the photo-induced charge separation process. The green and water-soluble CDs were prepared from rosemary leaves using an economic and facile hydrothermal approach by Behzad et al. The as-synthesized were served as an efficient photosensitizer by modifying the $\mathrm{TiO}_{2}$ photoanode. The resulting $\mathrm{CDs}$ modified $\mathrm{TiO}_{2} @ \mathrm{CDs} / \mathrm{N} 719$ device exhibited photovoltaic efficiencies of $7.32 \%$ which was much than that of the untreated device (3.25\%). ${ }^{159}$ Tesfaye et al. fabricated highly efficient $p-n$ heterojunction DSSCs by introducing CQDs as an additive in the $\mathrm{p}-\mathrm{NiO} / \mathrm{n}-\mathrm{ZnO}$ film. ${ }^{160}$ The $\mathrm{p}-\mathrm{n}$ heterojunction alignment contributed to the effective separation of the electron-hole and promote the photon-to-charge conversion and rapid charge transfer kinetics. As a consequence, of appropriate band-energy alignment and improved charge transfer kinetics higher performance of $13.02 \%$ was accomplished for $\mathrm{n}-\mathrm{ZnO} / \mathrm{Cdot} / \mathrm{p}-\mathrm{NiO}$ film compared with untreated devices.

Apart from the above-mentioned sensitizers and photoanode modifiers, the use of CQDs to control the photophysical and electronic properties of the CE material has been established as an operative way to improve the performance of devices. Accordingly, in 2017, Zhu and coworkers presented the strategy of interfacial engineering of metal selenide-based CEs with the incorporation of the CQDs. ${ }^{161}$ The bifacial DSSCs assembled with CQDs-based CoSe CEs exhibited high efficiency of $7.01 \%$, due to the enhanced optical transmission and wide absorption of CEs. The formation of CoSe alloyed structure and subsequent CQDs deposition was confirmed by scanning electron microscopy (SEM) and photoluminescence spectra, respectively. Further, it was proposed that a large number of photogenerated electrons were accumulated under solar light exposure which could enhance the electron density of CoSe catalyst thereby encourage the reduction of triiodide-iodide $\left(\mathrm{I}^{3-}\right.$ to $\left.\mathrm{I}^{-}\right)$redox couple. Duan et al. fabricated high-performance bifacial DSSCs through bi-tandem CQDs strategy in CoSe CEs. 
For this purpose, the aqueous solution of CQDs was deposited on the transparent CoSe CEs. It was observed that both CoSe and CoSe-CQDs exhibited higher transmittance than that of its reference (Pt) CE. The devices that illuminated under the front and rear conditions revealed an enhanced performance of $8.54 \%$ and $6.55 \%$, respectively, compared with that of the untreated device $(6.03 \%)$ because of the effective reduction of $\mathrm{I}^{3-}$ species in presence of the electron-enriched CoSe CEs. ${ }^{162}$ Recently, in 2021, Ali and co-workers developed a novel scalable and efficient catalyst by depositing NCQDs over the multiwalled carbon nanotubes (MWCNTs) by using microwave-assisted technique and used it as a CE in DSSCs. TEM analysis revealed that the NCQDs were successfully deposited over the MWCNTs. Benefiting from the electron-rich surface and auxochromic nature of doped $\mathrm{N}$ the electronic properties and surface reactivity of the MWCNTs were greatly improved. When NCQDs-MWCNTs were employed as CE, the higher efficiencies of $9.28 \%$ were realized than that of pristine MWCNT CE e $(6.17 \%)$ due to the enriched charge accumulation near the Fermi level and effective reduction of $\mathrm{I}^{-}$species. ${ }^{163}$

Similar to that of the DSSCs, the CQDs were also used as a sensitizer in the QDSSCs to boost their photovoltaic performance. For the first time, Zhao et al and coworkers synthesized up and down-convention luminescences Er-doped CQDs (E-CQDs) using a hydrothermal approach and used it as a sensitizer in QDSSCs application. They applied different layers of CdS QDs and E-CQDs over $\mathrm{TiO}_{2}$ photoanode by using successive ionic layer adsorption and reaction (SILAR). The efficiencies of $0.43 \%$ were obtained for the $\mathrm{CdS} / \mathrm{Er}-\mathrm{CQDS} / \mathrm{TiO}_{2}$ photoanode which was higher than that of the $\mathrm{CdS} / \mathrm{TiO}_{2}$ photoanode due to the improved light absorption and electron transport. ${ }^{164}$ Ping et al. introduced N-doped CQDs (NCQDs) into the CdS QDs and resulted in $40.9 \%$ higher performance compared to its reference device sensitized using pristine CdS QDs. The higher performance was attributed to the greatly improved absorption amount of film which could significantly decrease the back transfer of photo-induced electrons at the photoanode/electrolyte interface. ${ }^{165}$ In 2017 , by using a simple hydrothermal method Guo et al. prepared CQDs from different carbon precursors namely glucose (G-CQDs), citric acid (C-CQDs), and pollen (B-CQDs), and investigated its effect on different photovoltaic parameters. ${ }^{166}$ Resulting from the broad absorption in the solar spectrum and better charge kinetics, the improved efficiencies were deliberated for the CQDs-based sensitizers. 


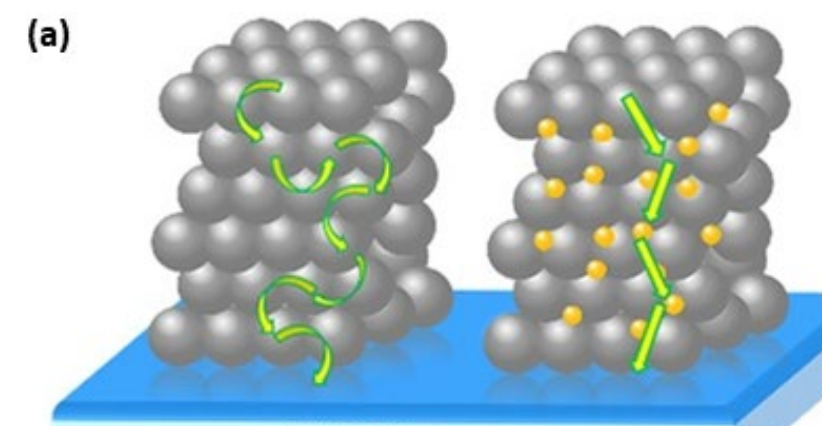

FTO Substrate
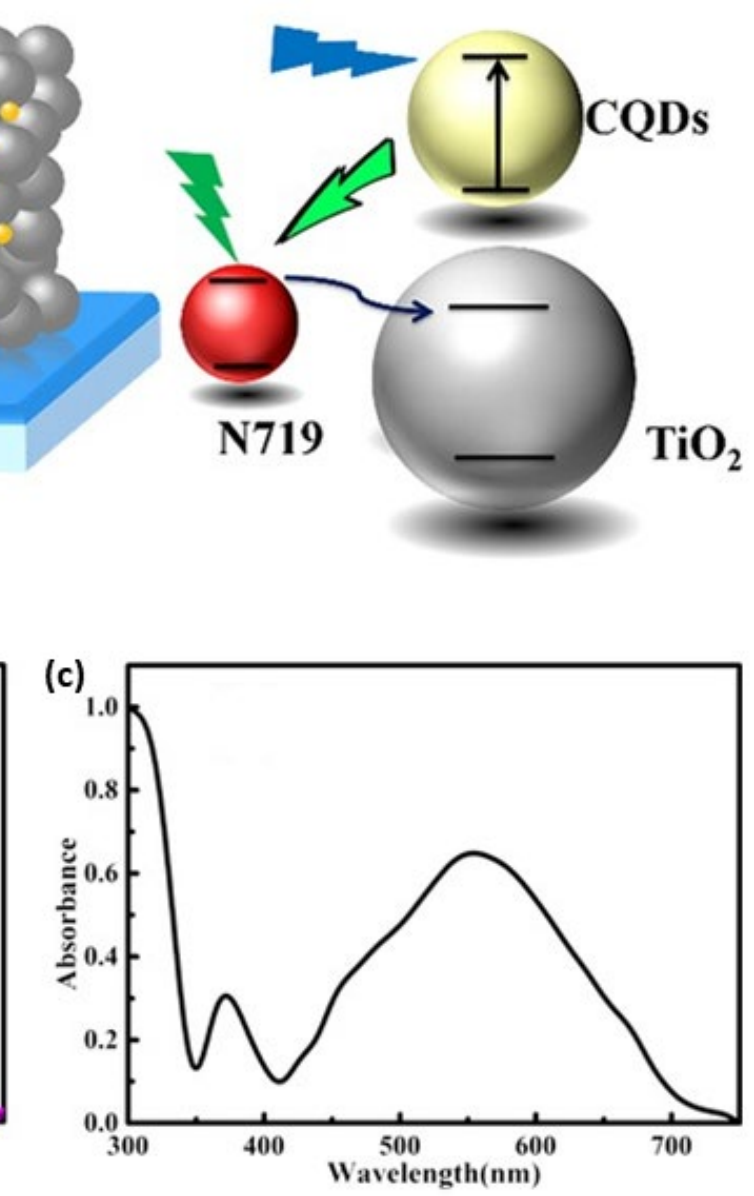

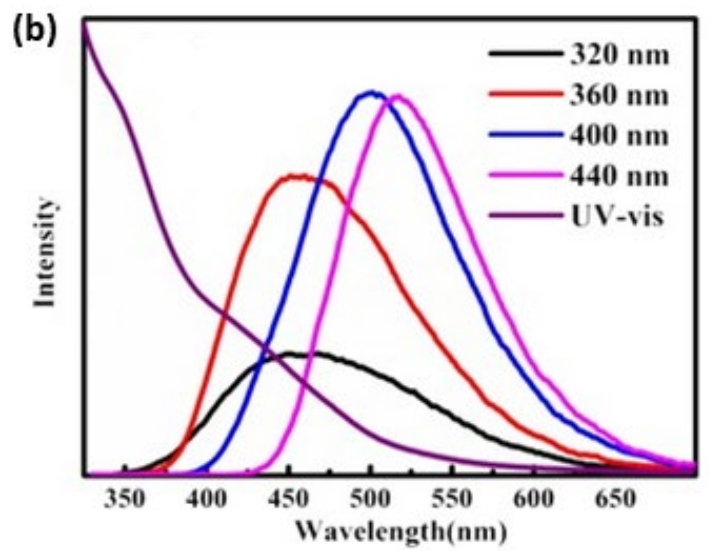

Figure 7: (a) A schematic illustrating the role of the CQDs in the N719-sensitized $\mathrm{TiO}_{2}$ film; (b) incident photon-to-current efficiency (IPCE) spectra and, (c) photocurrent density-voltage (J$V$ c curves of the pristine $\mathrm{TiO}_{2}$ and $\mathrm{CQDs}$ incorporated $\mathrm{TiO}_{2}$-photoanode. Reproduced with permission from ref ${ }^{167}$. Copyright 2016 Wiley-VCH.

\subsubsection{Perovskite solar cells (PSCs)}

In addition to DSSCs and QDSSCs, the use of CQDs in PSCs has been well established as a hole transport material (HTM) as well as for the control of charge recombination, in which the CQDs were used to modify the interfacial properties. The concept of the CQDs was proposed, many further endeavors have been undertaken to underlay its mechanism and increase the performance of the perovskite solar cell (PSC). For example, the first report of CQDs as a hole transport material (HTM) was proposed by Paulo et al. in $2016 .{ }^{142}$ They prepared solutionprocessed CQDs from citric acid by hydrothermal approach and used them as an additive in 
the methylammonium lead iodide (MAPI) perovskite. The electrochemical measurements revealed that the appropriate the highest occupied molecular orbital (HOMO) and the lowest unoccupied molecular orbital (LUMO) levels of the CQDs contributed to the effective hole transfer and suppress the leaking of the electron from the perovskite to CQDs. Benetti et al. fabricated highly efficient and stable PSCs by incorporating CDs on the graphene oxide (GO). ${ }^{168}$ Their findings suggest by applying an adequate amount of the CDs, the work function of GO could be shifted down which in turn not only faster the rate of hole injection but also suppresses the electron-hole recombination dynamics. As shown in Figure 8a, steady-state PL curves analysis perceived that with the incorporation of CDs over the perovskite film, the lifetimes of the corresponding PL curves were considerably decreased due to the enriched hole extraction from the perovskite film. Likewise, the shortest decay lifetime was obtained for the CDs-perovskite film which enlightened the improved charge transfer kinetics than those pristine perovskite film (Figure 8b). As a result of improved hole extraction and decreased recombination higher efficiencies of $16.2 \%$ were delivered for the GO-CDs HTM compared to that of GO HTM (14.7\%). Further, it observed that the GO-CDs are effective to longer the device stabilities due to the adequate down-converting properties of CDs which could assist in eliminating the soaking effect on the perovskite film. In another report, Kim et al. demonstrated that CQDs introduced p-type metal oxides, namely, nickel oxide ( $\mathrm{NiO}$ ) could be served as an efficient HTM in PSC. ${ }^{169}$ In their work, it was witnessed that the oxygen and the nitrogen-rich surface of the CQDs contributed to enrich the electronic properties of the $\mathrm{NiO}$ and appropriately match with the work-function of the perovskite and conducting glass thereby formed cascade type charge transport in planar p-i-n type PSCs. As depicted in Figure 8c; time-resolved PL (TRPL) spectra indicated that NiO@CQD perovskite film exhibited a lower average PL lifetime than NiO which directed higher hole-extraction rates in NiO@CQD perovskite film. As a result, improved photovoltaic efficiencies from $15.66 \%$ to $17.02 \%$ were observed for CQDs@NiO fabricated PSCs. Moreover, the devices that fabricated using CQDs@NiO were validated long-term stabilities of $192 \mathrm{~h}$ than bare NiO which attributed to the protective layer of the CQDs that obstruct the atmospheric moisture as well as reduce the hole accumulation process in perovskite film Figure $8 \mathrm{~d}$. 

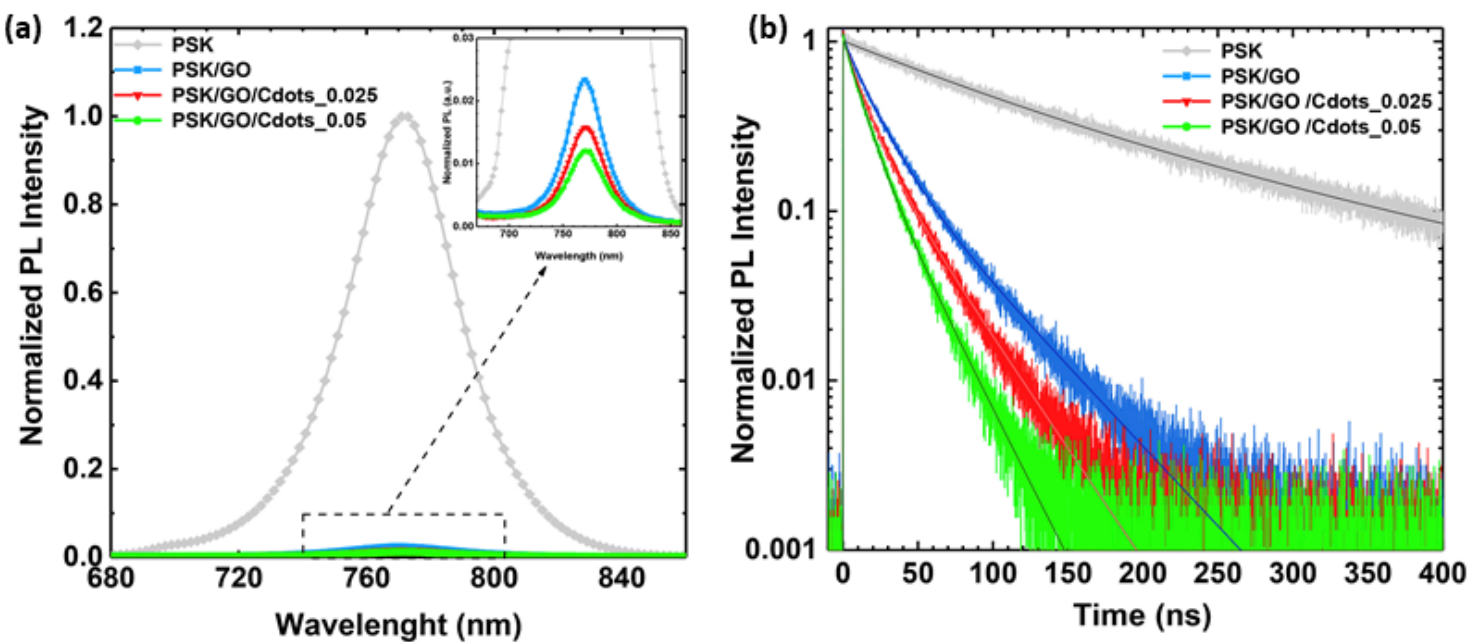

(c)

(d)
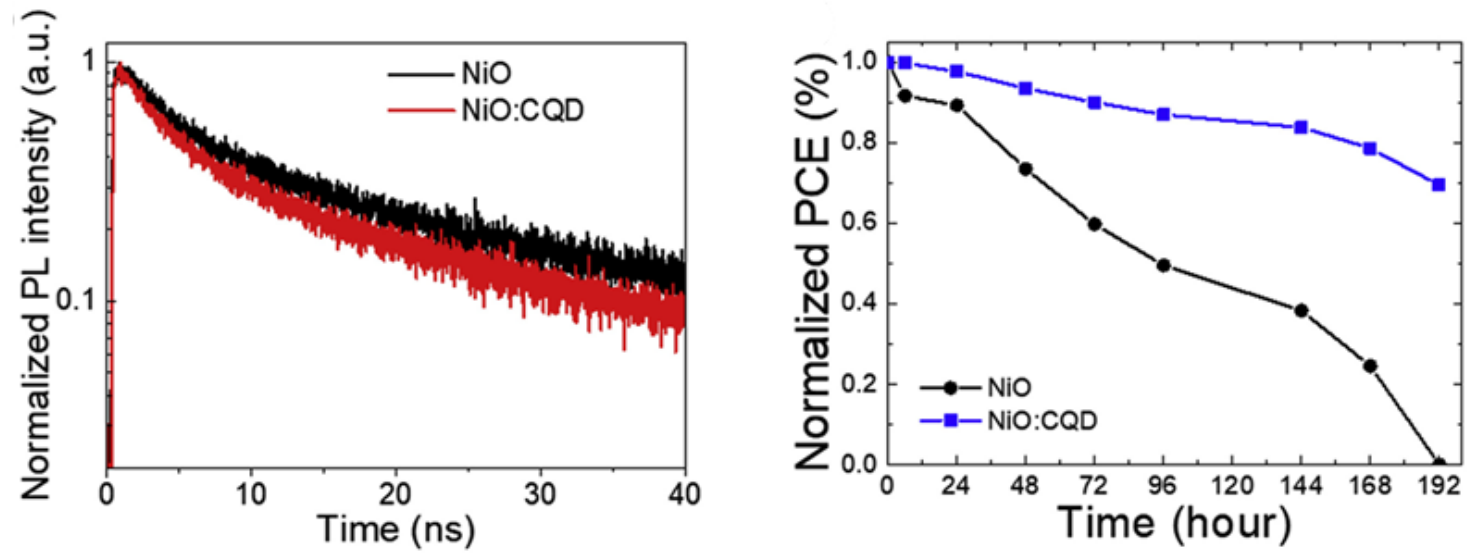

Figure 8: (a) Photoluminescence spectra and (b) transient PL decay curves based on the pristine GO and CDs modified GO (GO-CDs) in perovskite solar cells. Reproduced with permission from ref ${ }^{170}$. Copyright 2019 Elsevier. (c) PL decay curves (d) Normalized photovoltaic efficiency variation of perovskite-coated pristine $\mathrm{NiO}$ and NiO:CQDs. Reproduced with permission from ref ${ }^{171}$. Copyright 2020 Elsevier.

In addition to this, CQDs with surface-rich properties have also been used to enlarge the lightharvesting and passivate the grain boundaries of perovskite film. ${ }^{172,173}$ Accordingly, Ma et al. added CQDs in the perovskite material and found that the CQD can not only broaden the absorbance of the perovskite layer but also suppress the intrinsic defect of perovskite film because of the positive interaction between the $\mathrm{Pb}^{2+}$ ions and carbonyl groups on CQD. ${ }^{172} \mathrm{As}$ a consequence, higher efficiencies of $18.24 \%$ were obtained for CQDs added perovskite film. Additionally, the CQDs added perovskite exhibited better performance stability of about 48 h. The CQDs synthesized by using different precursors such as acetone (A-CQD) and citric acid (C-CQD) were applied as additives to control the growth rate of perovskite film by $\mathrm{Xu}$ and co- 
workers. ${ }^{174}$ SEM images (Figure 9a-c) showed that the existence of the different functional groups on the A-CQDs surface resulted in the improved grain size, crystallinity, and better hydrophobicity of perovskite film than C-CQDs. Whereas, the existence of more hydrophobic alkyl groups on the surface of CA-CQDs inhibits the grain sizes of film. Further, the AFM investigation showed that surface roughness values following the order pristine perovskite films (10.3 nm), A-CQDs films (14.5 nm), and CA-CQDs films (8.55 nm), respectively (Figure 9d-f). The performance of as high as $13.28 \%$ and $7.85 \%$ was acquired for the A-CQD and CCQDs based device. Also, A-CQD-based devices exhibited long-term stability and retaining $90 \%$ of their original performance after $200 \mathrm{~h}$. A similar kind of efficiency and stability enhancement was observed by Wen et al. with the introduction of CQDs in the MAPI solution which was attributed to the enriched crystallinity and grain size of MAPI film as well as suppressed carrier recombination process. ${ }^{175}$ Aside from this, there have few reports showing that the use of $\mathrm{CDs}$ as an interface modifier layer or interface engineering provides straightforward access to reducing the charge injection/extraction energy barrier, hindering the recombination associated with charges, also better the charge transfer kinetics. ${ }^{176,177}$ Han et al. fabricated simple, economic, stable, and HTL-free PSCs by using carbon-electrode that was prepared using a low-temperature painting technique. ${ }^{176}$ Further, the authors were deposited CQDs in the perovskite layer and carbon electrode which was functioned as an interface modifier. It was demonstrated that CQDs could not only assist the hole transfer towards the carbon electrode but also reduce the defect states in the perovskite layer, which in turn improved the photovoltaic performance up to $13.3 \%$.

Similar to supercapacitors, CQDs nanocomposite with other metal oxides/sulfide catalyst enrich the active surface sites by enlarging the specific surface area and electrical conductivity of electrode material and as well, it helps in maintaining the overall device performance over a long period by providing internal protection. Additionally, benefited from the superior photophysical and optoelectronic properties CQDs assist in improving light-harvesting efficiency through absorbing a large number of photons in a wide solar spectrum. Also, CQDs are capable of extending the life-time of the devices by providing a protective layer against moisture. In the last few years, CQDs have also been implemented to enhance the electron or hole extraction, to enlarge the light-harvesting, and to passivate the grain boundaries of perovskite film. However, it should be noted that the underlying mechanism has not been 
well understood. Therefore, it is essential to reasonably evaluate the several factors that affect the process, such as charge extraction, the effect of dopants in CQDs sensitizers as well as charge-recombination process to improve the overall performance and stability of devices.
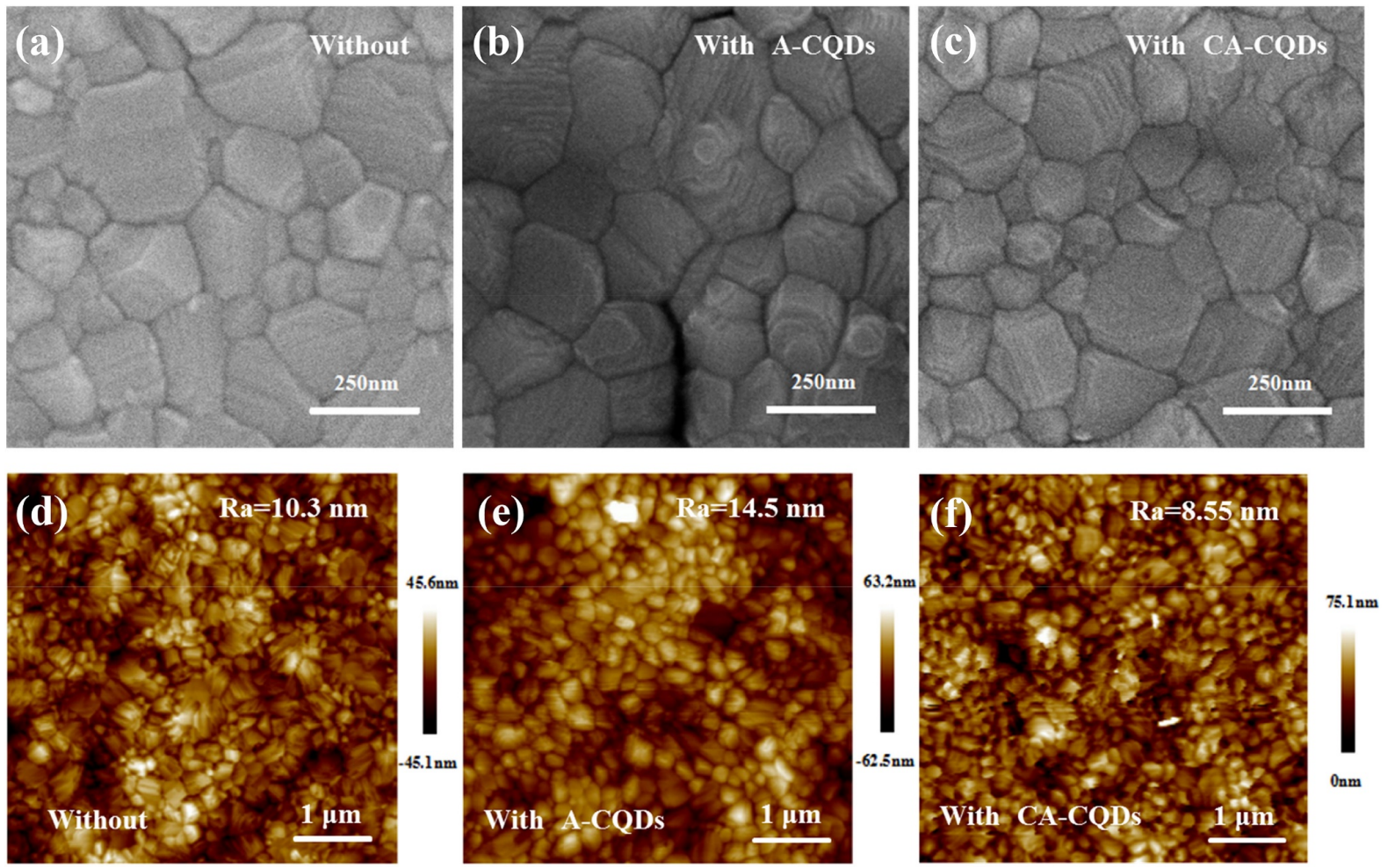

Figure 9: Top-view SEM (a-c) and AFM images (d-f) of the pristine perovskite film, acetonederived CQDs (A-CQDs), and citric acid-derived CQDs (CA-CQDs) film, respectively. Reproduced with permission from ref ${ }^{174}$. Copyright 2021 Elsevier.

Table 2: Photovoltaic Performance of different Solar Cells with CQDs as a photosensitizer.

\begin{tabular}{|c|c|c|c|c|c|c|c|c|}
\hline Device & Type & Source & $\begin{array}{l}\mathrm{Jsc}_{\mathrm{sc}} \\
\left(\mathrm{mA} \mathrm{cm}{ }^{-2}\right)\end{array}$ & $\begin{array}{l}V_{\text {oc }} \\
\text { (V) }\end{array}$ & $\begin{array}{l}\text { FF } \\
(\%)\end{array}$ & $\begin{array}{l}\text { PCE } \\
(\%)\end{array}$ & Note & Reference \\
\hline \multirow{5}{*}{ QDSSCS } & \multirow{5}{*}{ Sensitizer } & Uncoated & 0.083 & 0.015 & 0.34 & 0.0004 & \multirow{5}{*}{$\begin{array}{l}\text { CQDs improves the visible } \\
\text { light absorption in } \mathrm{ZnO} \\
\text { nanorods }\end{array}$} & \multirow{5}{*}{147} \\
\hline & & Chitin & 0.530 & 0.175 & 0.35 & 0.032 & & \\
\hline & & Chitosan & 0.500 & 0.275 & 0.44 & 0.061 & & \\
\hline & & Gluscose & 0.153 & 0.255 & 0.44 & 0.017 & & \\
\hline & & $\begin{array}{l}\text { Chitosan- } \\
\text { Chitin }\end{array}$ & 0.674 & 0.265 & 51.9 & 0.077 & & \\
\hline
\end{tabular}




\begin{tabular}{|c|c|c|c|c|c|c|c|c|}
\hline & & $\begin{array}{l}\text { Chitosan- } \\
\text { Gluscose }\end{array}$ & 0.054 & 0.300 & 0.38 & 0.006 & & \\
\hline \multirow{4}{*}{ QDSSCS } & \multirow{4}{*}{ Sensitizer } & $\mathrm{TiO}_{2}$ & 0.057 & 0.409 & 0.4 & 0.009 & \multirow{4}{*}{$\begin{array}{l}\text { CODs exhibits excitation } \\
\text { depend behavior owing to } \\
\text { their plentiful functional } \\
\text { groups on the surface }\end{array}$} & \multirow{4}{*}{166} \\
\hline & & Citric acid & 0.082 & 0.414 & 0.603 & 0.02 & & \\
\hline & & Glucose & 0.148 & 0.375 & 0.535 & 0.029 & & \\
\hline & & Bee pollen & 0.35 & 0.416 & 0.726 & 0.11 & & \\
\hline \multirow[b]{2}{*}{ QDSSCS } & \multirow[b]{2}{*}{ Sensitizer } & $\mathrm{MeOH}$ & 0.493 & 0.39 & 0.55 & 0.11 & \multirow{2}{*}{$\begin{array}{l}\text { CODs advances the charge } \\
\text { transport kinetics }\end{array}$} & \multirow[t]{2}{*}{$14 \varepsilon$} \\
\hline & & butyrolactone & 0.532 & 0.38 & 0.64 & 0.13 & & \\
\hline QDSSCS & Sensitizer & Soyabean & 0.03 & 0.347 & 66.1 & 7.97 & - & 149 \\
\hline QDSSCS & Sensitizer & $\mathrm{ZnO} / \mathrm{NCQD}$ & 5.48 & 0.343 & 0.52 & 1.18 & enhanced light absorption & $15 \mathrm{C}$ \\
\hline \multirow[b]{2}{*}{ DSSCS } & \multirow[b]{2}{*}{ Sensitizer } & N719 & 16.5 & 0.734 & 0.7 & 8.5 & \multirow{2}{*}{$\begin{array}{l}\text { NCQDs acts as donor } \\
\text { material and enhance } \\
\text { charge separation efficiency }\end{array}$} & \multirow[b]{2}{*}{15} \\
\hline & & N719/NCQDs & 17 & 0.735 & 0.72 & 9.15 & & \\
\hline \multirow[b]{2}{*}{ DSSCS } & \multirow[b]{2}{*}{ Sensitizer } & N719 & 21.26 & 0.691 & 0.61 & 8.7 & \multirow{2}{*}{$\begin{array}{l}\text { Better the charge collection } \\
\text { efficiency and electron } \\
\text { diffusion length of } \mathrm{TiO}_{2}\end{array}$} & \multirow[b]{2}{*}{152} \\
\hline & & N719/NCQDs & 16.12 & 0.74 & 0.60 & 7.25 & & \\
\hline \multirow[t]{2}{*}{ DSSCS } & \multirow[t]{2}{*}{ Sensitizer } & CQDs & 0.33 & 0.37 & 28 & 0.03 & \multirow{2}{*}{$\begin{array}{l}\mathrm{N} \text { doping enhanced } \\
\text { photocatalytic activity of } \\
\mathrm{NCQDS} / \mathrm{TiO}_{2}\end{array}$} & \multirow[t]{2}{*}{153} \\
\hline & & N-CQDs & 0.69 & 0.46 & 43 & 0.13 & & \\
\hline DSSCs & Sensitizer & PEG-CQDs & 19.59 & 0.717 & 70.4 & 9.89 & enhanced absorption & 15 \\
\hline \multirow[b]{2}{*}{ DSSCS } & \multirow[b]{2}{*}{ Sensitizer } & N719 & 13.77 & 0.72 & 69.9 & 6.90 & \multirow{2}{*}{$\begin{array}{l}\text { Improved light-harvesting } \\
\text { and charge extraction }\end{array}$} & \multirow[b]{2}{*}{15} \\
\hline & & $\begin{array}{l}\text { NCQD/N719/ } \\
\text { CQD/SCQD }\end{array}$ & 17.4 & 0.738 & 70.4 & 9.04 & & \\
\hline \multirow[b]{2}{*}{ DSSCS } & \multirow[b]{2}{*}{ Sensitizer } & ZnO@N719 & 0.52 & 0.30 & 0.57 & 0.16 & \multirow{2}{*}{$\begin{array}{l}\text { Improved } \mathrm{e}^{+} / \mathrm{h}^{-} \text {pair } \\
\text { separation efficiency }\end{array}$} & \multirow[b]{2}{*}{158} \\
\hline & & $\begin{array}{l}\text { ZnO@N719/C } \\
\text { QD }\end{array}$ & 2.34 & 0.67 & 0.59 & 5.92 & & \\
\hline
\end{tabular}




\begin{tabular}{|c|c|c|c|c|c|c|c|c|}
\hline \multirow[b]{2}{*}{ DSSCS } & \multirow[b]{2}{*}{ Sensitizer } & $\mathrm{TiO}_{2}$ & 7.92 & 0.765 & 0.73 & 3.25 & \multirow{2}{*}{$\begin{array}{l}\text { Extend absorption from UV } \\
\text { to NIR }\end{array}$} & \multirow[b]{2}{*}{159} \\
\hline & & $\mathrm{TiO}_{2} / \mathrm{CDs}$ & 16.94 & 0.788 & 0.74 & 7.32 & & \\
\hline & & CoSe & 15.73 & 0.712 & 0.720 & 8.06 & \multirow{2}{*}{ Promote reduction of $I_{3}^{-}$to $I$} & \\
\hline DSSCS & CE & $\mathrm{CQD} / \mathrm{CoSe}$ & 17.64 & 0.733 & 0.702 & 9.08 & & 161 \\
\hline \multirow[b]{2}{*}{ DSSCs } & \multirow[b]{2}{*}{ CE } & CoSe & 15.47 & 0.718 & 70.83 & 7.87 & \multirow{2}{*}{$\begin{array}{l}\text { Enhanced electron density } \\
\text { at CE }\end{array}$} & \multirow[b]{2}{*}{162} \\
\hline & & CQD/CoSe & 16.79 & 0.732 & 69.46 & 8.54 & & \\
\hline \multirow[b]{2}{*}{ DSSCs } & \multirow[b]{2}{*}{ CE } & MWCNT & 16.5 & 0.70 & 53.5 & 6.17 & \multirow{2}{*}{$\begin{array}{l}\text { Facilitate charge transfer } \\
\text { and exhibits electrolyte } \\
\text { binding capacity }\end{array}$} & \multirow[b]{2}{*}{163} \\
\hline & & $\begin{array}{l}\text { NCQD@ } \\
\text { MWCNT }\end{array}$ & 16.5 & 0.75 & 75 & 9.28 & & \\
\hline
\end{tabular}

\subsection{Lithium ion batteries}

Lithium-ion batteries (LIB) are a smart energy storage system and, due to their special characteristics such as lightweight, lighter, economically efficient, high energy density, and long cycle life, they have enhanced commercial demand for different consumer power sources and electric or hybrid vehicles. ${ }^{178-180}$ However, many LIBs electrode materials experience a rapid capacity fading during the charge-discharge process and poor rate performance, which are owing to self-aggregation, uncontrolled volume expansion in the electrode material, dissolution, formation of solid electrolyte interface layer over the electrode, and fast increased charge transfer resistances during cycles. In terms of the LIBs electrode materials, low coulombic efficiency, electrolyte depletion, and safety issues are common. ${ }^{181-183}$ Recently, these kinds of challenges in the LIBs electrode materials were addressed by compositing with CQDs with LIBs electrode materials, by modifying the surface states and the internal structures of electrode materials to enhance the LIB's next-generation efficiency.

Because CQDs help in increasing the conductivity of electrode materials, increase in the active surface sites over the electrode materials which account for the increase in the surface area and wettability of electrode material and besides that, it helps in controlling the volume expansion of electrode material during the charging-discharging process. ${ }^{184}$ For example, 
Prasath et al. employed bismuth oxide $\left(\mathrm{Bi}_{2} \mathrm{O}_{3}\right)$ and $\mathrm{CQDs}$ nanocomposite as an anode material for LIB's. ${ }^{113}$ These nanocomposites exhibited higher electrical conductivity and surface area compared to that of either $\mathrm{Bi}_{2} \mathrm{O}_{3}$ or CQDs. As a result, the coin cell constructed with $\mathrm{Bi}_{2} \mathrm{O}_{3}-$ CQDs revealed a better discharge capacity of $1500 \mathrm{mAh} \mathrm{g}^{-1}$ at $0.2 \mathrm{C}$ as well as maintained about $100 \%$ of its coulombic efficiency even in the 2500 th cycle. In another work, Zhang et al. established that the heteroatom doping into CDs could be a promising strategy to enlarge the surface area and electrochemical capability of carbon-based electrocatalyst. ${ }^{185}$ In order to achieve this, the author's synthesized a novel 3D porous nitrogen-rich carbon catalyst by doping nitrogen in CDs (N-PCFs). The structural investigation revealed that N-PCFs exhibited a pore diameter of about $0.5-100 \mathrm{~nm}$ and a large surface area of $483.7 \mathrm{~m}^{2} \mathrm{~g}^{-1}$ as confirmed from the SEM and Brunauer-Emmett-Teller (BET) analysis Figure 10a, b. The anode constructed using N-PCFs displayed contribution of capacitive behavior as well holds excellent rate capability in $0.01-3.0 \mathrm{~V}$ potential window, as witnessed from the corresponding CV curves displayed in Figure 10c. Furthermore, the N-PCFs anode demonstrated superior cycling capability retaining $840 \mathrm{mAh} \mathrm{g}^{-1}$ at $2 \mathrm{~A} \mathrm{~g}^{-1}$ after 1000 cycles in LIBs which was much better compared to its reference anode Figure $10 \mathrm{~d}$.

A similar kind of results was observed by Jing et al. with the coating CQDs surface of $\mathrm{Mn}_{3} \mathrm{O}_{4}$ particle. ${ }^{186}$ In their study, it stated that the CQDs coating that performed by using an alternating voltage electrochemical route caused the structural change in the $\mathrm{Mn}_{3} \mathrm{O}_{4}$ from particle to nano-octahedra structure which in turn significantly improved the surface area and electrochemical properties of resulting $\mathrm{Mn}_{3} \mathrm{O}_{4}-\mathrm{CQDs}$ nanocomposite. Benefited from the higher surface area, the nanocomposite greatly enhanced its discharge capacity in comparison with only the $\mathrm{Mn}_{3} \mathrm{O}_{4}$ particles which were revealed from the charge-discharge profile Figure 11a. As a consequence, high-performance LIBs especially high specific capacity (934 $\mathrm{mA} \mathrm{h} \mathrm{g}^{-1}$ ) and improved cycling stability retaining 99\% capacity under a large current density of $100 \mathrm{~mA} \mathrm{~g}^{-1}$ was deliberated which was higher than that of the individual samples when these nanocomposite applied as an anode Figure $11 \mathrm{~b}$. For sodium-ion batteries (SIBS), coulombic efficiency of as high as $91 \%$ was achieved from a CDs anode that was derived from the supernatant of hydrothermal carbonization (HTC). ${ }^{187}$ Kumar et al. synthesized the novel anode by depositing Sn nanoparticles decorated with Sn@CDs on the copper foil. ${ }^{51}$ This anode 
showed improved electrochemical properties and better coulombic efficiencies which were attributed to the reduced pulverization effects.

In addition, due to its strong dimensional stability, peculiar morphology, and high surface areas, highly conducting carbon-based materials such as graphene and CNTs or their nanocomposites are also investigated as anode materials. Besides, the utility of these materials as an effective anode material for LIBs can also be improved by defect engineering, such as increasing defects, increasing the grid disorder, and pores generation. However, these deficient graphenes and CNTs could be aggregated after a while due to intense correlations between van der Waals and high surface energy. If the surface of these highly conducting graphene and carbon nanotubes is functionalized with carbon-based carbon dots, a hybridized graphene and carbon nanotube composite is formed. The functional groups (-OH and $\mathrm{COO}^{-}$) on the graphene quantum dots create the negative charge over the surface of CNTs and avoid the aggregation of CNTs due to the same charge molecules repel to each other, besides these functionalized CNTs contributing to increase the massive Li-ion storage sites. These hybridized graphenes and CNTs showed higher performance than their individual components. It will not improve the number of active sites, but it will also help to reduce mechanical stress due to changes in volume during the charge-discharge process. Graphene quantum dots functionalized CNTs were synthesized by Zhao et al. using the hydrothermal process and subsequent heating at 400 and $800{ }^{\circ} \mathrm{C}$ in an $\mathrm{H}_{2} / \mathrm{Ar}$ atmosphere. ${ }^{188}$ The synthesized hybrid GQDs wrapped CNTs (GQDs@CNTs) are used as anode materials for Li-lon battery applications, and they have a high specific capacity (700 mAhg1 at $100 \mathrm{mAg}^{-1}$ after 100 cycles) and rate performance. Even at a high current density of $1,000 \mathrm{~mA} \cdot \mathrm{g}^{-1}$, the reversible specific capacity remained at $483 \mathrm{mAh} \cdot \mathrm{g}^{-1}$ after 350 cycles. 

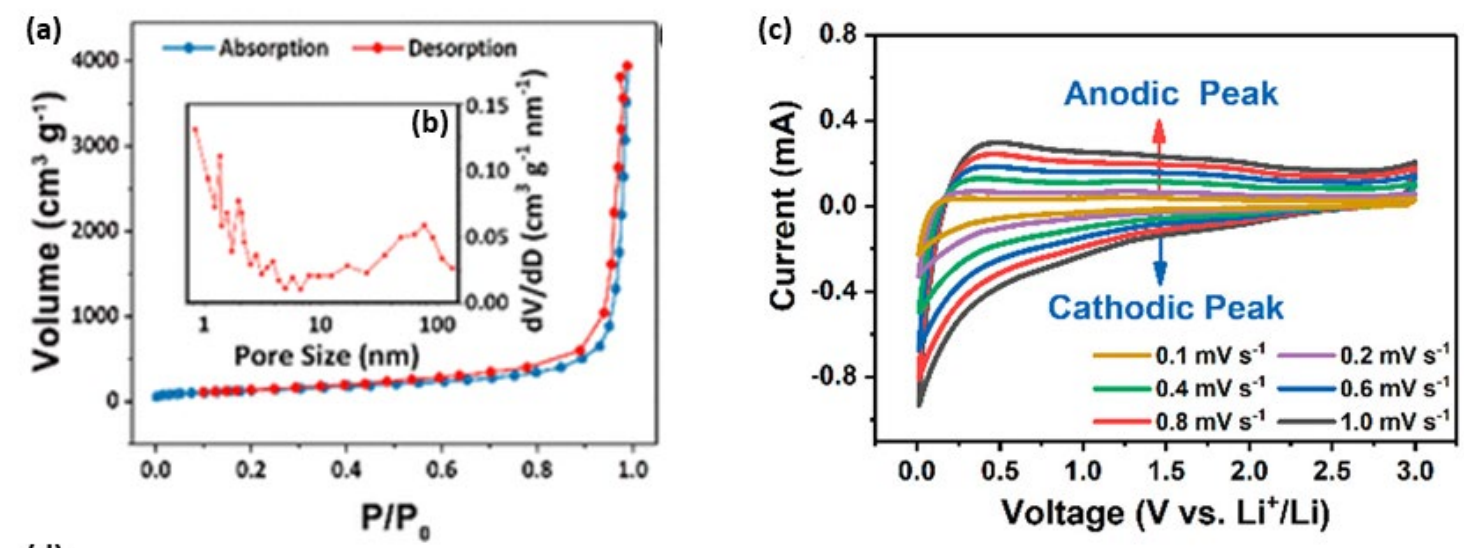

(d)

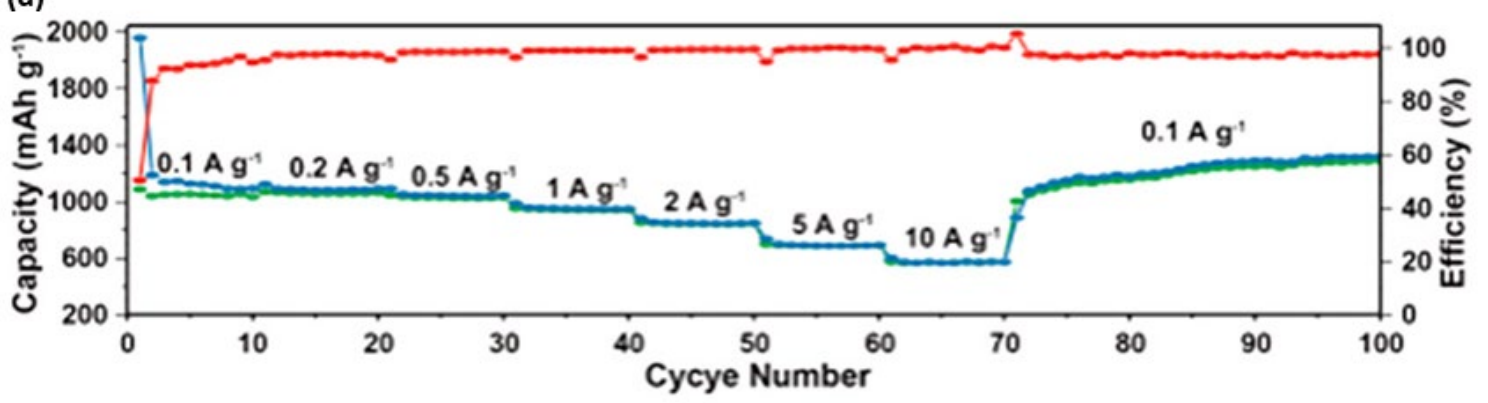

Figure 10: (a) $\mathrm{N}_{2}$ adsorption-desorption isotherms; inset of image (a) representing the pore sizes distribution curves of N-PCFs (b); CV curves at various scan rate (c) and (d) Cycling performances along with coulombic efficiencies of N-PCFs. Reproduced with permission from ref ${ }^{185}$. Copyright 2019 American Chemical Society.

On the other side, much of the research has been done to address the problem of sluggish ion transfer, low energy density, and poor cycling stability by modifying cathode with carbonbased materials such as graphene, PANI, CNT, CQDs, and doping of transition metals. ${ }^{189}$ As same as the anode, the functionalization of CNTs/graphene resulted in the capacity and cycle stability life. Appropriately, Chen et al. shown that the use of graphene-CNTs facilitated Liions diffusion and improve electron-ion mobility by generating conductive pathways for charge transfer. ${ }^{190}$ In the same way, PANI modified cathodes are demonstrated to enhance the lithium-ion diffusion rate in LIB's by avoiding the agglomeration of cathode material. ${ }^{191}$

The fact that, however, is a challenge with the performance of most of these carbon-based cathode materials is that they suffer from the problems of poor conductivity and slow charge transfer dynamics. Until further studies are being employed to improve these compounds to obtain more optimal electron mobility thus electrochemical performance by the addition of 
CQDs. Here is the main role of the CQDs to solve the conductivity problem of the cathode and anode materials as well as it helps to control the volume expansion during the intercalation and deintercalation of ions increases in the cycle stability of electrode material and also improve the capacity of electrode materials. ${ }^{184}$ For example, aiming to solve the poor conductivity and rate capability of the electrode, Liu et al. and coworkers modified $\mathrm{Na}_{3} \mathrm{~V}_{2}(\mathrm{PO} 4)_{2} \mathrm{~F}_{3}$ by using CQDs that were prepared using a facile solvothermal route. ${ }^{192}$ It observed that appropriate tuning of the reaction time and CQDs amounts greatly contributed to morphology, crystal structure, and electron-ion mobility. Benefiting from the higher surface area and rapid electron transport a higher performance of 126.6 and $84.7 \mathrm{mAh} \mathrm{g}^{-1}$ at $0.2 \mathrm{C}$ and $50 \mathrm{C}$, respectively, was achieved for the $\mathrm{Na}_{3} \mathrm{~V}_{2}\left(\mathrm{PO} \mathrm{P}_{2} \mathrm{~F}_{3} @ \mathrm{CQDs}\right.$ cathode. Additionally, these cathodes maintained their performance over a long period retaining $90.2 \%$ capacity 6000 cycles at 30C. Hu et al. have shown that the issues such as rapid polysulfides dissolution, loss of the active material, and shuttle reaction in lithium-sulfur (Li-S) batteries have been resolved by coating CQDs over coated sulphur. ${ }^{193}$ Particularly, the sulfur cathode modified from polyethyleneimine-functionalized CDs (PEI-CDs) has shown great ability to bind the polysulfides species and significantly enhanced lithium-ion conductivity thus obtained a high current density of $8 \mathrm{~mA} \mathrm{~cm}^{-2}$.
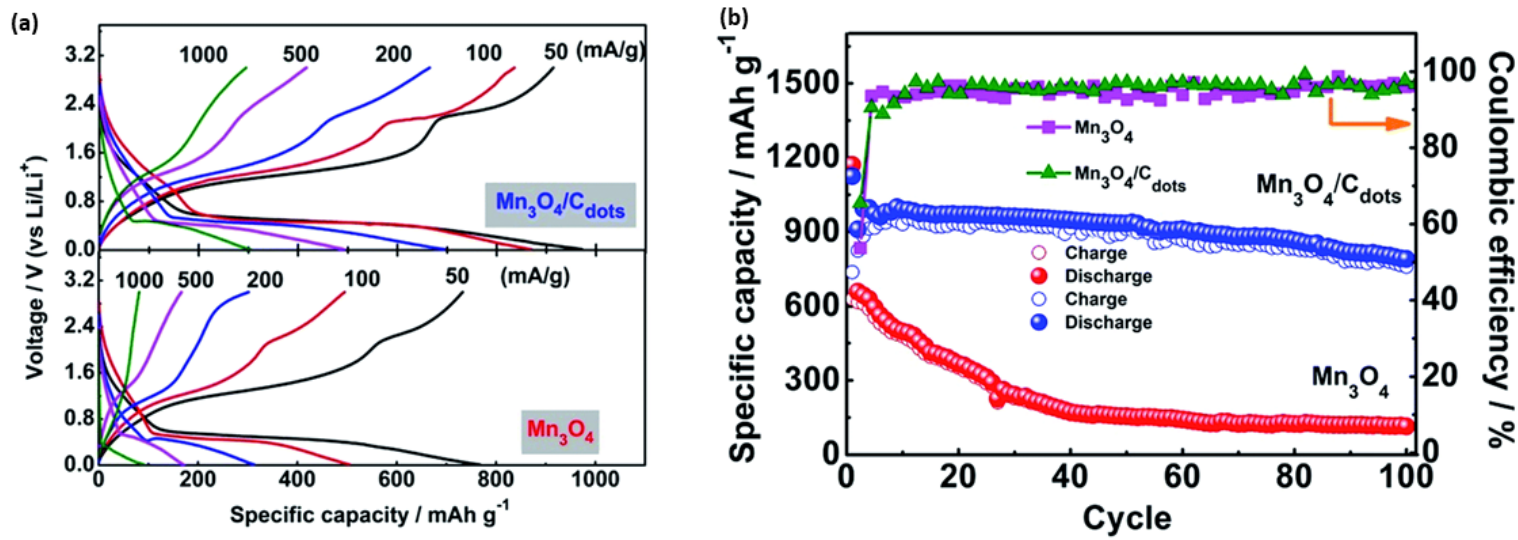

Figure 11: (a) Galvanostatic charge-discharge curves and (b) Comparison of cycle retention characteristics between pristine $\mathrm{Mn}_{3} \mathrm{O}_{4}$ and $\mathrm{Mn}_{3} \mathrm{O}_{4}-\mathrm{CD}$ s nanocomposites. Reproduced with permission from ref ${ }^{194}$. Copyright 2015 The Royal Society of Chemistry.

Similar to that of supercapacitor and PV applications, the nanocomposite strategy is an auspicious strategy to achieve economic and electrochemically rich i.e. high specific area and 
highly conductive electro catalysts. Additionally, it plays an important role in optimizing the morphology and surface properties of nanocomposites.

\subsection{Hydrogen evolution reaction}

Hydrogen is one of the best alternative renewable energy sources among other energy sources because it is carbon-free along with having a high energy density. Here is we can generate the hydrogen in two ways one is photo-catalytically water splitting and another one is the electrocatalytically water slitting. ${ }^{195-198}$ In the photocatalytic hydrogen evolution, hydrogen is generated with the help of sunlight fall on the catalyst and in the case of electrocatalytic hydrogen evolution, hydrogen is generated with the help of voltage applied to the catalyst. ${ }^{199}$ Nowadays, CQDs used as a catalyst for the hydrogen generation using a photocatalytic and electrochemical process. As, it has all the required properties for both process such as large surface area, multiple active edges such as $\mathrm{COOH}, \mathrm{OH}, \mathrm{CHO}, \mathrm{NH}_{2}$. Thus, they can contribute to increase the wettability of catalyst and also contribute to coordination with metal to form the metal-carbon dots composite 200,201 , defect sites, rapid electron transfer, tunable photoluminescence $(P L)^{202}$, and form the holes and electron by absorbing UV and visible light. ${ }^{203}$ Besides these unique properties, they are cost-effective and sizecontrollable. ${ }^{59,204}$ Here we have discussed some recently reported articles on the CQDs-based composite materials.

Elsayed et al. synthesized the metal-free photocatalyst by implanting the nitrogen-doped CQDs (NCQDs) polymer (PS-PEGCOOH) using a simple chemical route. ${ }^{205}$ In comparison to PSPEGCOOH, the prepared NCQDs covered by PS-PEGCOOH heterostructure material demonstrate a 5-fold hydrogen evolution efficiency in visible light. This enhanced hydrogen evolution efficiency of heterostructures catalyst due to the incorporated NCQDs help in enhancing the charge separation and the photocatalytic efficiency of PS-PEGCOOH. They are also demonstrated that after implantation of NCQDs over the PS-PEGCOOH, the recombination of generated charge almost double compared to un-implanted PS-PEGCOOH. Furthermore, these increased charges help in enhancing the stability of excited electrons. Likewise, Zhou et al. constructed g- $\mathrm{C}_{3} \mathrm{~N}_{4}$ quantum dot/a- $\mathrm{TiO}_{2} / \mathrm{r}-\mathrm{TiO}_{2}$ by simple mixing method of $\mathrm{g}-\mathrm{C}_{3} \mathrm{~N}_{4}$, anatase $\mathrm{TiO}_{2}$, and rutile $\mathrm{TiO}_{2}$ powder in water with the help of sonication method. ${ }^{206}$ The optimized $\mathrm{QCN} / \mathrm{a}-\mathrm{TiO}_{2} / \mathrm{r}-\mathrm{TiO}_{2}$ heterojunctions showed improved photocatalytic $\mathrm{H}_{2}$ and $\mathrm{O}_{2}$ evolution, with the hydrogen evolution rate $\left(49.3 \mathrm{~mol} \mathrm{~h}^{-1}\right)$ being 11.7 
times that of bare P25 under visible light irradiation, and ample catalytic stability, as demonstrated by recycling studies. The significantly increased photocatalytic activity was attributed to the synergistic effects of alignment of energy levels at interfaces, dimensionality, and heterojunction component. The main role of the $\mathrm{g}-\mathrm{C}_{3} \mathrm{~N}_{4}$ quantum dot to promote the separation and transfer of the photogenerated electron-hole pairs due to a similar kind of band structure and strong coupling with $\mathrm{TiO}_{2} / \mathrm{r}-\mathrm{TiO}_{2}$ heterojunction. Moreover, it contributes to absorbing the photon from the visible region and enhances the photogenerated charges.

In another report, Shen et al. used hydrothermal and subsequent chemical treatment with a reducing agent to create the graphene quantum dots-transition metal nanoparticles $(\mathrm{Rh}, \mathrm{Pt}$, and $\mathrm{Ru}$ ) composite. ${ }^{207}$ These synthesized composites were used to photocatalytic hydrolysis of $\mathrm{NaBH}_{4}$ and $\mathrm{NH}_{3} \mathrm{BH}_{3}$ for hydrogen evolution. For GQDs-RhNPs, GQDs-RuNPs, and GQDsPtNPs, the turnover frequency is 656,384 , and $281 \mathrm{~mol} \mathrm{H}_{2} \mathrm{~mol} \mathrm{cat}^{-1} \mathrm{~min}^{-1}$, respectively. The GQDs in this composite act as a stabilizing agent for transition metal particles, which contributes to the increased reusability of the HER catalyst without a noticeable decrease in catalytic activity. Nasir et al. successfully prepared the Au/HBTiO $/ g-\mathrm{C}_{3} \mathrm{~N}_{4} \mathrm{QD}$ 's composite by plasmonic Au NPs and g- $\mathrm{C}_{3} \mathrm{~N}_{4}$ Quantum Dots (QD's) loading on the branched $\mathrm{TiO}_{2}$ fibers. ${ }^{208}$ The composite exhibits significant improvement in photocatalytic hydrogen evolution, producing approximately $2.22 \mathrm{mmol} \mathrm{g}^{-1} \mathrm{~h}^{-1}$ hydrogen. The composite sample reveals the $19.5 \%$ quantum efficiency to produce hydrogen at the light of $420 \mathrm{~nm}$. This increased photocatalytic hydrogen efficiency due to the synergistic effect of all individual components and here g- $\mathrm{C}_{3} \mathrm{~N}_{4}$ QDs contribute to enhancing the composite optical properties in order to absorb visible light and it helps to reduce the bandgap of $\mathrm{Au} / \mathrm{HBTiO}_{2} / \mathrm{g}-\mathrm{C}_{3} \mathrm{~N}_{4} \mathrm{QD}$ 's composite. Additional information related to the performance studies of CQDs and their composites for electrocatalytic HER is summarized in Table 3.

Table 3: Performance studies of CQDs and their composites for electrocatalytic HER.

\begin{tabular}{|l|l|l|l|l|l|}
\hline Catalyst & $\begin{array}{l}\text { Overpotential } \\
(\eta \mathbf{1 0}) \mathbf{m V}\end{array}$ & $\begin{array}{l}\text { Current density } \\
\left(\mathbf{m A} / \mathbf{c m}^{2}\right)\end{array}$ & Electrolyte & $\begin{array}{l}\text { Tafel slope } \\
(\mathbf{m V} / \mathbf{d e c})\end{array}$ & Reference \\
\hline $\mathrm{RuP}_{2} / 1.03 C Q D s-900$ & 26 & 10 & $1 \mathrm{M} \mathrm{KOH}$ & 61.65 & 209 \\
\hline $\mathrm{Ni}_{5} \mathrm{Mo}_{3} \mathrm{P} @ \mathrm{CDs}_{3}$ & 183 & 10 & $0.5 \mathrm{M} \mathrm{H}_{2} \mathrm{SO}_{4}$ & 41.04 & 210 \\
\hline $\mathrm{Ni}-\mathrm{Cu} / \mathrm{RCQDs} / \mathrm{GCE}$ & -200 & 10 & $0.5 \mathrm{M} \mathrm{H}_{2} \mathrm{SO}_{4}$ & 83 & 211 \\
\hline
\end{tabular}




\begin{tabular}{|c|c|c|c|c|c|}
\hline Ru@CQDs 800 & 65 & 10 & $1 \mathrm{M} \mathrm{KOH}$ & 63 & 212 \\
\hline 3-CQDs/MnxNis-xP4 & 31 & 10 & $1 \mathrm{M} \mathrm{KOH}$ & 41 & 213 \\
\hline N-CQDs-17h & 341 & 10 & $0.5 \mathrm{M} \mathrm{H}_{2} \mathrm{SO}_{4}$ & 126 & 214 \\
\hline RuNi/CQDs & 13 & 10 & $1 \mathrm{M} \mathrm{KOH}$ & 40 & 215 \\
\hline Pt-CQDs/Gr-C400 & 38 & 10 & $0.5 \mathrm{M} \mathrm{H}_{2} \mathrm{SO}_{4}$ & 40 & 216 \\
\hline $\begin{array}{l}\mathrm{g}-\mathrm{C}_{3} \mathrm{~N}_{4} \text { (NS/QD) } / \mathrm{MoS}_{2} \\
\text { (NSt) }\end{array}$ & 280 & 2 & $0.5 \mathrm{M} \mathrm{H}_{2} \mathrm{SO}_{4}$ & 88 & 217 \\
\hline $\begin{array}{l}\text { NDCDs-AgNi alloy NPs } \\
500\end{array}$ & 79 & 1 & $0.5 \mathrm{M} \mathrm{H}_{2} \mathrm{SO}_{4}$ & 368 & 218 \\
\hline n-Pd@NDCDs/GC & -291 & 10 & $0.5 \mathrm{M} \mathrm{H}_{2} \mathrm{SO}_{4}$ & 135 & 219 \\
\hline \multirow[t]{3}{*}{ RuNi/CQDs-600 } & 13 & 10 & $1 \mathrm{M} \mathrm{KOH}$ & 40 & \multirow[t]{3}{*}{215} \\
\hline & 18 & 10 & $1 \mathrm{MPBS}$ & 76 & \\
\hline & 59 & 10 & $0.5 \mathrm{M} \mathrm{H}_{2} \mathrm{SO}_{4}$ & 55 & \\
\hline Pd@G-NS & 32 & 10 & $0.5 \mathrm{M} \mathrm{H}_{2} \mathrm{SO}_{4}$ & 33 & 220 \\
\hline 1\%Pt/CQDs/CNT & 29 & 10 & $0.5 \mathrm{M} \mathrm{H}_{2} \mathrm{SO}_{4}$ & 22 & 221 \\
\hline Au/Cdot nanohybrid & 150 & 10 & $0.5 \mathrm{M} \mathrm{H}_{2} \mathrm{SO}_{4}$ & 54 & 222 \\
\hline Ru1CoP/CDs1000 & 51 & 10 & $1 \mathrm{M} \mathrm{KOH}$ & 73.4 & 223 \\
\hline Ru1CoP/CDs1100 & 49 & 10 & $0.5 \mathrm{M} \mathrm{H}_{2} \mathrm{SO}_{4}$ & 52.3 & 223 \\
\hline NiCoPt/Graphene-dot & 45.54 & 10 & $0.5 \mathrm{M} \mathrm{H}_{2} \mathrm{SO}_{4}$ & 33.90 & 224 \\
\hline $\begin{array}{l}\text { Pt-QDs/MWCNT-BF } 4 \\
(30 \mathrm{~V})\end{array}$ & 35.3 & 10 & $0.5 \mathrm{M} \mathrm{H}_{2} \mathrm{SO}_{4}$ & 34 & 225 \\
\hline N-GQDs/GF & -72 & 10 & $0.5 \mathrm{M} \mathrm{H}_{2} \mathrm{SO}_{4}$ & 84 & 226 \\
\hline 30 mg/LCQDs@NiCoP & 108 & 10 & $0.5 \mathrm{M} \mathrm{H}_{2} \mathrm{SO}_{4}$ & 80 & 227 \\
\hline CQDs/MoP & 210 & 20 & $1 \mathrm{M} \mathrm{KOH}$ & 56 & 228 \\
\hline \multirow[t]{2}{*}{ N-C@Co NPs600 } & 137 & 10 & $0.5 \mathrm{M} \mathrm{H}_{2} \mathrm{SO}_{4}$ & 110.3 & \multirow[t]{2}{*}{229} \\
\hline & 134 & 10 & $1 \mathrm{M} \mathrm{KOH}$ & -- & \\
\hline GQD-Mo-Ni $\mathrm{S}_{2} / \mathrm{NF}$ & 68 & 10 & $1 \mathrm{M} \mathrm{KOH}$ & 68 & 230 \\
\hline $\mathrm{CDs} / \mathrm{NiCO}_{2} \mathrm{~S}_{4} / \mathrm{Ni}_{3} \mathrm{~S}_{2} / \mathrm{NF}$ & 127 & 10 & $1 \mathrm{M} \mathrm{KOH}$ & 148 & 231 \\
\hline $\begin{array}{l}\mathrm{NCDs} / \mathrm{Ni}_{3} \mathrm{~S}_{2} / \mathrm{NF} \\
\text { composites }\end{array}$ & 187 & 20 & $1 \mathrm{M} \mathrm{KOH}$ & 127 & 232 \\
\hline $\mathrm{CuCO}_{2} \mathrm{O}_{4} @ \mathrm{CQDS}$ & 331 & 10 & $1 \mathrm{M} \mathrm{KOH}$ & 65 & 233 \\
\hline
\end{tabular}




\subsection{Oxygen evolution reaction}

Oxygen evolution reaction is one of the half parts of the hydrogen fuel cell to generate hydrogen. The oxygen evolution process is sluggish because, OER mandated the high overpotential to evaluate oxygen from the water, in which an $\mathrm{O}-\mathrm{O}$ a covalent bond is formed by four electrons transfer process. ${ }^{234,235}$ Here well-known Ir and Ru-based catalysts can easily break water molecule and form the $\mathrm{O}-\mathrm{O}$ bond easily. ${ }^{236,237}$ However, there are some downsides with these catalysts such as high cost and scarcity, which limits their large-scale application and commercial. Whereas transition metal-based catalyst is a non-precious alternative catalyst for oxygen evolution, but this catalyst is not completely released to largescale production of oxygen due to its poor activity. ${ }^{238-240}$ Nevertheless, few research groups demonstrated that this issue could be bottlenecked by incorporating carbon-based materials with a transition metal. ${ }^{241,242}$ In recent years, the CQDs nanocomposites have shown excellent catalytic activity towards the oxygen evolution because of CQDs that could not only improve the electronic conductivity of nanocomposites but also protect it from the corrosion of metal oxide and oxidation during water splitting. ${ }^{243}$

Chang et al. synthesized the single atomically anchored iron-on graphene quantum dots by using hydrothermal and subsequent use the simple chemical method to prepare composite and the prepared material used as electrocatalyst for electrocatalytic OER. ${ }^{244}$ The optimized $1.5 \mathrm{Fe}(\mathrm{NO})_{2}-\mathrm{N}-\mathrm{GQDs}$ composite demonstrates overall excellent electrocatalytic activity compared to the $\mathrm{N}-\mathrm{GQDs}, \mathrm{RuO}_{2}$, and various concentrations of iron-loaded $\mathrm{Fe}(\mathrm{NO})_{2}-\mathrm{N}-\mathrm{GQDs}$, the $1.5 \mathrm{Fe}(\mathrm{NO})_{2}-\mathrm{N}-\mathrm{GQDs}$ catalyst required only $270 \mathrm{mV}$ overpotential to achieve $10 \mathrm{~mA} / \mathrm{cm}_{2}$ current density. Moreover, it shows a very low Tafel slope $(48 \mathrm{mV} / \mathrm{dec})$ and a highly stable i-t curve for OER for 4 hours. They have claimed that excellent OER activity is due to the synergistic effect of both $\mathrm{Fe}(\mathrm{NO})_{2}$ and $\mathrm{N}-\mathrm{GQDS}$. The main role of $\mathrm{N}-\mathrm{GQD}$ s to increase the conductivity of composite material and provide a large surface area to accumulate the charge which contributes to the increase in the oxygen evolution concentration. In another work, Bai et al. prepared the $\mathrm{CdP}_{2}-\mathrm{CDs}-\mathrm{CoP}$ nanoarrays over the nickel foam using hydrothermal and subsequent, as prepared film heated at $450 \mathrm{C}$ in the presence of $1 \mathrm{~g}$ sodium hypophosphite powder in a tube furnace. ${ }^{245}$ The prepared film demonstrates the excellent OER activity in 1 $\mathrm{M} \mathrm{KOH}$ electrolyte compared to the individual and without the added $\mathrm{CdP}_{2}$-Cop composite film. It takes just $285 \mathrm{mV}$ overpotential to reach a current density of $10 \mathrm{~mA} / \mathrm{cm}^{2}$ and has a 
small Tafel slope $(81.7 \mathrm{mV} / \mathrm{dec})$. The excellent OER activity attributed to the quasi-zerodimensional CDs enriches the structure/composition, exposes more active sites for electrocatalytic reactions, and improves the conductivity.

The carbon-dots@metal organic framework composite (CQDs@MOF) was synthesized by Rehman et al. using hydrothermal methods and was investigated as a catalyst for oxygen production. In comparison to state-of-the-art electro-catalytic systems i.e. $\mathrm{RO}_{2}$ and $\mathrm{IrO}_{2}$, prepared CQDs@MOF to give excellent OER operation in 1 MKH electrolyte solution. ${ }^{246}$ The prepared composite catalyst only needed output of $1.55 \mathrm{~V}$ to achieve a current density of 10 $\mathrm{mA} / \mathrm{cm}^{2}$ and it has a low $62 \mathrm{mV} / \mathrm{dec}$ Tafel slope. It also has a high OER stability of up to 40 hours and up to $100 \mathrm{CV}$ cycles. These excellent results are attributed to the use of CQD composites, which help to increase the conductivity and stability of MOF. Tian et al. used a microwave-assisted hydrothermal approach to build varying amounts of carbon-quantumdots-embedded $\mathrm{MnO}_{2}$ nanoflowers. ${ }^{247}$ The synthesized CQDs0.15- $\mathrm{MnO}_{2}$ composite exhibits excellent electrocatalytic behavior, requiring just $343 \mathrm{mV}$ overpotential to achieve $10 \mathrm{~mA} / \mathrm{cm}^{2}$ current density and a very low Tafel slope of $43.6 \mathrm{mV} / \mathrm{dec}$. This increases electrocatalytic activity due to the integration of CQDs with $\mathrm{MnO}_{2}$, which helps to increase active surface areas, improved conductivity, and rapid charge transfer pathways, resulting in not only significantly enhanced electrocatalytic activity but also high stability (35 hours) for OER.

Zhong et al. used a simple chemical reaction to create cobalt(III) tetraphenylporphyrin (CoP) nanowires (NWs), which were then converted in situ into zero-dimensional CoP/NGQDs nanocomposites by adding nitrogen-doped graphene quantum dots (NGQDs) as the template and dopant. ${ }^{248}$ Extensive experiments show that NGQDs-limiting self-assembly of CoP molecules along the axial path, followed by the creation of Z-scheme CoP/NGQDs heterojunctions, is critical for effective photocatalytic oxygen evolution. These unagglomerated CoP nanowires are effectively interacting with the light and increase the stability of photoinduced charge in CoP/NGQDs than the CoP nanowire. Table 4 shows the performance of CQDs and their composites for electrocatalytic OER. The advantages of combining CQDs with transition metal-based materials composite to enhance the catalytic properties of transition metal-based materials for hydrogen and oxygen evolution reactions have been briefly discussed in Sections 3.4 and 3.5. 
Table 4: Performance studies of CQDs and their composites for electrocatalytic OER.

\begin{tabular}{|c|c|c|c|c|c|}
\hline Catalyst & $\begin{array}{l}\text { Overpotential } \\
\left(\eta_{10}\right) \mathrm{mV}\end{array}$ & $\begin{array}{l}\text { Current density } \\
\left(\mathrm{mA} / \mathrm{cm}^{2}\right)\end{array}$ & Electrolyte & $\begin{array}{l}\text { Tafel slope } \\
\text { (mV/dec) }\end{array}$ & Reference \\
\hline $\mathrm{CQDs} / \mathrm{SnO}_{2}-\mathrm{Co}_{3} \mathrm{O}_{4}$ & 575 & 10 & $1 \mathrm{M} \mathrm{KOH}$ & 60 & 249 \\
\hline $\mathrm{NiFeO}_{x} @ \mathrm{NC}$ & 195 & 10 & $1 \mathrm{M} \mathrm{KOH}$ & 33 & 250 \\
\hline $1.5 \mathrm{Fe}(\mathrm{NO})_{2}-\mathrm{N}-\mathrm{GQDs}$ & 270 & 10 & $1 \mathrm{M} \mathrm{KOH}$ & 48 & 251 \\
\hline $\mathrm{CdP}_{2}-\mathrm{CDs}-\mathrm{CoP}$ & 285 & 10 & $1 \mathrm{M} \mathrm{KOH}$ & 81.77 & 252 \\
\hline CQDs@MOF & 320 & 10 & $1 \mathrm{M} \mathrm{KOH}$ & 62 & 253 \\
\hline $\mathrm{CQDS}_{0.15}-\mathrm{MnO}_{2}$ & 343 & 10 & $1 \mathrm{M} \mathrm{KOH}$ & 43.6 & 247 \\
\hline NiFe LDHs@GQDs & 189 & 10 & $1 \mathrm{M} \mathrm{KOH}$ & 23.6 & 254 \\
\hline N-GQDs/NiFe-LDH & 279 & 10 & $1 \mathrm{M} \mathrm{KOH}$ & 47 & 255 \\
\hline $\mathrm{Co}(\mathrm{OH})_{2} @ \mathrm{NCDs}$ & 296 & 10 & $1 \mathrm{M} \mathrm{KOH}$ & 70.5 & 256 \\
\hline $\begin{array}{l}\text { CQDs decorated } \\
\mathrm{Ba}_{0.5} \mathrm{Sr}_{0.5} \mathrm{Co}_{0.8} \mathrm{Fe}_{0.2} \mathrm{O}_{3-} \\
\delta\end{array}$ & 350 & 10 & $1 \mathrm{M} \mathrm{KOH}$ & 66 & 257 \\
\hline N-C@Co NPs600 & 304 & 10 & $1 \mathrm{M} \mathrm{KOH}$ & -- & 229 \\
\hline GQD-Mo-Ni ${ }_{3} \mathrm{~S}_{2} / \mathrm{NF}$ & 326 & 20 & $1 \mathrm{M} \mathrm{KOH}$ & 69 & 230 \\
\hline $\mathrm{N}-\mathrm{GQDs}) / \mathrm{Co}_{3} \mathrm{O}_{4}$ & 330 & 10 & $0.1 \mathrm{M} \mathrm{KOH}$ & 71 & 258 \\
\hline $\begin{array}{l}\mathrm{CDs} / \mathrm{NiCO}_{2} \mathrm{~S}_{4} / \mathrm{Ni}_{3} \mathrm{~S}_{2} / \mathrm{N} \\
\mathrm{F}\end{array}$ & 116 & 10 & $1 \mathrm{M} \mathrm{KOH}$ & 99 & 231 \\
\hline $\begin{array}{l}\mathrm{NCDs} / \mathrm{Ni}_{3} \mathrm{~S}_{2} / \mathrm{NF} \\
\text { composites }\end{array}$ & 340 & 200 & $1 \mathrm{M} \mathrm{KOH}$ & 67 & 232 \\
\hline $\mathrm{CuCo}_{2} \mathrm{O}_{4} @ \mathrm{CQDs}$ & 290 & 10 & $1 \mathrm{M} \mathrm{KOH}$ & 64 & 233 \\
\hline CoFe-CDs & 308 & 10 & $1 \mathrm{M} \mathrm{KOH}$ & 60.9 & 259 \\
\hline $\mathrm{Co}_{3} \mathrm{O}_{4}-\delta-\mathrm{QDs}$ & 270 & 10 & $1 \mathrm{M} \mathrm{KOH}$ & 38.8 & 260 \\
\hline
\end{tabular}

\section{Future research directions and Conclusion}

Luminescent CQDs are intriguing newcomers to the nanomaterials world in various energy applications. In this paper, the key synthesis methods and photochemical properties of CQDs are discussed, and their application in the field of energy is emphasized. The effect of various synthesis methods on the physical, chemical, optical, and electronic properties of CQDs are 
discussed. CQDs have several imperative applications in the prospective field of energy storage and conversion, which are a result of their unique and intrinsic characteristics. There is growing recognition among researchers and the scientific community of the importance of using a greater capacity and green conversion of energy. In the recent course of years, studies on the use of CQDs or CQDs modified nanomaterials have greatly expanded. Among all the synthesis methods, hydrothermal and electrochemical methods have the upper hand due to ease of composition and morphology control. In these methods, large surface are and uniform particle size can be obtained. The size, shape, surface functional groups, and heteroatom doping of CQDs can all affect their specific electronic and chemical structures. Note that the extent that doping and modification causes an increase in electrical conductivity, improves their physiochemical properties. Because of its astonishing optoelectronic properties that can separate charge carriers that have low light absorption and tuneable bandgap, the incorporation of CQDs into nanomaterials enhances the ability of extraction of solar cells to become more efficient. CQDs have a large surface area and high electron mobility, which is highly advantageous for the absorption of light in a wide spectrum therefore; they are often used as photo-sensitizers or active layers for photovoltaic devices. On the other side, the CQDs modified electrodes are outstanding at counter electrodes that alleviate volume expansion, boost ion diffusion rate, and enhance the electronic double layer kinetics, as well as improving interfacial electrical conductivity and electrochemical performance when applied in Li/Na ion batteries. Furthermore, the energy density, specific capacitance, and conductivity of supercapacitors could be dramatically increased by blending CQDs with conducting polymers, carbonates, as well as activated carbon materials. Thus, CQDs are accountable for providing more active sites in such structures and sites (either by creating new ones or activating existing ones).

However, progress has been made in this area in the development of CQDs and their uses in recent years, and the issue is not yet resolved. CQDs expand in extremely wide ranges when no particular size limit is imposed on their growth. Additionally, there are unknown properties in the CQDs that have yet to be investigated and it also leaves their nano-sized chemical and physical nature undefined which in turn restricts their application in energy storage devices. Another urgent issue facing CQDs industrialization and synthesis is that must be confronted is the fast development of the sources of their raw materials. Apart from this, the ability to 
reduce the manufacturing cost of CQDs is that this lack of standardization, which now hinders their large-scale application and commercialization. The ultimate goal is to combine environmentally clean, inexpensive, minimal toxicity, and efficient methods of production. There are still places where further development can take place to expand the progress made in this synthesis. This kind of development in particular has an abundance of opportunities where green chemical combinations are involved, where inexpensive production processes can be used.

Typically, CQD nanocomposites contributed to shortening the charge transfer pathways and maintain the cycle stability of electrode material because of its improved crystal structure and surface properties. Taking into consideration the above-mentioned advantages and limitations, more research expected in designing cost-efficient and environment-friendly nanocomposites using CQDs for delivering high energy density and stable electrodes for energy storage applications. Although CQDs have shown to have a role in energy application, several critical problems and obstacles yet to addressed for a thorough understanding of the underlying mechanism and process, and important knowledge of electrochemical performance. First, CQDs with high quantum yields are still hard to come by. Future research endeavours should concentrate on increasing the high quantum yield as well as chemical and photostability. Secondly, application-focused research should at the same time on improving the quality, selectivity, and robustness of CQDs for energy-driven platforms. We anticipate the production of more cost-effective, simple, and revolutionary synthetic methods, as well as novel promising energy applications, in the future to better realize the potential of these increasingly important carbon materials. 


\section{Author Information}

Corresponding Author

*Jia-Yaw Chang, Department of Chemical Engineering, National Taiwan University of Science and Technology, Taipei, 10607, Taiwan, Republic of China. E-mail: jychang@mail.ntust.edu.tw

Tel.: +886-2-27303636

Fax: $+886-2-27376644$

\section{Acknowledgment and Funding sources}

The authors would like to acknowledge financial supports from the Ministry of Science and Technology of the Republic of China (Contract No. MOST 108-2218-E-011-017 and 109-2113M-011-001). This work was financially supported by the Taiwan Building Technology Center from The Featured Areas Research Center Program within the framework of the Higher Education Sprout Project by the Ministry of Education in Taiwan.

\section{Author's contribution}

The review has been written through the contributions of all authors. All authors have approved the final version of the review.

\section{Declaration of competing interest}

The authors declare that they have no known competing financial interests or personal relationships that could have appeared to influence the work reported in this paper.

\section{References}

1. Ozkan, M., Quantum dots and other nanoparticles: what can they offer to drug discovery? Drug Discovery Today 2004, 9 (24), 1065-1071.

2. Warburton, R. J., Self-assembled semiconductor quantum dots. Contemporary physics 2002, 43 (5), 351-364.

3. Cao, L.; Wang, X.; Meziani, M. J.; Lu, F.; Wang, H.; Luo, P. G.; Lin, Y.; Harruff, B. A.; Veca, L. M.; Murray, D., Carbon dots for multiphoton bioimaging. Journal of the American Chemical Society 2007, 129 (37), 11318-11319.

4. $\quad$ Larson, D. R.; Zipfel, W. R.; Williams, R. M.; Clark, S. W.; Bruchez, M. P.; Wise, F. W.; Webb, W. W., Water-soluble quantum dots for multiphoton fluorescence imaging in vivo. Science 2003, 300 (5624), 1434-1436. 
5. Wang, R.; Lu, K.-Q.; Tang, Z.-R.; Xu, Y.-J., Recent progress in carbon quantum dots: synthesis, properties and applications in photocatalysis. Journal of Materials Chemistry A 2017, 5 (8), 3717-3734. 6. $\quad$ Li, S.-H.; Qi, M.-Y.; Fan, Y.-Y.; Yang, Y.; Anpo, M.; Yamada, Y. M.; Tang, Z.-R.; Xu, Y.-J., Modulating photon harvesting through dynamic non-covalent interactions for enhanced photochemical CO2 reduction. Applied Catalysis B: Environmental 2021, 292, 120157.

7. Xu, X.; Ray, R.; Gu, Y.; Ploehn, H. J.; Gearheart, L.; Raker, K.; Scrivens, W. A., Electrophoretic analysis and purification of fluorescent single-walled carbon nanotube fragments. Journal of the American Chemical Society 2004, 126 (40), 12736-12737.

8. Mai, X.-D.; Chi, T. T. K.; Nguyen, T.-C.; Ta, V.-T., Scalable synthesis of highly photoluminescence carbon quantum dots. Mater. Lett. 2020, 268, 127595.

9. Devi, P.; Saini, S.; Kim, K.-H., The advanced role of carbon quantum dots in nanomedical applications. Biosensors and Bioelectronics 2019, 141, 111158.

10. Jelinek, R., Carbon quantum dots. Carbon quantum dots. Springer International Publishing, Cham 2017, 29-46.

11. Sun, Y.-P.; Zhou, B.; Lin, Y.; Wang, W.; Fernando, K. S.; Pathak, P.; Meziani, M. J.; Harruff, B. A.; Wang, X.; Wang, H., Quantum-sized carbon dots for bright and colorful photoluminescence. Journal of the American Chemical Society 2006, 128 (24), 7756-7757.

12. Desmond, L.; Phan, A.; Gentile, P., Critical overview on the green synthesis of carbon quantum dots and their application for cancer therapy. Environmental Science: Nano 2021, 8, 848-862.

13. de Oliveira, B. P.; da Silva Abreu, F. O. M., Carbon quantum dots synthesis from waste and byproducts: Perspectives and challenges. Mater. Lett. 2021, 282, 128764.

14. Zhang, Y.; Chung, T.-S., Graphene oxide membranes for nanofiltration. Current Opinion in Chemical Engineering 2017, 16, 9-15.

15. Tian, X.; Zeng, A.; Liu, Z.; Zheng, C.; Wei, Y.; Yang, P.; Zhang, M.; Yang, F.; Xie, F., Carbon Quantum Dots: In vitro and in vivo Studies on Biocompatibility and Biointeractions for Optical Imaging. International journal of nanomedicine 2020, 15, 6519-6529.

16. Nurunnabi, M.; Khatun, Z.; Huh, K. M.; Park, S. Y.; Lee, D. Y.; Cho, K. J.; Lee, Y.-k., In Vivo Biodistribution and Toxicology of Carboxylated Graphene Quantum Dots. ACS Nano 2013, 7 (8), 68586867.

17. Zhao, D. L.; Chung, T.-S., Applications of carbon quantum dots (CQDs) in membrane technologies: A review. Water Research 2018, 147, 43-49.

18. Bhol, P.; Yadav, S.; Altaee, A.; Saxena, M.; Misra, P. K.; Samal, A. K., Graphene-Based Membranes for Water and Wastewater Treatment: A Review. ACS Applied Nano Materials 2021, 4 (4), 3274-3293.

19. Yadav, S.; Saleem, H.; Ibrar, I.; Naji, O.; Hawari, A. A.; Alanezi, A. A.; Zaidi, S. J.; Altaee, A.; Zhou, J., Recent developments in forward osmosis membranes using carbon-based nanomaterials. Desalination 2020, 482, 114375.

20. Gai, W.; Zhao, D. L.; Chung, T.-S., Thin film nanocomposite hollow fiber membranes comprising Na+-functionalized carbon quantum dots for brackish water desalination. Water Res. 2019, 154, 54-61.

21. Zhao, D. L.; Das, S.; Chung, T.-S., Carbon quantum dots grafted antifouling membranes for osmotic power generation via pressure-retarded osmosis process. Environ. Sci. Technol. 2017, 51 (23), 14016-14023.

22. Nazri, N. A. A.; Azeman, N. H.; Luo, Y.; Bakar, A. A. A., Carbon quantum dots for optical sensor applications: A review. Optics \& Laser Technology 2021, 139, 106928.

23. Song, Y.; Zhu, S.; Yang, B., Bioimaging based on fluorescent carbon dots. Rsc Advances 2014, 4 (52), 27184-27200.

24. Wang, Z.; Hu, T.; Liang, R.; Wei, M., Application of Zero-Dimensional Nanomaterials in Biosensing. Frontiers in Chemistry 2020, 8 (320).

25. Xia, C.; Zhu, S.; Feng, T.; Yang, M.; Yang, B., Evolution and Synthesis of Carbon Dots: From Carbon Dots to Carbonized Polymer Dots. Advanced Science 2019, 6 (23), 1901316. 
26. Tao, S.; Feng, T.; Zheng, C.; Zhu, S.; Yang, B., Carbonized Polymer Dots: A Brand New Perspective to Recognize Luminescent Carbon-Based Nanomaterials. J Phys Chem Lett 2019, 10 (17), 5182-5188.

27. Lim, S. Y.; Shen, W.; Gao, Z., Carbon quantum dots and their applications. Chem. Soc. Rev. 2015, 44 (1), 362-381.

28. Wang, Y.; Hu, A., Carbon quantum dots: synthesis, properties and applications. Journal of Materials Chemistry C 2014, 2 (34), 6921-6939.

29. Atchudan, R.; Edison, T. N. J. I.; Shanmugam, M.; Perumal, S.; Somanathan, T.; Lee, Y. R., Sustainable synthesis of carbon quantum dots from banana peel waste using hydrothermal process for in vivo bioimaging. Physica E: Low-dimensional Systems and Nanostructures 2021, 126, 114417.

30. Mohanraj, J.; Durgalakshmi, D.; Prabha, S.; Saravanan, R.; Vo, D.-V. N.; Aruna, P.; Ganesan, S., Green synthesis of white light emitting carbon quantum dots: fabrication of white fluorescent film and optical sensor applications. J. Hazard. Mater. 2021, 416, 125091.

31. Liu, W.; Li, C.; Ren, Y.; Sun, X.; Pan, W.; Li, Y.; Wang, J.; Wang, W., Carbon dots: surface engineering and applications. Journal of Materials Chemistry B 2016, 4 (35), 5772-5788.

32. Baker, S. N.; Baker, G. A., Luminescent carbon nanodots: emergent nanolights. Angew. Chem. Int. Ed. 2010, 49 (38), 6726-6744.

33. Lee, T.; Won, S.; Park, Y.; Kwon, W., Oxygen-less Carbon Nanodots with an Absolute Quantum Yield of 80\% for Display Applications. ACS Applied Nano Materials 2021, 4 (3), 2462-2469.

34. Zhu, B.; Sun, S.; Wang, Y.; Deng, S.; Qian, G.; Wang, M.; Hu, A., Preparation of carbon nanodots from single chain polymeric nanoparticles and theoretical investigation of the photoluminescence mechanism. Journal of Materials Chemistry C 2013, 1 (3), 580-586.

35. Peng, J.; Gao, W.; Gupta, B. K.; Liu, Z.; Romero-Aburto, R.; Ge, L.; Song, L.; Alemany, L. B.; Zhan, X.; Gao, G.; Vithayathil, S. A.; Kaipparettu, B. A.; Marti, A. A.; Hayashi, T.; Zhu, J.-J.; Ajayan, P. M., Graphene Quantum Dots Derived from Carbon Fibers. Nano Letters 2012, 12 (2), 844-849.

36. Jiang, K.; Sun, S.; Zhang, L.; Lu, Y.; Wu, A.; Cai, C.; Lin, H., Red, Green, and Blue Luminescence by Carbon Dots: Full-Color Emission Tuning and Multicolor Cellular Imaging. Angewandte Chemie International Edition 2015, 54 (18), 5360-5363.

37. Yuan, F.; Wang, Z.; Li, X.; Li, Y.; Tan, Z. a.; Fan, L.; Yang, S., Bright Multicolor Bandgap Fluorescent Carbon Quantum Dots for Electroluminescent Light-Emitting Diodes. Advanced Materials 2017, 29 (3), 1604436.

38. Schmidt, R.; Krasselt, C.; Göhler, C.; von Borczyskowski, C., The Fluorescence Intermittency for Quantum Dots Is Not Power-Law Distributed: A Luminescence Intensity Resolved Approach. ACS Nano 2014, 8 (4), 3506-3521.

39. Das, S. K.; Liu, Y.; Yeom, S.; Kim, D. Y.; Richards, C. I., Single-Particle Fluorescence Intensity Fluctuations of Carbon Nanodots. Nano Letters 2014, 14 (2), 620-625.

40. Choi, Y.; Kang, B.; Lee, J.; Kim, S.; Kim, G. T.; Kang, H.; Lee, B. R.; Kim, H.; Shim, S.-H.; Lee, G.; Kwon, O.-H.; Kim, B.-S., Integrative Approach toward Uncovering the Origin of Photoluminescence in Dual Heteroatom-Doped Carbon Nanodots. Chemistry of Materials 2016, 28 (19), 6840-6847.

41. Hu, S.-L.; Niu, K.-Y.; Sun, J.; Yang, J.; Zhao, N.-Q.; Du, X.-W., One-step synthesis of fluorescent carbon nanoparticles by laser irradiation. Journal of Materials Chemistry 2009, 19 (4), 484-488.

42. Sun, Y.-P.; Zhou, B.; Lin, Y.; Wang, W.; Fernando, K. A. S.; Pathak, P.; Meziani, M. J.; Harruff, B. A.; Wang, X.; Wang, H.; Luo, P. G.; Yang, H.; Kose, M. E.; Chen, B.; Veca, L. M.; Xie, S.-Y., QuantumSized Carbon Dots for Bright and Colorful Photoluminescence. Journal of the American Chemical Society 2006, 128 (24), 7756-7757.

43. Strauss, V.; Margraf, J. T.; Dolle, C.; Butz, B.; Nacken, T. J.; Walter, J.; Bauer, W.; Peukert, W.; Spiecker, E.; Clark, T.; Guldi, D. M., Carbon Nanodots: Toward a Comprehensive Understanding of Their Photoluminescence. Journal of the American Chemical Society 2014, 136 (49), 17308-17316.

44. Biazar, N.; Poursalehi, R.; Delavari, H. In Optical and structural properties of carbon dots/TiO2 nanostructures prepared via DC arc discharge in liquid, AIP Conference Proceedings, AIP Publishing LLC: 2018; p 020033. 
45. Dey, S.; Govindaraj, A.; Biswas, K.; Rao, C., Luminescence properties of boron and nitrogen doped graphene quantum dots prepared from arc-discharge-generated doped graphene samples. Chem. Phys. Lett. 2014, 595, 203-208.

46. Wang, X.; Feng, Y.; Dong, P.; Huang, J., A Mini Review on Carbon Quantum Dots: Preparation, Properties, and Electrocatalytic Application. Frontiers in Chemistry 2019, 7 (671).

47. Talat, M.; Awasthi, K.; Singh, V. K.; Srivastava, O., Investigations on Exotic Forms of Carbon: Nanotubes, Graphene, Fullerene, and Quantum Dots. Functionalized Nanomaterials I: Fabrications 2020, 125.

48. Hu, S.; Liu, J.; Yang, J.; Wang, Y.; Cao, S., Laser synthesis and size tailor of carbon quantum dots. Journal of Nanoparticle Research 2011, 13 (12), 7247-7252.

49. Jiang, H.; Chen, F.; Lagally, M. G.; Denes, F. S., New strategy for synthesis and functionalization of carbon nanoparticles. Langmuir 2010, 26 (3), 1991-1995.

50. Kumar, V. B.; Tang, J.; Lee, K. J.; Pol, V. G.; Gedanken, A., In situ sonochemical synthesis of luminescent Sn@ C-dots and a hybrid Sn@ C-dots@ Sn anode for lithium-ion batteries.RSC advances 2016, 6 (70), 66256-66265.

51. Kumar, V. B.; Tang, J.; Lee, K. J.; Pol, V. G.; Gedanken, A., In situ sonochemical synthesis of luminescent Sn@C-dots and a hybrid Sn@C-dots@Sn anode for lithium-ion batteries. RSC Advances 2016, 6 (70), 66256-66265.

52. Li, H.; Liu, R.; Liu, Y.; Huang, H.; Yu, H.; Ming, H.; Lian, S.; Lee, S.-T.; Kang, Z., Carbon quantum dots/Cu2O composites with protruding nanostructures and their highly efficient (near) infrared photocatalytic behavior. Journal of Materials Chemistry 2012, 22 (34), 17470-17475.

53. Zhuo, S.; Shao, M.; Lee, S.-T., Upconversion and Downconversion Fluorescent Graphene Quantum Dots: Ultrasonic Preparation and Photocatalysis. ACS Nano 2012, 6 (2), 1059-1064.

54. Kumar, R.; Kumar, V. B.; Gedanken, A., Sonochemical synthesis of carbon dots, mechanism, effect of parameters, and catalytic, energy, biomedical and tissue engineering applications. Ultrasonics Sonochemistry 2020, 64, 105009.

55. Liu, H.; Ye, T.; Mao, C., Fluorescent Carbon Nanoparticles Derived from Candle Soot. Angewandte Chemie International Edition 2007, 46 (34), 6473-6475.

56. S, T.; D, R. S., Green synthesis of highly fluorescent carbon quantum dots from sugarcane bagasse pulp. Applied Surface Science 2016, 390, 435-443.

57. Zhou, J.; Booker, C.; Li, R.; Zhou, X.; Sham, T.-K.; Sun, X.; Ding, Z., An Electrochemical Avenue to Blue Luminescent Nanocrystals from Multiwalled Carbon Nanotubes (MWCNTs). Journal of the American Chemical Society 2007, 129 (4), 744-745.

58. Lu, J.; Yang, J.-X.; Wang, J.; Lim, A.; Wang, S.; Loh, K. P., One-Pot Synthesis of Fluorescent Carbon Nanoribbons, Nanoparticles, and Graphene by the Exfoliation of Graphite in Ionic Liquids. ACS Nano 2009, 3 (8), 2367-2375.

59. Li, H.; He, X.; Kang, Z.; Huang, H.; Liu, Y.; Liu, J.; Lian, S.; Tsang, C. H. A.; Yang, X.; Lee, S.T., Water-Soluble Fluorescent Carbon Quantum Dots and Photocatalyst Design. Angewandte Chemie International Edition 2010, 49 (26), 4430-4434.

60. Liu, M.; Xu, Y.; Niu, F.; Gooding, J. J.; Liu, J., Carbon quantum dots directly generated from electrochemical oxidation of graphite electrodes in alkaline alcohols and the applications for specific ferric ion detection and cell imaging. Analyst 2016, 141 (9), 2657-2664.

61. Zhai, X.; Zhang, P.; Liu, C.; Bai, T.; Li, W.; Dai, L.; Liu, W., Highly luminescent carbon nanodots by microwave-assisted pyrolysis. Chem. Commun. 2012, 48 (64), 7955-7957.

62. Hsu, P.-C.; Chang, H.-T., Synthesis of high-quality carbon nanodots from hydrophilic compounds: role of functional groups. Chem. Commun. 2012, 48 (33), 3984-3986.

63. Gu, Z. G.; Li, D. J.; Zheng, C.; Kang, Y.; Wöll, C.; Zhang, J., MOF-Templated Synthesis of Ultrasmall Photoluminescent Carbon-Nanodot Arrays for Optical Applications. Angew. Chem. Int. Ed. 2017, 56 (24), 6853-6858. 
64. Zhu, H.; Wang, X.; Li, Y.; Wang, Z.; Yang, F.; Yang, X., Microwave synthesis of fluorescent carbon nanoparticles with electrochemiluminescence properties. Chemical Communications 2009, (34), 5118-5120.

65. Tang, L.; Ji, R.; Cao, X.; Lin, J.; Jiang, H.; Li, X.; Teng, K. S.; Luk, C. M.; Zeng, S.; Hao, J.; Lau, S. P., Deep Ultraviolet Photoluminescence of Water-Soluble Self-Passivated Graphene Quantum Dots. ACS Nano 2012, 6 (6), 5102-5110.

66. Zhang, B.; Liu, C.-y.; Liu, Y., A Novel One-Step Approach to Synthesize Fluorescent Carbon Nanoparticles. European Journal of Inorganic Chemistry 2010, 2010 (28), 4411-4414.

67. Yang, Z.-C.; Wang, M.; Yong, A. M.; Wong, S. Y.; Zhang, X.-H.; Tan, H.; Chang, A. Y.; Li, X.; Wang, J., Intrinsically fluorescent carbon dots with tunable emission derived from hydrothermal treatment of glucose in the presence of monopotassium phosphate. Chemical Communications 2011, 47 (42), 11615-11617.

68. Bian, J.; Huang, C.; Wang, L.; Hung, T.; Daoud, W. A.; Zhang, R., Carbon Dot Loading and TiO2 Nanorod Length Dependence of Photoelectrochemical Properties in Carbon Dot/TiO2 Nanorod Array Nanocomposites. ACS Applied Materials \& Interfaces 2014, 6 (7), 4883-4890.

69. Qu, D.; Zheng, M.; Du, P.; Zhou, Y.; Zhang, L.; Li, D.; Tan, H.; Zhao, Z.; Xie, Z.; Sun, Z., Highly luminescent $\mathrm{S}, \mathrm{N}$ co-doped graphene quantum dots with broad visible absorption bands for visible light photocatalysts. Nanoscale 2013, 5 (24), 12272-12277.

70. Yro, P. A. N. d.; Quaichon, G. M. O.; Cruz, R. A. T.; Emolaga, C. S.; Que, M. C. O.; MagdaluyoJr, E. R.; Basilia, B. A., Hydrothermal synthesis of carbon quantum dots from biowaste for bio-imaging. AIP Conference Proceedings 2019, 2083 (1), 020007.

71. Bourlinos, A. B.; Stassinopoulos, A.; Anglos, D.; Zboril, R.; Karakassides, M.; Giannelis, E. P., Surface Functionalized Carbogenic Quantum Dots. Small 2008, 4 (4), 455-458.

72. Krysmann, M. J.; Kelarakis, A.; Dallas, P.; Giannelis, E. P., Formation Mechanism of Carbogenic Nanoparticles with Dual Photoluminescence Emission. Journal of the American Chemical Society 2012, 134 (2), 747-750.

73. Lai, C.-W.; Hsiao, Y.-H.; Peng, Y.-K.; Chou, P.-T., Facile synthesis of highly emissive carbon dots from pyrolysis of glycerol; gram scale production of carbon dots/mSiO2 for cell imaging and drug release. Journal of Materials Chemistry 2012, 22 (29), 14403-14409.

74. Li, X.; Chang, J.; Xu, F.; Wang, X.; Lang, Y.; Gao, Z.; Wu, D.; Jiang, K., Pyrolytic synthesis of carbon quantum dots, and their photoluminescence properties. Research on Chemical Intermediates 2015, 41 (2), 813-819.

75. Amali, A. J.; Hoshino, H.; Wu, C.; Ando, M.; Xu, Q., From Metal-Organic Framework to Intrinsically Fluorescent Carbon Nanodots. Chemistry - A European Journal 2014, 20 (27), 8279-8282. 76. Xu, H.; Zhou, S.; Xiao, L.; Wang, H.; Li, S.; Yuan, Q., Fabrication of a nitrogen-doped graphene quantum dot from MOF-derived porous carbon and its application for highly selective fluorescence detection of Fe3+. Journal of Materials Chemistry C 2015, 3 (2), 291-297.

77. Yang, Y.; Wu, D.; Han, S.; Hu, P.; Liu, R., Bottom-up fabrication of photoluminescent carbon dots with uniform morphology via a soft-hard template approach. Chemical Communications 2013, 49 (43), 4920-4922.

78. Zhou, J.; Sheng, Z.; Han, H.; Zou, M.; Li, C., Facile synthesis of fluorescent carbon dots using watermelon peel as a carbon source. Mater. Lett. 2012, 66 (1), 222-224.

79. Sahu, S.; Behera, B.; Maiti, T. K.; Mohapatra, S., Simple one-step synthesis of highly luminescent carbon dots from orange juice: application as excellent bio-imaging agents. Chem. Commun. 2012, 48 (70), 8835-8837.

80. Alam, A.-M.; Park, B.-Y.; Ghouri, Z. K.; Park, M.; Kim, H.-Y., Synthesis of carbon quantum dots from cabbage with down-and up-conversion photoluminescence properties: excellent imaging agent for biomedical applications. Green Chem. 2015, 17 (7), 3791-3797.

81. Luo, P. G.; Sahu, S.; Yang, S.-T.; Sonkar, S. K.; Wang, J.; Wang, H.; LeCroy, G. E.; Cao, L.; Sun, Y.-P., Carbon "quantum" dots for optical bioimaging. Journal of Materials Chemistry B 2013, 1 (16), 2116-2127. 
82. Yin, B.; Deng, J.; Peng, X.; Long, Q.; Zhao, J.; Lu, Q.; Chen, Q.; Li, H.; Tang, H.; Zhang, Y.; Yao, S., Green synthesis of carbon dots with down- and up-conversion fluorescent properties for sensitive detection of hypochlorite with a dual-readout assay. Analyst 2013, 138 (21), 6551-6557.

83. Lu, W.; Qin, X.; Liu, S.; Chang, G.; Zhang, Y.; Luo, Y.; Asiri, A. M.; Al-Youbi, A. O.; Sun, X., Economical, Green Synthesis of Fluorescent Carbon Nanoparticles and Their Use as Probes for Sensitive and Selective Detection of Mercury(II) lons. Analytical Chemistry 2012, 84 (12), 5351-5357. 84. Li, H.; Kang, Z.; Liu, Y.; Lee, S.-T., Carbon nanodots: synthesis, properties and applications. Journal of Materials Chemistry 2012, 22 (46), 24230-24253.

85. Das, R.; Bandyopadhyay, R.; Pramanik, P., Carbon quantum dots from natural resource: A review. Materials Today Chemistry 2018, 8, 96-109.

86. Dey, S.; Govindaraj, A.; Biswas, K.; Rao, C. N. R., Luminescence properties of boron and nitrogen doped graphene quantum dots prepared from arc-discharge-generated doped graphene samples. Chemical Physics Letters 2014, 595-596, 203-208.

87. Li, B.; Jiang, L.; Li, X.; Ran, P.; Zuo, P.; Wang, A.; Qu, L.; Zhao, Y.; Cheng, Z.; Lu, Y., Preparation of Monolayer MoS2 Quantum Dots using Temporally Shaped Femtosecond Laser Ablation of Bulk MoS2 Targets in Water. Scientific Reports 2017, 7 (1), 11182.

88. Wang, J.; Sahu, S.; Sonkar, S. K.; Tackett Ii, K. N.; Sun, K. W.; Liu, Y.; Maimaiti, H.; Anilkumar, P.; Sun, Y.-P., Versatility with carbon dots - from overcooked BBQ to brightly fluorescent agents and photocatalysts. RSC Advances 2013, 3 (36), 15604-15607.

89. Wang, W.; Ni, Y.; Xu, Z., One-step uniformly hybrid carbon quantum dots with high-reactive TiO2 for photocatalytic application. Journal of Alloys and Compounds 2015, 622, 303-308.

90. Wang, F.; Pang, S.; Wang, L.; Li, Q.; Kreiter, M.; Liu, C.-y., One-Step Synthesis of Highly Luminescent Carbon Dots in Noncoordinating Solvents. Chemistry of Materials 2010, 22 (16), 45284530.

91. Yang, Y.; Cui, J.; Zheng, M.; Hu, C.; Tan, S.; Xiao, Y.; Yang, Q.; Liu, Y., One-step synthesis of amino-functionalized fluorescent carbon nanoparticles by hydrothermal carbonization of chitosan. Chemical Communications 2012, 48 (3), 380-382.

92. Yin, J.-Y.; Liu, H.-J.; Jiang, S.; Chen, Y.; Yao, Y., Hyperbranched Polymer Functionalized Carbon Dots with Multistimuli-Responsive Property. ACS Macro Letters 2013, 2 (11), 1033-1037.

93. Zhao, H. X.; Liu, L. Q.; Liu, Z. D.; Wang, Y.; Zhao, X. J.; Huang, C. Z., Highly selective detection of phosphate in very complicated matrixes with an off-on fluorescent probe of europium-adjusted carbon dots. Chemical Communications 2011, 47 (9), 2604-2606.

94. Li, H.; Zhang, Y.; Wang, L.; Tian, J.; Sun, X., Nucleic acid detection using carbon nanoparticles as a fluorescent sensing platform. Chemical Communications 2011, 47 (3), 961-963.

95. Liao, B.; Long, P.; He, B.; Yi, S.; Ou, B.; Shen, S.; Chen, J., Reversible fluorescence modulation of spiropyran-functionalized carbon nanoparticles. Journal of Materials Chemistry C 2013, 1 (23), 3716-3721.

96. Wang, F.; Xie, Z.; Zhang, H.; Liu, C.-y.; Zhang, Y.-g., Highly Luminescent OrganosilaneFunctionalized Carbon Dots. Advanced Functional Materials 2011, 21 (6), 1027-1031.

97. Hola, K.; Bourlinos, A. B.; Kozak, O.; Berka, K.; Siskova, K. M.; Havrdova, M.; Tucek, J.; Safarova, K.; Otyepka, M.; Giannelis, E. P.; Zboril, R., Photoluminescence effects of graphitic core size and surface functional groups in carbon dots: COO- induced red-shift emission. Carbon 2014, 70, 279286.

98. Kwon, W.; Do, S.; Kim, J.-H.; Seok Jeong, M.; Rhee, S.-W., Control of Photoluminescence of Carbon Nanodots via Surface Functionalization using Para-substituted Anilines. Scientific Reports 2015, 5 (1), 12604.

99. Ding, H.; Yu, S.-B.; Wei, J.-S.; Xiong, H.-M., Full-Color Light-Emitting Carbon Dots with a Surface-State-Controlled Luminescence Mechanism. ACS Nano 2016, 10 (1), 484-491.

100. Waikar, M. R.; Rasal, A. S.; Shinde, N. S.; Dhas, S. D.; Moholkar, A. V.; Shirsat, M. D.; Chakarvarti, S. K.; Sonkawade, R. G., Electrochemical performance of Polyaniline based symmetrical energy storage device. Materials Science in Semiconductor Processing 2020, 120, 105291. 
101. Kamble, G. P.; Kashale, A. A.; Rasal, A. S.; Mane, S. A.; Chavan, R. A.; Chang, J.-Y.; Ling, Y.C.; Kolekar, S. S.; Ghule, A. V., Marigold micro-flower like NiCo2O4 grown on flexible stainless-steel mesh as an electrode for supercapacitors. RSC Advances 2021, 11 (6), 3666-3672.

102. Kamble, G.; Kashale, A.; Rasal, A.; Dengale, S.; Kolekar, S.; Chang, J. Y.; Han, S.-H.; Ghule, A., Investigating the Influence of Reflux Condensation Reaction Temperature on the Growth of FeCo2O4 Thin Film for Flexible Supercapacitor. ChemistrySelect 2021, 6 (8), 1838-1844.

103. Permatasari, F. A.; Irham, M. A.; Bisri, S. Z.; Iskandar, F., Carbon-Based Quantum Dots for Supercapacitors: Recent Advances and Future Challenges. Nanomaterials 2021, 11 (1), 91.

104. Hoang, V. C.; Dave, K.; Gomes, V. G., Carbon quantum dot-based composites for energy storage and electrocatalysis: Mechanism, applications and future prospects. Nano Energy 2019, 66, 104093.

105. Dubal, D. P.; Gomez-Romero, P.; Sankapal, B. R.; Holze, R., Nickel cobaltite as an emerging material for supercapacitors: An overview. Nano Energy 2015, 11, 377-399.

106. Iqbal, M. F.; Ashiq, M. N.; Zhang, M., Design of Metals Sulfides with Carbon Materials for Supercapacitor Applications: A Review. Energy Technology n/a (n/a), 2000987.

107. Xu, J.; Xue, Y.; Cao, J.; Wang, G.; Li, Y.; Wang, W.; Chen, Z., Carbon quantum dots/nickel oxide (CQDs/NiO) nanorods with high capacitance for supercapacitors. RSC Advances 2016, 6 (7), 5541-5546.

108. Prasath, A.; Athika, M.; Duraisamy, E.; Sharma, A. S.; Elumalai, P., Carbon-Quantum-DotDerived Nanostructured $\mathrm{MnO} 2$ and Its Symmetrical Supercapacitor Performances. ChemistrySelect 2018, 3 (30), 8713-8723.

109. Quan, Y.; Wang, G.; Lu, L.; Wang, Z.; Xu, H.; Liu, S.; Wang, D., High-performance pseudocapacitor energy storage device based on a hollow-structured copper sulfide nanoflower and carbon quantum dot nanocomposite. Electrochimica Acta 2020, 353, 136606.

110. Chen, G.; Wu, S.; Hui, L.; Zhao, Y.; Ye, J.; Tan, Z.; Zeng, W.; Tao, Z.; Yang, L.; Zhu, Y., Assembling carbon quantum dots to a layered carbon for high-density supercapacitor electrodes. Scientific Reports 2016, 6 (1), 19028.

111. Genc, R.; Alas, M. O.; Harputlu, E.; Repp, S.; Kremer, N.; Castellano, M.; Colak, S. G.; Ocakoglu, K.; Erdem, E., High-Capacitance Hybrid Supercapacitor Based on Multi-Colored Fluorescent Carbon-Dots. Scientific Reports 2017, 7 (1), 11222.

112. Unnikrishnan, B.; Wu, C.-W.; Chen, I. W. P.; Chang, H.-T.; Lin, C.-H.; Huang, C.-C., Carbon Dot-Mediated Synthesis of Manganese Oxide Decorated Graphene Nanosheets for Supercapacitor Application. ACS Sustainable Chemistry \& Engineering 2016, 4 (6), 3008-3016.

113. Prasath, A.; Athika, M.; Duraisamy, E.; Selva Sharma, A.; Sankar Devi, V.; Elumalai, P., Carbon Quantum Dot-Anchored Bismuth Oxide Composites as Potential Electrode for Lithium-Ion Battery and Supercapacitor Applications. ACS Omega 2019, 4 (3), 4943-4954.

114. Barik, R.; Ingole, P. P., Challenges and prospects of metal sulfide materials for supercapacitors. Current Opinion in Electrochemistry 2020, 21, 327-334.

115. Khalid, S.; Khan, Y.; Ahmed, E.; Nawaz, S.; Khalid, N. R.; Ahmed, W., Chapter 16 - Transition metal sulfides for supercapacitors. In Emerging Nanotechnologies for Renewable Energy, Ahmed, W.; Booth, M.; Nourafkan, E., Eds. Elsevier: 2021; pp 407-445.

116. Ikkurthi, K. D.; Srinivasa Rao, S.; Jagadeesh, M.; Reddy, A. E.; Anitha, T.; Kim, H.-J., Synthesis of nanostructured metal sulfides via a hydrothermal method and their use as an electrode material for supercapacitors. New Journal of Chemistry 2018, 42 (23), 19183-19192.

117. Sahoo, S.; Satpati, A. K.; Sahoo, P. K.; Naik, P. D., Incorporation of carbon quantum dots for improvement of supercapacitor performance of nickel sulfide. ACS omega 2018, 3 (12), 17936-17946. 118. Zheng, J.; Zhang, R.; Wang, X.; Yu, P., Importance of carbon quantum dots for improving the electrochemical performance of MoS2@ZnS composite. Journal of Materials Science 2019, 54 (21), 13509-13522.

119. Bi, Z.; Huang, L.; Shang, C.; Wang, X.; Zhou, G., Stable Copper Tin Sulfide Nanoflower Modified Carbon Quantum Dots for Improved Supercapacitors. Journal of Chemistry 2019, 2019, 6109758. 
120. Qu, D.; Wen, J.; Liu, D.; Xie, Z.; Zhang, X.; Zheng, D.; Lei, J.; Zhong, W.; Tang, H.; Xiao, L.; $\mathrm{Qu}, \mathrm{D}$., Hydrogen Ion Supercapacitor: A New Hybrid Configuration of Highly Dispersed MnO2 in Porous Carbon Coupled with Nitrogen-Doped Highly Ordered Mesoporous Carbon with Enhanced H-Insertion. ACS Applied Materials \& Interfaces 2014, 6 (24), 22687-22694.

121. Lin, T.; Chen, I.-W.; Liu, F.; Yang, C.; Bi, H.; Xu, F.; Huang, F., Nitrogen-doped mesoporous carbon of extraordinary capacitance for electrochemical energy storage. Science 2015, 350 (6267), 1508-1513.

122. Cai, J.; Niu, H.; Li, Z.; Du, Y.; Cizek, P.; Xie, Z.; Xiong, H.; Lin, T., High-Performance Supercapacitor Electrode Materials from Cellulose-Derived Carbon Nanofibers. ACS Applied Materials \& Interfaces 2015, 7 (27), 14946-14953.

123. Ba, Y.; Pan, W.; Pi, S.; Zhao, Y.; Mi, L., Nitrogen-doped hierarchical porous carbon derived from a chitosan/polyethylene glycol blend for high performance supercapacitors. RSC Advances 2018, 8 (13), 7072-7079.

124. Hulicova-Jurcakova, D.; Puziy, A. M.; Poddubnaya, O. I.; Suárez-García, F.; Tascón, J. M. D.; Lu, G. Q., Highly Stable Performance of Supercapacitors from Phosphorus-Enriched Carbons. Journal of the American Chemical Society 2009, 131 (14), 5026-5027.

125. Carriazo, D.; Gutiérrez, M. C.; Picó, F.; Rojo, J. M.; Fierro, J. L. G.; Ferrer, M. L.; del Monte, F., Phosphate-Functionalized Carbon Monoliths from Deep Eutectic Solvents and their Use as Monolithic Electrodes in Supercapacitors. ChemSusChem 2012, 5 (8), 1405-1409.

126. Zhao, X.; Zhang, Q.; Zhang, B.; Chen, C.-M.; Wang, A.; Zhang, T.; Su, D. S., Dual-heteroatommodified ordered mesoporous carbon: Hydrothermal functionalization, structure, and its electrochemical performance. Journal of Materials Chemistry 2012, 22 (11), 4963-4969.

127. Hoang, V. C.; Gomes, V. G., High performance hybrid supercapacitor based on doped zucchiniderived carbon dots and graphene. Materials Today Energy 2019, 12, 198-207.

128. Wang, Q.; Wang, H.; Liu, D.; Du, P.; Liu, P., Synthesis of flake-shaped nitrogen-doped carbon quantum dot/polyaniline (N-CQD/PANI) nanocomposites via rapid-mixing polymerization and their application as electrode materials in supercapacitors. Synthetic Metals 2017, 231, 120-126.

129. Samantara, A. K.; Chandra Sahu, S.; Ghosh, A.; Jena, B. K., Sandwiched graphene with nitrogen, sulphur co-doped CQDs: an efficient metal-free material for energy storage and conversion applications. Journal of Materials Chemistry A 2015, 3 (33), 16961-16970.

130. Feng, H.; Xie, P.; Xue, S.; Li, L.; Hou, X.; Liu, Z.; Wu, D.; Wang, L.; Chu, P. K., Synthesis of three-dimensional porous reduced graphene oxide hydrogel/carbon dots for high-performance supercapacitor. Journal of Electroanalytical Chemistry 2018, 808, 321-328.

131. Wang, P.; Zhou, H.; Meng, C.; Wang, Z.; Akhtar, K.; Yuan, A., Cyanometallic frameworkderived hierarchical Co3O4-NiO/graphene foam as high-performance binder-free electrodes for supercapacitors. Chemical Engineering Journal 2019, 369, 57-63.

132. Chen, L.-F.; Zhang, X.-D.; Liang, H.-W.; Kong, M.; Guan, Q.-F.; Chen, P.; Wu, Z.-Y.; Yu, S.-H., Synthesis of Nitrogen-Doped Porous Carbon Nanofibers as an Efficient Electrode Material for Supercapacitors. ACS Nano 2012, 6 (8), 7092-7102.

133. Díez, N.; Botas, C.; Mysyk, R.; Goikolea, E.; Rojo, T.; Carriazo, D., Highly packed grapheneCNT films as electrodes for aqueous supercapacitors with high volumetric performance. Journal of Materials Chemistry A 2018, 6 (8), 3667-3673.

134. Mehare, M. D.; Deshmukh, A. D.; Dhoble, S. J., Carbon Quantum Dots/Polyaniline Nanocomposite (S-CQD/PANI) for High Capacitive Asymmetric Supercapacitor Device. Journal of nanoscience and nanotechnology 2020, 20 (6), 3785-3794.

135. Zhao, X.; Li, M.; Dong, H.; Liu, Y.; Hu, H.; Cai, Y.; Liang, Y.; Xiao, Y.; Zheng, M., Interconnected $3 \mathrm{D}$ Network of Graphene-Oxide Nanosheets Decorated with Carbon Dots for High-Performance Supercapacitors. ChemSusChem 2017, 10 (12), 2626-2634.

136. Hoang, V. C.; Nguyen, L. H.; Gomes, V. G., High efficiency supercapacitor derived from biomass based carbon dots and reduced graphene oxide composite. Journal of Electroanalytical Chemistry 2019, 832, 87-96. 
137. Li, Q.; Cheng, H.; Wu, X.; Wang, C. F.; Wu, G.; Chen, S., Enriched carbon dots/graphene microfibers towards high-performance micro-supercapacitors. Journal of Materials Chemistry A 2018, $6(29), 14112-14119$.

138. Shaker, M.; Riahifar, R.; Li, Y., A review on the superb contribution of carbon and graphene quantum dots to electrochemical capacitors' performance: Synthesis and application. FlatChem 2020, $22,100171$.

139. Safaei, J.; Mohamed, N. A.; Mohamad Noh, M. F.; Soh, M. F.; Ludin, N. A.; Ibrahim, M. A.; Roslam Wan Isahak, W. N.; Mat Teridi, M. A., Graphitic carbon nitride (g-C3N4) electrodes for energy conversion and storage: a review on photoelectrochemical water splitting, solar cells and supercapacitors. Journal of Materials Chemistry A 2018, 6 (45), 22346-22380.

140. Vaghasiya, J. V.; Mayorga-Martinez, C. C.; Sofer, Z.; Pumera, M., MXene-Based Flexible Supercapacitors: Influence of an Organic lonic Conductor Electrolyte on the Performance. ACS Applied Materials \& Interfaces 2020, 12 (47), 53039-53048.

141. Rasal, A. S.; Dehvari, K.; Getachew, G.; korupalli, c.; Ghule, A. V.; Chang, J.-Y., Efficient Quantum Dot-Sensitized Solar Cells through Sulfur-rich Carbon Nitride Modified Electrolyte. Nanoscale 2021, 13, 5730-5743.

142. Paulo, S.; Stoica, G.; Cambarau, W.; Martinez-Ferrero, E.; Palomares, E., Carbon quantum dots as new hole transport material for perovskite solar cells. Synthetic Metals 2016, 222, 17-22.

143. Pan, Z.; Rao, H.; Mora-Seró, I.; Bisquert, J.; Zhong, X., Quantum dot-sensitized solar cells. Chemical Society Reviews 2018, 47 (20), 7659-7702.

144. Rasal, A. S.; Chen, Y. H.; Dehvari, K.; Getachew, G.; Tseng, P. J.; Waki, K.; Bela, S.; Chang, J. Y., Efficient quantum-dot-sensitized solar cells with improved stability using thixotropic polymer/nanoparticles-based gel electrolyte. Materials Today Energy 2021, 19, 100615.

145. Gao, N.; Huang, L.; Li, T.; Song, J.; Hu, H.; Liu, Y.; Ramakrishna, S., Application of carbon dots in dye-sensitized solar cells: A review. Journal of Applied Polymer Science 2020, 137 (10), 48443.

146. Guo, X.; Zhang, H.; Sun, H.; Tade, M. O.; Wang, S., Green Synthesis of Carbon Quantum Dots for Sensitized Solar Cells. ChemPhotoChem 2017, 1 (4), 116-119.

147. Briscoe, J.; Marinovic, A.; Sevilla, M.; Dunn, S.; Titirici, M., Biomass-Derived Carbon Quantum Dot Sensitizers for Solid-State Nanostructured Solar Cells. Angewandte Chemie International Edition 2015, 54 (15), 4463-4468.

148. Mirtchev, P.; Henderson, E. J.; Soheilnia, N.; Yip, C. M.; Ozin, G. A., Solution phase synthesis of carbon quantum dots as sensitizers for nanocrystalline TiO2 solar cells. Journal of Materials Chemistry 2012, 22 (4), 1265-1269.

149. Meng, Y.; Zhang, Y.; Sun, W.; Wang, M.; He, B.; Chen, H.; Tang, Q., Biomass converted carbon quantum dots for all-weather solar cells. Electrochimica Acta 2017, 257, 259-266.

150. Chava, R. K.; Im, Y.; Kang, M., Nitrogen doped carbon quantum dots as a green luminescent sensitizer to functionalize $\mathrm{ZnO}$ nanoparticles for enhanced photovoltaic conversion devices. Materials Research Bulletin 2017, 94, 399-407.

151. Yang, Q.; Yang, W.; Zhang, Y.; Ge, W.; Yang, X.; Yang, P., Precise Surface State Control of Carbon Quantum Dots to Enhance Charge Extraction for Solar Cells. Nanomaterials (Basel) 2020, 10 (3), 460 .

152. Shi, Y.; Na, Y.; Su, T.; Li, L.; Yu, J.; Fan, R.; Yang, Y., Fluorescent Carbon Quantum Dots Incorporated into Dye-Sensitized TiO2 Photoanodes with Dual Contributions. ChemSusChem 2016, 9 (12), 1498-503.

153. Zhang, Y.-Q.; Ma, D.-K.; Zhang, Y.-G.; Chen, W.; Huang, S.-M., N-doped carbon quantum dots for TiO2-based photocatalysts and dye-sensitized solar cells. Nano Energy 2013, 2 (5), 545-552.

154. Zhu, W.; Duan, J.; Duan, Y.; Zhao, Y.; Tang, Q., Efficiency enhancement of hybridized solar cells through co-sensitization and fast charge extraction by up-converted polyethylene glycol modified carbon quantum dots. Journal of Power Sources 2017, 367, 158-166. 
155. Shi, Y.; Na, Y.; Su, T.; Li, L.; Yu, J.; Fan, R.; Yang, Y., Fluorescent Carbon Quantum Dots Incorporated into Dye-Sensitized TiO2 Photoanodes with Dual Contributions. ChemSusChem 2016, 9 (12), 1498-1503.

156. Margraf, J. T.; Lodermeyer, F.; Strauss, V.; Haines, P.; Walter, J.; Peukert, W.; Costa, R. D.; Clark, T.; Guldi, D. M., Using carbon nanodots as inexpensive and environmentally friendly sensitizers in mesoscopic solar cells. Nanoscale horizons 2016, 1 (3), 220-226.

157. Liu, L.; Yu, X.; Yi, Z.; Chi, F.; Wang, H.; Yuan, Y.; Li, D.; Xu, K.; Zhang, X., High efficiency solar cells tailored using biomass-converted graded carbon quantum dots. Nanoscale 2019, 11 (32), 1508315090.

158. Efa, M. T.; Imae, T., Effects of carbon dots on ZnO nanoparticle-based dye-sensitized solar cells. Electrochimica Acta 2019, 303, 204-210.

159. Rezaei, B.; Irannejad, N.; Ensafi, A. A.; Kazemifard, N., The impressive effect of eco-friendly carbon dots on improving the performance of dye-sensitized solar cells. Solar Energy 2019, 182, 412419.

160. Geleta, T. A.; Imae, T., Nanocomposite Photoanodes Consisting of p-NiO/n-ZnO Heterojunction and Carbon Quantum Dot Additive for Dye-Sensitized Solar Cells. ACS Applied Nano Materials 2021, 4 (1), 236-249.

161. Zhu, W.; Zhao, Y.; Duan, J.; Duan, Y.; Tang, Q.; He, B., Carbon quantum dot tailored counter electrode for $7.01 \%$-rear efficiency in a bifacial dye-sensitized solar cell. Chemical Communications 2017, 53 (71), 9894-9897.

162. Duan, J.; Zhao, Y.; He, B.; Tang, Q., Efficiency enhancement of bifacial dye-sensitized solar cells through bi-tandem carbon quantum dots tailored transparent counter electrodes. Electrochimica Acta 2018, 278, 204-209.

163. Ali, M.; Riaz, R.; Anjum, A. S.; Sun, K. C.; Li, H.; Ahn, S.; Jeong, S. H.; Ko, M. J., Microwaveassisted ultrafast in-situ growth of $\mathrm{N}$-doped carbon quantum dots on multiwalled carbon nanotubes as an efficient electrocatalyst for photovoltaics. Journal of Colloid and Interface Science 2021, 586, 349-361.

164. Zhao, C.; Zhang, X.; Shu, X.; Liu, X.; Fang, D.; Song, Y.; Wang, J., Er-doped carbon dots broadening light absorption range and accelerating electron transport for enhancing photovoltaic performance of CdS quantum dots sensitized cells. Optical Materials 2018, 84, 242-251.

165. Huang, P.; Xu, S.; Zhang, M.; Zhong, W.; Xiao, Z.; Luo, Y., Carbon quantum dots improving photovoltaic performance of CdS quantum dot-sensitized solar cells. Optical Materials 2020, 110, 110535.

166. Guo, X.; Zhang, H.; Sun, H.; Tade, M.; Wang, S., Green Synthesis of Carbon Quantum Dots for Sensitized Solar Cells. ChemPhotoChem 2017, 1.

167. Shi, Y.; Na, Y.; Su, T.; Li, L.; Yu, J.; Fan, R.; Yang, Y., Fluorescent carbon quantum dots incorporated into dye-sensitized TiO2 photoanodes with dual contributions. ChemSusChem 2016, 9 (12), 1498-1503.

168. Benetti, D.; Jokar, E.; Yu, C.-H.; Fathi, A.; Zhao, H.; Vomiero, A.; Wei-Guang Diau, E.; Rosei, F., Hole-extraction and photostability enhancement in highly efficient inverted perovskite solar cells through carbon dot-based hybrid material. Nano Energy 2019, 62, 781-790.

169. Kim, J. K.; Nguyen, D. N.; Lee, J.-H.; Kang, S.; Kim, Y.; Kim, S.-S.; Kim, H.-K., Carbon quantum dot-incorporated nickel oxide for planar $\mathrm{p}$-i-n type perovskite solar cells with enhanced efficiency and stability. Journal of Alloys and Compounds 2020, 818, 152887.

170. Benetti, D.; Jokar, E.; Yu, C.-H.; Fathi, A.; Zhao, H.; Vomiero, A.; Diau, E. W.-G.; Rosei, F., Hole-extraction and photostability enhancement in highly efficient inverted perovskite solar cells through carbon dot-based hybrid material. Nano Energy 2019, 62, 781-790.

171. Kim, J. K.; Nguyen, D. N.; Lee, J.-H.; Kang, S.; Kim, Y.; Kim, S.-S.; Kim, H.-K., Carbon quantum dot-incorporated nickel oxide for planar pin type perovskite solar cells with enhanced efficiency and stability. J. Alloys Compd. 2020, 818, 152887. 
172. Ma, Y.; Zhang, H.; Zhang, Y.; Hu, R.; Jiang, M.; Zhang, R.; Lv, H.; Tian, J.; Chu, L.; Zhang, J.; Xue, Q.; Yip, H.-L.; Xia, R.; Li, X. a.; Huang, W., Enhancing the Performance of Inverted Perovskite Solar Cells via Grain Boundary Passivation with Carbon Quantum Dots. ACS Applied Materials \& Interfaces 2019, 11 (3), 3044-3052.

173. Maxim, A. A.; Sadyk, S. N.; Aidarkhanov, D.; Surya, C.; Ng, A.; Hwang, Y.-H.; Atabaev, T. S.; Jumabekov, A. N., PMMA Thin Film with Embedded Carbon Quantum Dots for Post-Fabrication Improvement of Light Harvesting in Perovskite Solar Cells. Nanomaterials 2020, 10 (2), 291.

174. Xu, T.; Wan, Z.; Tang, H.; Zhao, C.; Lv, S.; Chen, Y.; Chen, L.; Qiao, Q.; Huang, W., Carbon quantum dot additive engineering for efficient and stable carbon-based perovskite solar cells. J. Alloys Compd. 2021, 859, 157784.

175. Wen, Y.; Zhu, G.; Shao, Y., Improving the power conversion efficiency of perovskite solar cells by adding carbon quantum dots. Journal of Materials Science 2020, 55 (7), 2937-2946.

176. Han, J.; Zhou, Y.; Yin, X.; Nan, H.; Tai, M.; Gu, Y.; Li, J.; Oron, D.; Lin, H., An Excellent Modifier: Carbon Quantum Dots for Highly Efficient Carbon-Electrode-Based Methylammonium Lead lodide Solar Cells. Solar RRL 2019, 3 (9), 1900146.

177. Niu, Y.-C.; Yang, L.-F.; Aldamasy, M. H.; Li, M.; Lan, W.-J.; Xu, Q.; Liu, Y.; Feng, S.-L.; Yang, Y.-G., Efficient application of carbon-based nanomaterials for high-performance perovskite solar cells. Rare Metals 2021, 40, 2747-2762.

178. Evarts, E. C., Lithium batteries: To the limits of lithium. Nature 2015, 526 (7575), S93-S95.

179. Diouf, B.; Pode, R., Potential of lithium-ion batteries in renewable energy. Renewable Energy 2015, 76, 375-380.

180. Zhang, Z.; Ramadass, P., Lithium-Ion Batterylithium-ion batterySystems and Technologylithium-ion batterytechnology. In Encyclopedia of Sustainability Science and Technology, Meyers, R. A., Ed. Springer New York: New York, NY, 2012; pp 6122-6149.

181. Pender, J. P.; Jha, G.; Youn, D. H.; Ziegler, J. M.; Andoni, I.; Choi, E. J.; Heller, A.; Dunn, B. S.; Weiss, P. S.; Penner, R. M.; Mullins, C. B., Electrode Degradation in Lithium-Ion Batteries. ACS Nano 2020, $14(2), 1243-1295$.

182. Yu, X.; Manthiram, A., Electrode-Electrolyte Interfaces in Lithium-based Batteries. Energy \& Environmental Science 2018, 11.

183. Pinson, M. B.; Bazant, M. Z., Theory of SEI Formation in Rechargeable Batteries: Capacity Fade, Accelerated Aging and Lifetime Prediction. Journal of The Electrochemical Society 2012, 160 (2), A243A250.

184. Song, T.-B.; Huang, Z.-H.; Niu, X.-Q.; Liu, J.; Wei, J.-S.; Chen, X.-B.; Xiong, H.-M., Applications of Carbon Dots in Next-generation Lithium-Ion Batteries. ChemNanoMat 2020, 6 (10), 1421-1436.

185. Zhang, X.; Zhang, Z.; Hu, F.; Li, D.; Zhou, D.; Jing, P.; Du, F.; Qu, S., Carbon-dots-derived 3D highly nitrogen-doped porous carbon framework for high-performance lithium ion storage. ACS Sustainable Chemistry \& Engineering 2019, 7 (11), 9848-9856.

186. Jing, M.; Wang, J.; Hou, H.; Yang, Y.; Zhang, Y.; Pan, C.; Chen, J.; Zhu, Y.; Ji, X., Carbon quantum dot coated $\mathrm{Mn3O} 4$ with enhanced performances for lithium-ion batteries. Journal of Materials Chemistry A 2015, 3 (32), 16824-16830.

187. Xie, F.; Xu, Z.; Jensen, A. C. S.; Ding, F.; Au, H.; Feng, J.; Luo, H.; Qiao, M.; Guo, Z.; Lu, Y.; Drew, A. J.; Hu, Y.-S.; Titirici, M.-M., Unveiling the role of hydrothermal carbon dots as anodes in sodium-ion batteries with ultrahigh initial coulombic efficiency. Journal of Materials Chemistry A 2019, 7 (48), 27567-27575.

188. Zhao, X.; Wu, Y.; Wang, Y.; Wu, H.; Yang, Y.; Wang, Z.; Dai, L.; Shang, Y.; Cao, A., Highperformance Li-ion batteries based on graphene quantum dot wrapped carbon nanotube hybrid anodes. Nano Research 2020, 13 (4), 1044-1052.

189. Kashale, A. A.; Rasal, A. S.; Kamble, G. P.; Ingole, V. H.; Dwivedi, P. K.; Rajoba, S. J.; Jadhav, L. D.; Ling, Y.-C.; Chang, J.-Y.; Ghule, A. V., Biosynthesized Co-doped TiO2 nanoparticles based anode for lithium-ion battery application and investigating the influence of dopant concentrations on its performance. Composites Part B: Engineering 2019, 167, 44-50. 
190. Chen, Y. T.; Zhang, H. Y.; Chen, Y. M.; Qin, G.; Lei, X. L.; Liu, L. Y., Graphene-Carbon Nanotubes-Modified LiFePO4 Cathode Materials for High-Performance Lithium-Ion Batteries. Materials Science Forum 2018, 913, 818-830.

191. Gong, C.; Deng, F.; Tsui, C.-P.; Xue, Z.; Ye, Y. S.; Tang, C.-Y.; Zhou, X.; Xie, X., PANI-PEG copolymer modified LiFePO4 as a cathode material for high-performance lithium ion batteries. Journal of Materials Chemistry A 2014, 2 (45), 19315-19323.

192. Liu, S.; Cao, X.; Zhang, Y.; Wang, K.; Su, Q.; Chen, J.; He, Q.; Liang, S.; Cao, G.; Pan, A., Carbon quantum dot modified Na3V2(PO4)2F3 as a high-performance cathode material for sodiumion batteries. Journal of Materials Chemistry A 2020, 8 (36), 18872-18879.

193. Hu, Y.; Chen, W.; Lei, T.; Zhou, B.; Jiao, Y.; Yan, Y.; Du, X.; Huang, J.; Wu, C.; Wang, X.; Wang, Y.; Chen, B.; Xu, J.; Wang, C.; Xiong, J., Carbon Quantum Dots-Modified Interfacial Interactions and Ion Conductivity for Enhanced High Current Density Performance in Lithium-Sulfur Batteries. Advanced Energy Materials 2019, 9 (7), 1802955.

194. Jing, M.; Wang, J.; Hou, H.; Yang, Y.; Zhang, Y.; Pan, C.; Chen, J.; Zhu, Y.; Ji, X., Carbon quantum dot coated $\mathrm{Mn} 3 \mathrm{O} 4$ with enhanced performances for lithium-ion batteries. Journal of Materials Chemistry A 2015, 3 (32), 16824-16830.

195. Tachibana, Y.; Vayssieres, L.; Durrant, J. R., Artificial photosynthesis for solar water-splitting. Nature Photonics 2012, 6 (8), 511-518.

196. Fujishima, A.; Honda, K., Electrochemical Photolysis of Water at a Semiconductor Electrode. Nature 1972, 238 (5358), 37-38.

197. Han, M.; Zhu, S.; Lu, S.; Song, Y.; Feng, T.; Tao, S.; Liu, J.; Yang, B., Recent progress on the photocatalysis of carbon dots: Classification, mechanism and applications. Nano Today 2018, 19, 201218.

198. Meng, W.; Bai, X.; Wang, B.; Liu, Z.; Lu, S.; Yang, B., Biomass-Derived Carbon Dots and Their Applications. ENERGY \& ENVIRONMENTAL MATERIALS 2019, 2 (3), 172-192.

199. Venkatesan, S.; Liu, I. P.; Chen, L.-T.; Hou, Y.-C.; Li, C.-W.; Lee, Y.-L., Effects of TiO2 and TiC Nanofillers on the Performance of Dye Sensitized Solar Cells Based on the Polymer Gel Electrolyte of a Cobalt Redox System. ACS Applied Materials \& Interfaces 2016, 8 (37), 24559-24566.

200. Liu, Y.; Yang, Y.; Peng, Z.; Liu, Z.; Chen, Z.; Shang, L.; Lu, S.; Zhang, T., Self-crosslinking carbon dots loaded ruthenium dots as an efficient and super-stable hydrogen production electrocatalyst at all pH values. Nano Energy 2019, 65, 104023.

201. Li, W.; Liu, Y.; Wu, M.; Feng, X.; Redfern, S. A. T.; Shang, Y.; Yong, X.; Feng, T.; Wu, K.; Liu, Z.; Li, B.; Chen, Z.; Tse, J. S.; Lu, S.; Yang, B., Carbon-Quantum-Dots-Loaded Ruthenium Nanoparticles as an Efficient Electrocatalyst for Hydrogen Production in Alkaline Media. Advanced Materials 2018, 30 (31), 1800676.

202. Lu, S.; Sui, L.; Liu, J.; Zhu, S.; Chen, A.; Jin, M.; Yang, B., Near-Infrared Photoluminescent Polymer-Carbon Nanodots with Two-Photon Fluorescence. Advanced Materials 2017, 29 (15), 1603443.

203. Wei, Z.; Liu, Y.; Peng, Z.; Song, H.; Liu, Z.; Liu, B.; Li, B.; Yang, B.; Lu, S., Cobalt-Ruthenium Nanoalloys Parceled in Porous Nitrogen-Doped Graphene as Highly Efficient Difunctional Catalysts for Hydrogen Evolution Reaction and Hydrolysis of Ammonia Borane. ACS Sustainable Chemistry \& Engineering 2019, 7 (7), 7014-7023.

204. Wang, L.; Wu, X.; Guo, S.; Han, M.; Zhou, Y.; Sun, Y.; Huang, H.; Liu, Y.; Kang, Z., Mesoporous nitrogen, sulfur co-doped carbon dots/CoS hybrid as an efficient electrocatalyst for hydrogen evolution. Journal of Materials Chemistry A 2017, 5 (6), 2717-2723.

205. Elsayed, M. H.; Jayakumar, J.; Abdellah, M.; Mansoure, T. H.; Zheng, K.; Elewa, A. M.; Chang, C.-L.; Ting, L.-Y.; Lin, W.-C.; Yu, H.-h.; Wang, W.-H.; Chung, C.-C.; Chou, H.-H., Visible-light-driven hydrogen evolution using nitrogen-doped carbon quantum dot-implanted polymer dots as metal-free photocatalysts. Applied Catalysis B: Environmental 2021, 283, 119659.

206. Zhou, B.-X.; Ding, S.-S.; Wang, Y.; Wang, X.-R.; Huang, W.-Q.; Li, K.; Huang, G.-F., TypeII/type-II band alignment to boost spatial charge separation: a case study of g-C3N4 quantum dots/a- 
TiO2/r-TiO2 for highly efficient photocatalytic hydrogen and oxygen evolution. Nanoscale 2020, 12 (10), 6037-6046.

207. Shen, J.; Chen, W.; Lv, G.; Yang, Z.; Yan, J.; Liu, X.; Dai, Z., Hydrolysis of NH3BH3 and NaBH4 by graphene quantum dots-transition metal nanoparticles for highly effective hydrogen evolution. International Journal of Hydrogen Energy 2021, 46 (1), 796-805.

208. Nasir, M. S.; Yang, G.; Ayub, I.; Wang, S.; Yan, W., In situ decoration of g-C3N4 quantum dots on 1D branched TiO2 loaded with plasmonic Au nanoparticles and improved the photocatalytic hydrogen evolution activity. Applied Surface Science 2020, 519, 146208.

209. Song, H.; Cheng, Y.; Li, B.; Fan, Y.; Liu, B.; Tang, Z.; Lu, S., Carbon Dots and RuP2 Nanohybrid as an Efficient Bifunctional Catalyst for Electrochemical Hydrogen Evolution Reaction and Hydrolysis of Ammonia Borane. ACS Sustainable Chem. Eng. 2020, 8 (9), 3995-4002.

210. Tian, L.; Qiu, G.; Shen, Y.; Wang, X.; Wang, J.; Wang, P.; Song, M.; Li, J.; Li, T.; Zhuang, W.; $\mathrm{Du}, \mathrm{X}$., Carbon Quantum Dots Modulated NiMoP Hollow Nanopetals as Efficient Electrocatalysts for Hydrogen Evolution. Ind. Eng. Chem. Res. 2019, 58 (31), 14098-14105.

211. Javan, H.; Asghari, E.; Ashassi-Sorkhabi, H.; Haghighi, M. M., A low-cost platinum-free electrocatalyst based on carbon quantum dots decorated $\mathrm{Ni}-\mathrm{Cu}$ hierarchical nanocomposites for hydrogen evolution reaction. Int. J. Hydrogen Energy 2020, 45 (38), 19324-19334.

212. Li, W.; Wei, Z.; Wang, B.; Liu, Y.; Song, H.; Tang, Z.; Yang, B.; Lu, S., Carbon quantum dots enhanced the activity for the hydrogen evolution reaction in ruthenium-based electrocatalysts. Mater. Chem. Front. 2020, 4 (1), 277-284.

213. Chen, W.; Qin, Z.; McElhenny, B.; Zhang, F.; Chen, S.; Bao, J.; Wang, Z. M.; Song, H.-Z.; Ren, Z., The effect of carbon quantum dots on the electrocatalytic hydrogen evolution reaction of manganese-nickel phosphide nanosheets. J. Mater. Chem. A 2019, 7 (37), 21488-21495.

214. Liu, Y.; Ye, N.; Li, X.; Li, X.; Liu, H.; Wang, E.; Liang, C.; Peng, X., Nitrogen-doped carbon quantum dots via a facile reflux assisted polymerization of $\mathrm{N}$-Methyl-Pyrrolidone for hydrogen evolution reaction. J. Solid State Chem. 2021, 293, 121781.

215. Liu, Y.; Li, X.; Zhang, Q.; Li, W.; Xie, Y.; Liu, H.; Shang, L.; Liu, Z.; Chen, Z.; Gu, L.; Tang, Z.; Zhang, T.; Lu, S., A General Route to Prepare Low-Ruthenium-Content Bimetallic Electrocatalysts for pH-Universal Hydrogen Evolution Reaction by Using Carbon Quantum Dots. Angew. Chem. Int. Ed. 2020, 59 (4), 1718-1726.

216. Xiao, H.; Zhang, J.; Zhao, M.; Ma, J.; Li, Y.; Hu, T.; Zheng, Z.; Jia, J.; Wu, H., Electric fieldassisted synthesis of $\mathrm{Pt}$, carbon quantum dots-coloaded graphene hybrid for hydrogen evolution reaction. J. Power Sources 2020, 451, 227770.

217. Yousefzadeh, S.; Morovati, N., Modification of the ultrasonication derived-g-C3N4 nanosheets/quantum dots by MoS2 nanostructures to improve electrocatalytic hydrogen evolution reaction. Int. J. Hydrogen Energy 2020, 45 (58), 33512-33520.

218. Raza Naqvi, S. T.; Rasheed, T.; Majeed, S.; Hussain, D.; Fatima, B.; Najam ul Haq, M.; Nawaz, R.; Ahmad, N.; Noon, T., Nitrogen doped carbon quantum dots conjugated with AgNi alloy nanoparticles as potential electrocatalyst for efficient water splitting. J. Alloys Compd. 2020, 847, 156492.

219. Chandrasekaran, P.; Jebakumar Immanuel Edison, T. N.; Sethuraman, M. G., Electrocatalytic performance of carbon dots/palladium nanoparticles composite towards hydrogen evolution reaction in acid medium. Int. J. Hydrogen Energy 2020, 45 (53), 28800-28811.

220. Nguyen, V.-T.; Ha, H.; Nguyen, N.-A.; An, H.; Kim, H. Y.; Choi, H.-S., In Situ Engineering of Pd Nanosponge Armored with Graphene Dots Using $\mathrm{Br}$ - toward High-Performance and Stable Electrocatalyst for the Hydrogen Evolution Reaction. ACS Appl. Mater. Interfaces 2020, 12 (13), 1550015506.

221. Liang, J.; Liu, Y.; Liu, R.; Zheng, S.; Si, Z.; Weng, D.; Kang, F., Stable Pt atomic clusters on carbon nanotubes grafted with carbon quantum dots as electrocatalyst for $\mathrm{H} 2$ evolution in acidic electrolyte. Nano Select 2021, n/a (n/a), 1-9. 
222. Nguyen, N.-A.; Le, T.-H.; Trinh, V.-H.; Ngo, Q.-T.; Nguyen, V.-T.; Lee, G.; Choi, H.-S.; Chen, G., Au/Cdot-Nanohybrid Electrocatalyst Synthesized by Rice-Straw-Derived Carbon Dots as a Reducing Agent for Improved Hydrogen Evolution Reactions. J. Electrochem. Soc. 2021, 168 (4), 044509.

223. Song, H.; Wu, M.; Tang, Z.; Tse, J. S.; Yang, B.; Lu, S., Single Atom Ruthenium-Doped CoP/CDs Nanosheets via Splicing of Carbon-Dots for Robust Hydrogen Production. Angew. Chem. Int. Ed. 2021, 60 (13), 7234-7244.

224. Nguyen, N.-A.; Ali, Y.; Nguyen, V.-T.; Omelianovych, O.; Larina, L. L.; Choi, H.-S., Data on a highly stable electrocatalyst of NiCoPt/Graphene-dot nanosponge for efficient hydrogen evolution reaction. Data Brief 2020, 33, 106332.

225. Xiao, H.; Xue, S.; Zhang, J.; Zhao, M.; Ma, J.; Chen, S.; Zheng, Z.; Jia, J.; Wu, H., FacileelectrolyticsynthesisofPtandcarbonquantumdotscoloadedmultiwallcarbonnanotubeashighlyeff icientelectrocatalystforhydrogenevolutionandethanoloxidation. Chem. Eng. J. 2021, 408, 127271.

226. Guo, X.; Zhu, Y.; Han, W.; Fan, X.; Li, Y.; Zhang, F.; Zhang, G.; Peng, W.; Wang, S., Nitrogendoped graphene quantum dots decorated graphite foam as ultra-high active free-standing electrode for electrochemical hydrogen evolution and phenol degradation. Chem. Eng. Sci. 2019, 194, 54-57.

227. Bao, T.; Song, L.; Zhang, S., Synthesis of carbon quantum dot-doped NiCoP and enhanced electrocatalytic hydrogen evolution ability and mechanism. Chem. Eng. J. 2018, 351, 189-194.

228. Zhang, L.; Yang, Y.; Ziaee, M. A.; Lu, K.; Wang, R., Nanohybrid of Carbon Quantum Dots/Molybdenum Phosphide Nanoparticle for Efficient Electrochemical Hydrogen Evolution in Alkaline Medium. ACS Appl. Mater. Interfaces 2018, 10 (11), 9460-9467.

229. Feng, T.; Zeng, Q.; Lu, S.; Yang, M.; Tao, S.; Chen, Y.; Zhao, Y.; Yang, B., Morphological and Interfacial Engineering of Cobalt-Based Electrocatalysts by Carbon Dots for Enhanced Water Splitting. ACS Sustainable Chem. Eng. 2019, 7 (7), 7047-7057.

230. Li, J.; Zhang, X.; Zhang, Z.; Li, Z.; Gao, M.; Wei, H.; Chu, H., Graphene-Quantum-Dots-induced facile growth of porous molybdenum doped Ni3S2 nanoflakes as efficient bifunctional electrocatalyst for overall water splitting. Electrochim. Acta 2019, 304, 487-494.

231. Zhao, X.; Liu, H.; Rao, Y.; Li, X.; Wang, J.; Xia, G.; Wu, M., Carbon Dots Decorated Hierarchical NiCo2S4/Ni3S2 Composite for Efficient Water Splitting. ACS Sustainable Chem. Eng. 2019, 7 (2), 26102618.

232. Rao, Y.; Ning, H.; Ma, X.; Liu, Y.; Wang, Y.; Liu, H.; Liu, J.; Zhao, Q.; Wu, M., Template-free synthesis of coral-like nitrogen-doped carbon dots/Ni3S2/Ni foam composites as highly efficient electrodes for water splitting. Carbon 2018, 129, 335-341.

233. Wei, G.; He, J.; Zhang, W.; Zhao, X.; Qiu, S.; An, C., Rational Design of Co(II) Dominant and Oxygen Vacancy Defective CuCo2O4@CQDs Hollow Spheres for Enhanced Overall Water Splitting and Supercapacitor Performance. Inorg. Chem. 2018, 57 (12), 7380-7389.

234. Anantharaj, S.; Ede, S. R.; Karthick, K.; Sam Sankar, S.; Sangeetha, K.; Karthik, P. E.; Kundu, S., Precision and correctness in the evaluation of electrocatalytic water splitting: revisiting activity parameters with a critical assessment. Energy \& Environmental Science 2018, 11 (4), 744-771.

235. Suen, N.-T.; Hung, S.-F.; Quan, Q.; Zhang, N.; Xu, Y.-J.; Chen, H. M., Electrocatalysis for the oxygen evolution reaction: recent development and future perspectives. Chem. Soc. Rev. 2017, 46 (2), 337-365.

236. Oh, H.-S.; Nong, H. N.; Reier, T.; Bergmann, A.; Gliech, M.; Ferreira de Araújo, J.; Willinger, E.; Schlögl, R.; Teschner, D.; Strasser, P., Electrochemical Catalyst-Support Effects and Their Stabilizing Role for IrOx Nanoparticle Catalysts during the Oxygen Evolution Reaction. J. Am. Chem. Soc. 2016, 138 (38), 12552-12563.

237. Reier, T.; Oezaslan, M.; Strasser, P., Electrocatalytic Oxygen Evolution Reaction (OER) on Ru, Ir, and Pt Catalysts: A Comparative Study of Nanoparticles and Bulk Materials. ACS Catal. 2012, 2 (8), 1765-1772.

238. Zhu, Y.; Zhang, B., Nanocarbon-based metal-free and non-precious metal bifunctional electrocatalysts for oxygen reduction and oxygen evolution reactions. Journal of Energy Chemistry 2021, 58, 610-628. 
239. Hong, W. T.; Risch, M.; Stoerzinger, K. A.; Grimaud, A.; Suntivich, J.; Shao-Horn, Y., Toward the rational design of non-precious transition metal oxides for oxygen electrocatalysis. Energy \& Environmental Science 2015, 8 (5), 1404-1427.

240. Chen, Z.; Higgins, D.; Yu, A.; Zhang, L.; Zhang, J., A review on non-precious metal electrocatalysts for PEM fuel cells. Energy Environ. Sci. 2011, 4, 3167-3192.

241. Andersen, N. I.; Serov, A.; Atanassov, P., Metal oxides/CNT nano-composite catalysts for oxygen reduction/oxygen evolution in alkaline media. Applied Catalysis B: Environmental 2015, 163, 623-627.

242. Hazarika, K. K.; Goswami, C.; Saikia, H.; Borah, B. J.; Bharali, P., Cubic Mn2O3 nanoparticles on carbon as bifunctional electrocatalyst for oxygen reduction and oxygen evolution reactions. Molecular Catalysis 2018, 451, 153-160.

243. Tian, L.; Li, Z.; Wang, P.; Zhai, X.; Wang, X.; Li, T., Carbon quantum dots for advanced electrocatalysis. Journal of Energy Chemistry 2021, 55, 279-294.

244. Chang, C.-Y.; Kashale, A. A.; Lee, C.-M.; Chu, S.-L.; Lin, Y.-F.; Chen, I. W. P., Single Atomically Anchored Iron on Graphene Quantum Dots for Highly Efficient Oxygen Evolution Reaction. Materials Today Energy 2021, 100693.

245. Bai, Y.; Zhang, L. C.; Li, Q.; Wu, Y.; Wang, Y.; Xu, M.; Bao, S. J., Self-Supported CdP2-CDsCoP for High-Performance OER Catalysts. ACS Sustainable Chemistry \& Engineering 2021, 9 (3), 12971303.

246. Rehman, M. Y. u.; Manzoor, S.; Nazar, N.; Abid, A. G.; Qureshi, A. M.; Chughtai, A. H.; Joya, K. S.; Shah, A.; Ashiq, M. N., Facile synthesis of novel carbon dots@metal organic framework composite for remarkable and highly sustained oxygen evolution reaction. Journal of Alloys and Compounds 2021, 856, 158038.

247. Tian, L.; Wang, J.; Wang, K.; Wo, H.; Wang, X.; Zhuang, W.; Li, T.; Du, X., Carbon-quantumdots-embedded $\mathrm{MnO} 2$ nanoflower as an efficient electrocatalyst for oxygen evolution in alkaline media. Carbon 2019, 143, 457-466.

248. Zhong, Z.; Liu, J.; Xu, X.; Cao, A.; Tao, Z.; You, W.; Kang, L., Synthesis of Z-scheme cobalt porphyrin/nitrogen-doped graphene quantum dot heterojunctions for efficient molecule-based photocatalytic oxygen evolution. Journal of Materials Chemistry A 2021, 9 (4), 2404-2413.

249. Zhao, S.; Li, C.; Liu, J.; Liu, N.; Qiao, S.; Han, Y.; Huang, H.; Liu, Y.; Kang, Z., Carbon quantum dots/SnO2-Co3O4 composite for highly efficient electrochemical water oxidation. Carbon 2015, 92, 64-73.

250. Yang, S.; Du, R.; Yu, Y.; Zhang, Z.; Wang, F., One-step electrodeposition of carbon quantum dots and transition metal ions for $\mathrm{N}$-doped carbon coupled with NiFe oxide clusters: A highperformance electrocatalyst for oxygen evolution. Nano Energy 2020, 77, 105057.

251. Chang, C.-Y.; Kashale, A. A.; Lee, C.-M.; Chu, S.-L.; Lin, Y.-F.; Chen, I. W. P., Single Atomically Anchored Iron on Graphene Quantum Dots for Highly Efficient Oxygen Evolution Reaction. Mater. Today Energy 2021, 20, 100693.

252. Bai, Y.; Zhang, L. C.; Li, Q.; Wu, Y.; Wang, Y.; Xu, M.; Bao, S. J., Self-Supported CdP2-CDsCoP for High-Performance OER Catalysts. ACS Sustainable Chem. Eng. 2021, 9 (3), 1297-1303.

253. Rehman, M. Y. u.; Manzoor, S.; Nazar, N.; Abid, A. G.; Qureshi, A. M.; Chughtai, A. H.; Joya, K. S.; Shah, A.; Ashiq, M. N., Facile synthesis of novel carbon dots@metal organic framework composite for remarkable and highly sustained oxygen evolution reaction. J. Alloys Compd. 2021, 856, 158038.

254. Guo, X.; Zheng, X.; Hu, X.; Zhao, Q.; Li, L.; Yu, P.; Jing, C.; Zhang, Y.; Huang, G.; Jiang, B.; $\mathrm{Xu}, \mathrm{C}$.; Pan, F., Electrostatic adsorbing graphene quantum dot into nickel-based layered double hydroxides: Electron absorption/donor effects enhanced oxygen electrocatalytic activity. Nano Energy 2021, 84, 105932.

255. Dong, Q.; Shuai, C.; Mo, Z.; Liu, Z.; Liu, G.; Wang, J.; Chen, Y.; Liu, W.; Liu, N.; Guo, R., Nitrogen-doped graphene quantum dots anchored on NiFe layered double-hydroxide nanosheets catalyze the oxygen evolution reaction. New J. Chem. 2020, 44 (41), 17744-17752. 
256. Liu, Y.; Ge, R.; Chen, Y.; Huang, M.; Zhu, R.; Li, W.; Liu, Y.; Feng, L.; Che, R., Urchin-like cobalt hydroxide coupled with $\mathrm{N}$-doped carbon dots hybrid for enhanced electrocatalytic water oxidation. Chem. Eng. J. 2020, 127598.

257. Li, G.; Hou, S.; Gui, L.; Feng, F.; Zhang, D.; He, B.; Zhao, L., Carbon quantum dots decorated $\mathrm{Ba} 0.5 \mathrm{Sr} 0.5 \mathrm{Co} 0.8 \mathrm{Fe} 0.2 \mathrm{O}-\delta$ perovskite nanofibers for boosting oxygen evolution reaction. Appl. Catal., B 2019, 257, 117919.

258. Muthurasu, A.; Sheen Mers, S. V.; Ganesh, V., Nitrogen doped graphene quantum dots (NGQDs)/Co3O4 composite material as an efficient bi-functional electrocatalyst for oxygen evolution and oxygen reduction reactions. Int. J. Hydrogen Energy 2018, 43 (9), 4726-4737.

259. Yang, M.; Feng, T.; Chen, Y.; Zhao, X.; Yang, B., lonic-State Cobalt and Iron Co-doped Carbon Dots with Superior Electrocatalytic Activity for the Oxygen Evolution Reaction. ChemElectroChem 2019, 6 (7), 2088-2094.

260. Zhang, G.; Yang, J.; Wang, H.; Chen, H.; Yang, J.; Pan, F., Co3O4- $\delta$ Quantum Dots As a Highly Efficient Oxygen Evolution Reaction Catalyst for Water Splitting. ACS Appl. Mater. Interfaces 2017, 9 (19), 16159-16167. 